ALDEN

UNIVERSITY

A higher degree. A higher purpose.

Walden University ScholarWorks

2016

\title{
Emotional Intelligence, Job Satisfaction, and Burnout for Dietitians
}

Cara Perdue

Walden University

Follow this and additional works at: https://scholarworks.waldenu.edu/dissertations

Part of the Human and Clinical Nutrition Commons, and the Medicine and Health Sciences Commons

This Dissertation is brought to you for free and open access by the Walden Dissertations and Doctoral Studies Collection at ScholarWorks. It has been accepted for inclusion in Walden Dissertations and Doctoral Studies by an authorized administrator of ScholarWorks. For more information, please contact ScholarWorks@waldenu.edu. 


\title{
Walden University
}

\author{
College of Health Sciences
}

This is to certify that the doctoral dissertation by

\author{
Cara Perdue
}

has been found to be complete and satisfactory in all respects, and that any and all revisions required by the review committee have been made.

\section{Review Committee}

Dr. Shirley Gerrior, Committee Chairperson, Health Services Faculty

Dr. Pat Carmoney, Committee Member, Health Services Faculty

Dr. Diana Naser, University Reviewer, Health Services Faculty

\section{Chief Academic Officer}

Eric Riedel, Ph.D.

Walden University

2015 


\begin{abstract}
Emotional Intelligence, Job Satisfaction, and Burnout for Dietitians

by

Cara N. Perdue
\end{abstract}

MHS, Western Carolina University, 2010

BS, Western Carolina University, 2007

\author{
Dissertation Submitted in Partial Fulfillment \\ of the Requirements for the Degree of \\ Doctor of Philosophy \\ Health Services
}

Walden University

February 2016 


\begin{abstract}
There are low retention rates of dietitians and this impacts quality of care. Emotional intelligence (EI) may be the missing component to improve retention, due to EI increasing job satisfaction and decreasing burnout for other health providers. The purpose of this study was to examine the relationship between EI, job satisfaction, and burnout for dietitians. The theoretical framework utilized was the 4-branch model of EI. Method of inquiry was convenience, quantitative non-experimental design. Registered dietitians ( $N$ $=84,173$ ) living in the United States were contacted via e-mail. Approximately $9.5 \%$ of dietitians $(n=8,038)$ completed the Wong and Law EI Scale, Job Diagnostic Survey, Copenhagen Burnout Inventory, and a demographic survey. Frequency was calculated based on coded data that $89.38 \%$ of dietitians indicated high level of EI (score $\geq 4.5$ ). Levels of EI and burnout for dietitians were examined with a $\mathrm{Chi}^{2}(p=0.000)$, Pearson $r$ correlation $(r=0.28, p=0.000)$, and positive linear regression $\left(r^{2}=0.075, p=0.000\right)$. Levels of EI and job satisfaction for dietitians were examined with a $\mathrm{Chi}^{2}(p=0.000)$, Pearson $r$ correlation $(r=0.271, p=0.000)$, and positive linear regression $\left(r^{2}=0.070, p=\right.$ 0.000). Significant findings reveal that dietitians possess increased levels of EI, a positive correlation exists between EI and burnout, and a positive correlation exists between EI and job satisfaction. Results may contribute to social change by highlighting the importance of EI in the field of dietetics to integrate EI in curriculum, encourage professional growth, and improve client outcomes.
\end{abstract}


Emotional Intelligence, Job Satisfaction, and Burnout for Dietitians

by

Cara N. Perdue

MHS, Western Carolina University, 2010

BS, Western Carolina University, 2007

Dissertation Submitted in Partial Fulfillment

of the Requirements for the Degree of

Doctor of Philosophy

Health Services

Walden University

February 2016 


\section{Dedication}

I would like to dedicate this dissertation to my wonderfully supportive husband

David. Without his constant and loving support, I would not have achieved this goal. 


\section{Acknowledgments}

I am most grateful to my dissertation chair Dr. Shirley Gerrior, for her guidance and support throughout the entire dissertation process. I would also like to thank my committee member Dr. Pat Carmoney and URR Dr. Diana Naser. I especially wish to recognize my family and friends for their unwavering support and encouragement. 


\section{Table of Contents}

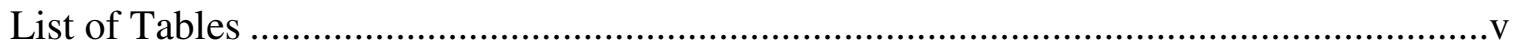

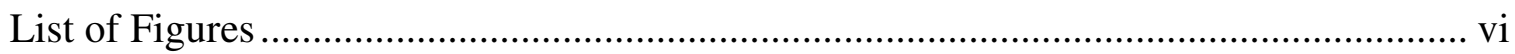

Chapter 1: Introduction to the Study .......................................................................

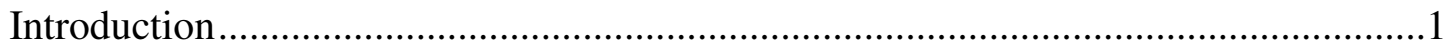

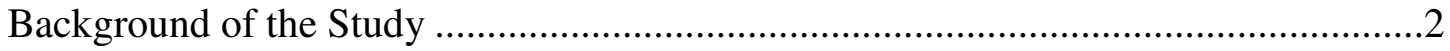

Statement of the Problem......................................................................................

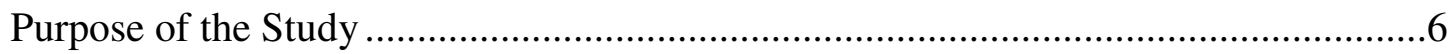

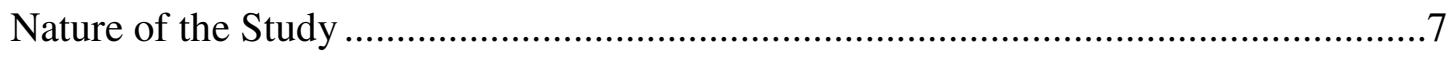

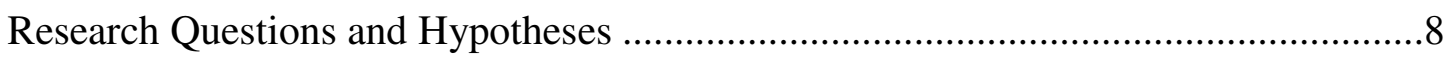

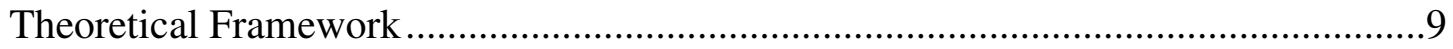

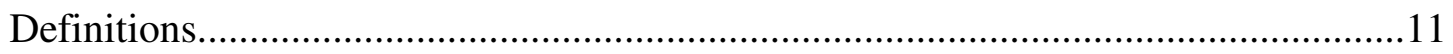

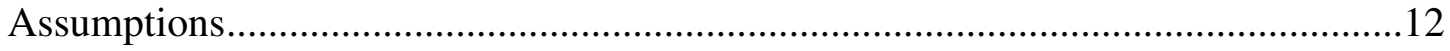

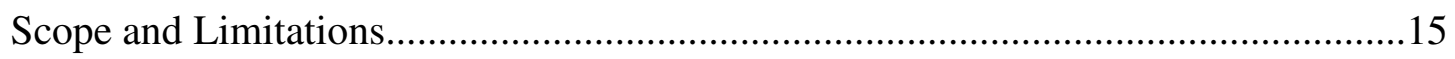

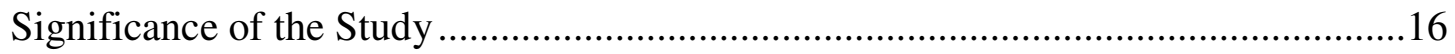

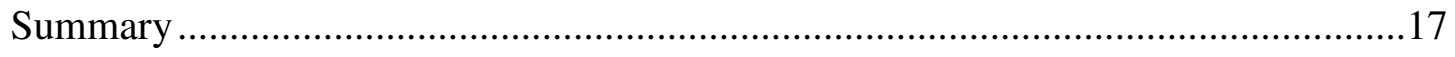

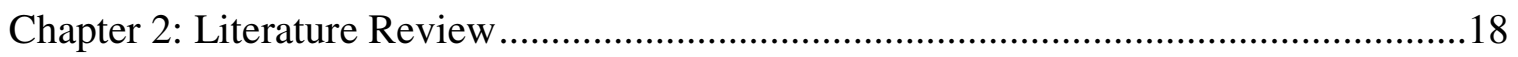

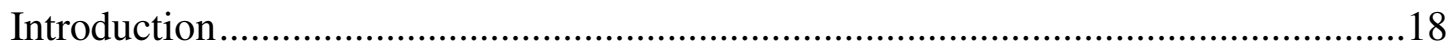

Theoretical Foundation for Emotional Intelligence .............................................18

Emotional Intelligence and Altruism .....................................................20

Emotional Intelligence and Empathy ................................................20

Various Foundations of Emotional Intelligence .................................................21 
Trait Based Emotional Intelligence ........................................................23

Ability Based Emotional Intelligence ...................................................24

Mixed Based Emotional Intelligence ......................................................24

Development of Emotional Intelligence .....................................................27

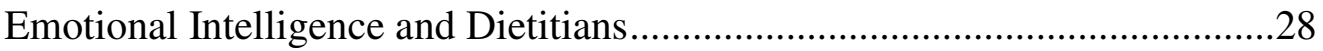

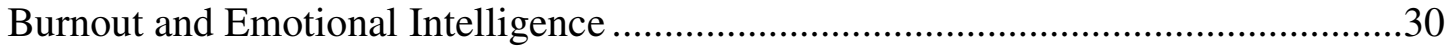

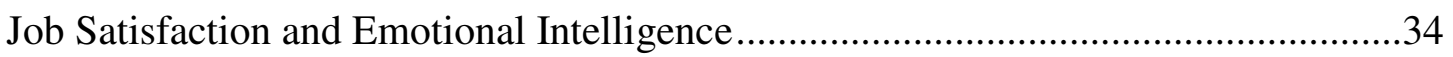

Emotional Intelligence, Job Satisfaction, and Burnout..........................................36

Emotional Intelligence and Advanced Practice ................................................... 36

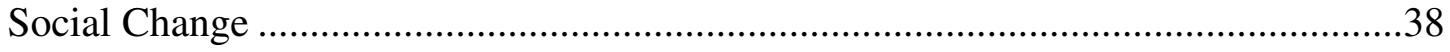

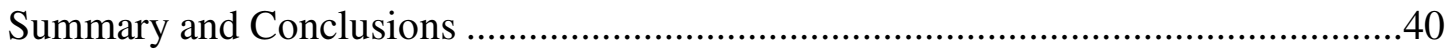

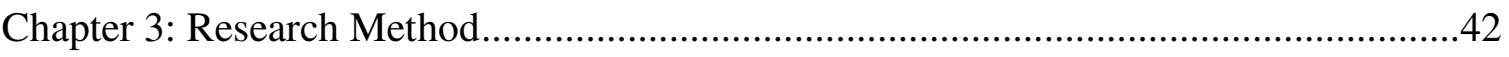

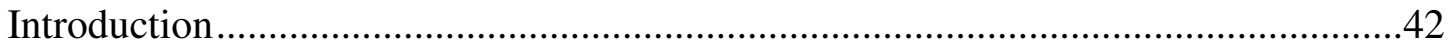

Research Design \& Rationale .................................................................. 43

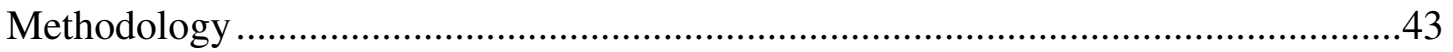

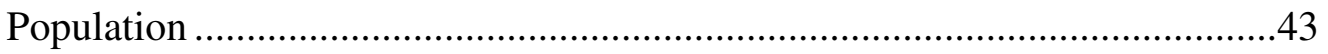

Sampling and Sampling Procedures ...................................................44

Procedures for Recruitment, Participation, and Data Collection ...................46

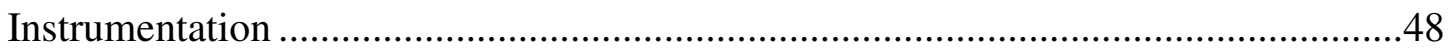

Wong and Law Emotional Intelligence Scale...........................................48

The Copenhagen Burnout Inventory ….................................................50

Job Diagnostic Survey ...................................................................51 


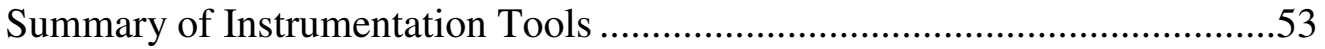

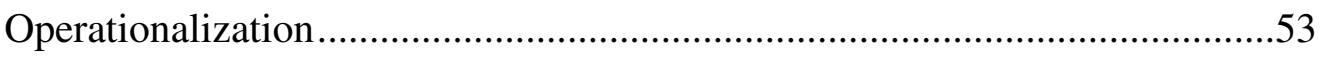

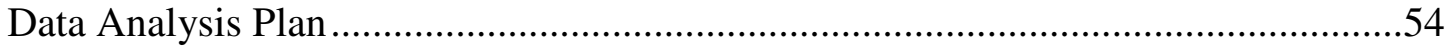

Non-parametric Testing ......................................................................56

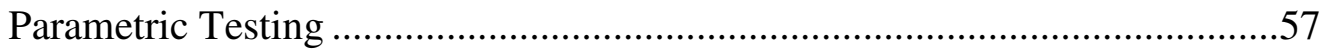

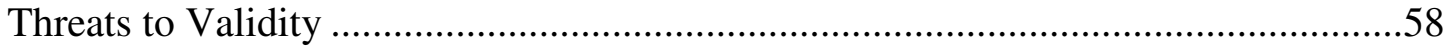

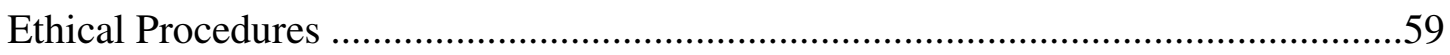

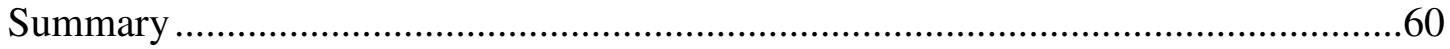

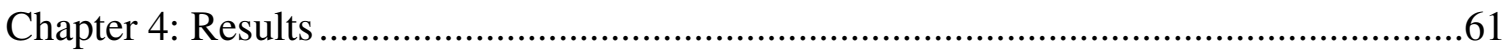

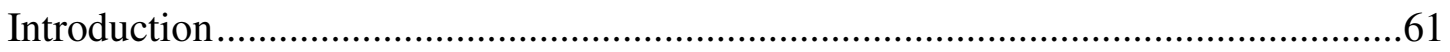

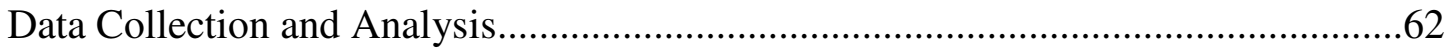

Descriptive Characteristics of the Sample …....................................................63

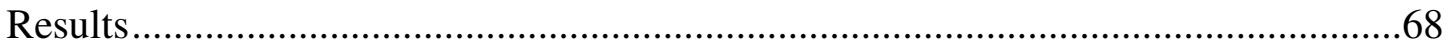

Research Question \#1 .......................................................................68

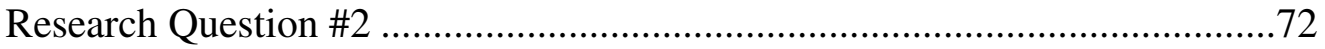

Research Question \#3 ........................................................................... 79

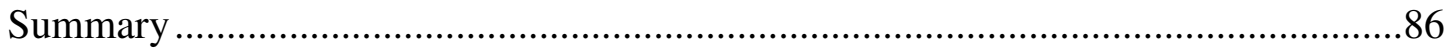

Chapter 5: Discussion, Conclusions, and Recommendations ......................................87

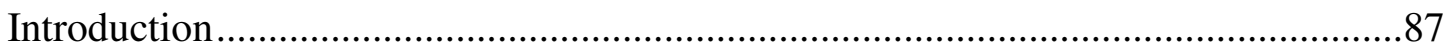

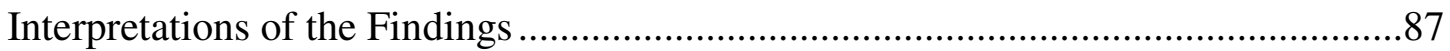

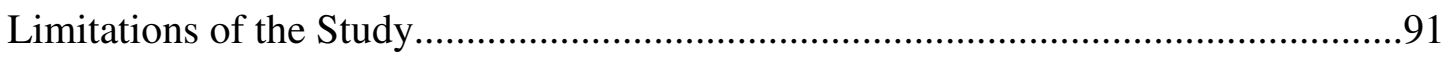

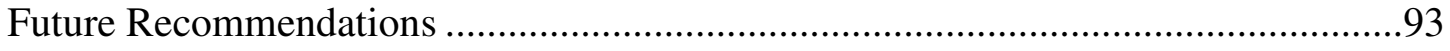




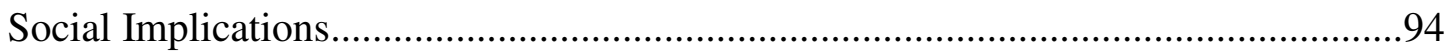

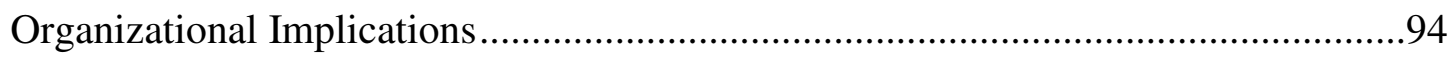

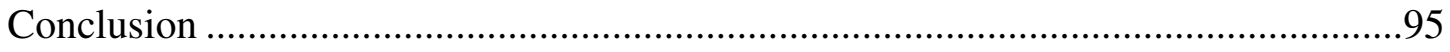

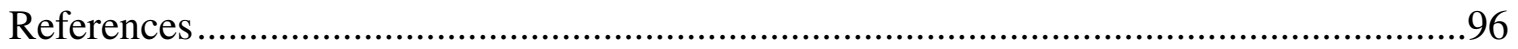

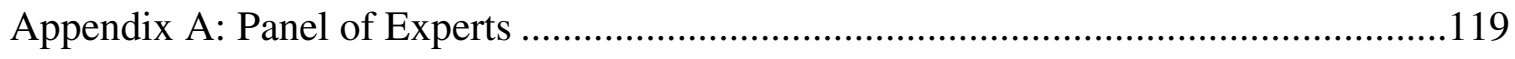

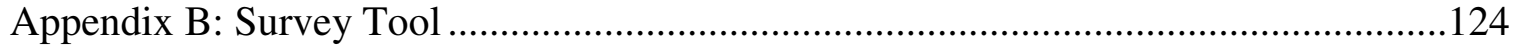


List of Tables

Table 1: Extreme Values for WLEIS

Table 2: Extreme Values for CBI

Table 3: Model Summary for WLEIS/CBI 78

Table 4: Linear Regression WLEIS/CBI

Table 5: Extreme Values for JDS

Table 6: Model Summary of WLEIS/JDS 85

Table 7: Linear Regression for WLEIS/JDS 86 


\section{List of Figures}

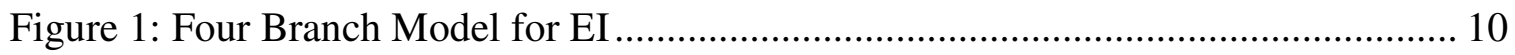

Figure 2: Foundations of Emotional Intelligence ................................................. 23

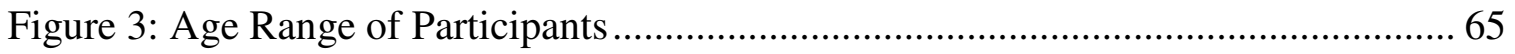

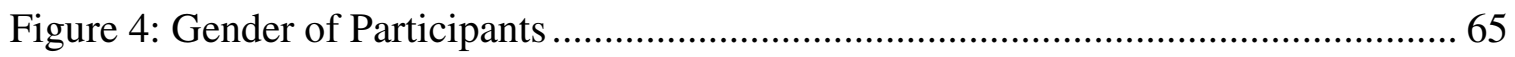

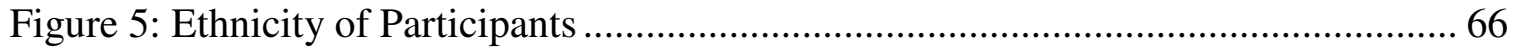

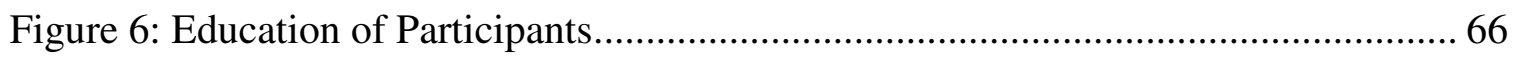

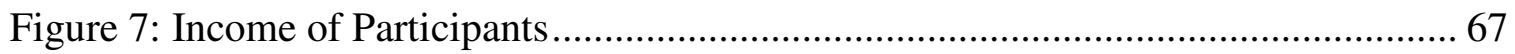

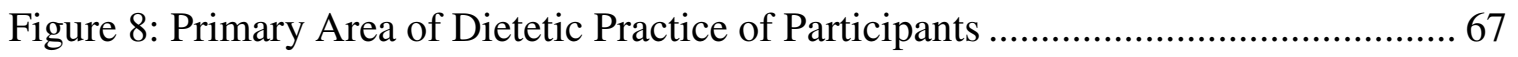

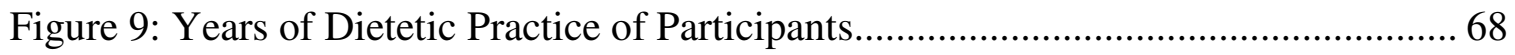

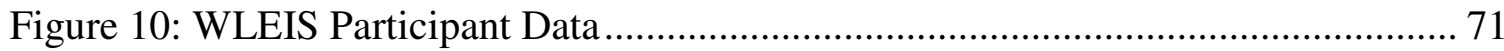

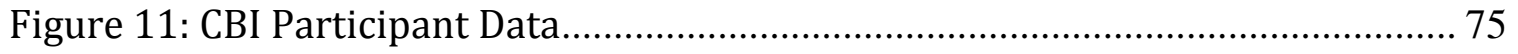

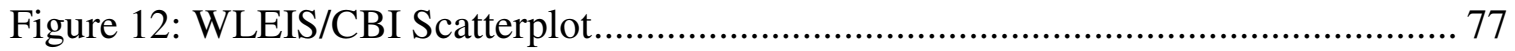

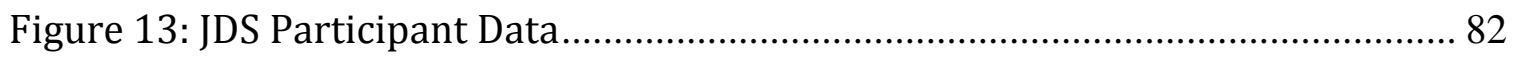

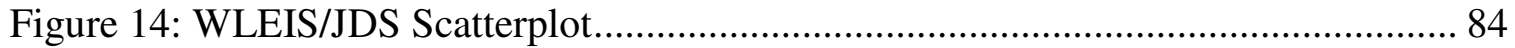


Chapter 1: Introduction to the Study

Introduction

Emotional intelligence (EI) consists of an individual's ability to control and manage their emotions (Zijlmans, Embregts, Gerits, Bosman, \& Derksen, 2011). Emotional control can be characterized as a skill that can be improved and refined (Doherty, Cronin, \& Offiah, 2013; Zijlmans et al., 2011). Increased EI in health practitioners has been shown to be a desirable trait for health organizations because of its relationship to improved job satisfaction (Demirel \& Sarlak, 2009; Gutierrez, Candela, \& Carver, 2012). Increased levels of EI may also provide a protective measure for practitioners in coping with challenging and stressful environments associated with increased burnout rates (Birks \& Watt, 2007; Gorgens-Ekermans \& Brand, 2012). Additionally, increased EI allows for improved stress management that impacts organizational retention rates (Gorgens-Ekermans \& Brand, 2012). Birks, McKendree, and Watt (2009) argued that when EI is lacking for specific health practitioners, it may impact client outcomes. Improving client outcomes drives multiple aspects of the client/practitioner relationship and has implications for positive change. Dietitians are of particular importance due to the varied roles the profession takes within the health care team. Dietitians serve as nutrition experts, and nutritional health impacts overall health and wellbeing of clients. Investigating the relationship between EI, job satisfaction, and burnout for dietitians has multiple implications for social change. Social change may result through improved patient care, revamped educational opportunities or requirements, and more dietitians who ascend to a professional level of advanced care. 
Organizational change may also be impacted, as organizations can foster EI development in order to promote advanced-practice, and reduce retention rates. Each of these potential changes could impact the field of dietetics, and may play an influential role in the future of dietetics. The current study investigated the foundation of EI models, and the advantages and disadvantages of each. The importance of EI as a desirable trait for dietitians was the underlying focus of this research study.

\section{Background of the Study}

There has been a solid research foundation for analyzing EI, but a gap exists for health professionals in specific fields, including for dietitians. Focusing research on EI for health practitioners ensures a holistic view of client-centered care. Effective health care should not just focus on patients, but also on providers. Sauer, Canter, and Shanklin (2012) argued that the future of dietetics-related research should focus on the retention of qualified professionals. In order to achieve a highly qualified and skilled workforce, the field of dietetics needs experienced employees.

Various health professional fields have demonstrated the importance of EI. Emotional competency can result in longer retention rates for nurses (Diefendorff, Erickson, Grandey, \& Dahling, 2011; Humpel \& Caputi, 2001). This relationship may exist for the dietetic field as well, and therefore it was important to examine the effect of EI on employee retention there as well. Gaining skills in EI can provide an array of benefits for dietitians. Wildish and Evers (2010) argued that the development of clientfocused care assists in the development of advanced-practice in the field of dietetics. Advanced-practice of dietetics improves the knowledge that dietitians have and adds 
skills to the dietetic repertoire. Additionally, advanced-practice in the field of dietetics allows for increasing the number of advanced dietetic practitioners, which enhances the quality of care received by patients (Wildish \& Evers, 2010). Currently, there is a lack of registered dietitians who achieve advanced-practice status (Hooker et al., 2012), but the reason for this lack of advancement has not been determined. Typically, practitioners achieve a level of advanced-practice through experience. Gardner, Chang, Duffield, and Duobrovsky (2013) determined that achieving an advanced level of practice for the nursing field included five distinct domains, comprehensive care, support of systems, education, research, and publications/professional leadership. Each of these domains requires a practitioner to thoroughly integrate into the field, and retaining professionals within an organization allows for practitioners to refine and build upon current skills. The dietetic profession may hold similar expectations in terms of defining advanced-practice. Examining the importance of EI for the dietetic profession may clarify a potential characteristic that would assist in improving retention rates for dietitians, which may have an impact on advancing level of practice. Improved retention rates for dietetic professionals may assist in promoting advanced-practice within the field, since advancedpractice is obtained through developing knowledge and experience within the field. Improving dietetic advanced-practice is only one beneficial change that may result from the analysis of EI.

The combination of individual change in behaviors and attitude, as well as social change at the organizational level, will inform organizational policies in order to retain employees. Promoting EI increases the awareness one has about their feelings and 
emotions. EI also allows for better stress management and handling of conflict. Understanding how burnout impacts dietitians, as well as how it relates to EI can provide valuable information for health organizations and employee training. This research will add credence to the field, and raise awareness about the important role that dietitians serve. Other health professionals including nurses and doctors are frequently examined for research purposes, due to their commonality in the health care setting. Since dietitians are a small percentage of the health care provider population, they are often overlooked.

Understanding the relationship between EI, job satisfaction, and level of burnout may help to change behaviors and attitudes of health organizations. Additionally, practice-based change may also occur for educational facilities that train students to become health providers. Integrating self-awareness and empathy training for practitioners can reduce the risk of burnout in the health care setting (Burks \& Kobus, 2012; Cohen \& Gagin, 2005). The results of this study build a foundation for continuing research on other health professionals, and broaden existing studies.

\section{Statement of the Problem}

Dietitians are a key part of patient care, and serve an influential role in assisting nutrition-related behavior change. An important aspect of patient care is retention rates of employees, as advanced-practice practitioners provide the field of dietetics with a wealth of knowledge and experience. Skipper (2009) argued that low retention rates for dietitians were a major concern for health organizations. There are many factors that can contribute to reduced retention rates, and burnout is specifically related to low retention, due to increased levels of emotional stress. Another component related to retention rates 
is job satisfaction. If a dietitian is not content with his or her work, then retention within an organization is not likely to continue. Lack of job satisfaction may also prevent dietitians from achieving an advanced level of practice within the field, which can impact client health outcomes. Not only are burnout and job satisfaction related to retention, they appear to be interconnected with EI. A relationship exists between EI and decreasing rates of burnout (Gorgens-Ekermans \& Brand, 2012), and improved job satisfaction (Wong \& Law, 2002). Understanding the relationship that EI may have on job satisfaction and level of burnout for dietitians may lead to the conclusion that EI is a desired trait. Examining how EI impacts dietitian burnout and job satisfaction could provide valuable information for health organizations with low retention rates. The lack of research for dietitians may be due in part to the dietetic profession being in an earlier stage of professional development (Thorensen, Rothenberg, Beck, \& Irtun, 2008), and further research will assist with the advancement of the dietetic field (Brotherton, 2009; Brotherton, 2012). Additionally, the Academy of Nutrition and Dietetics has recognized EI as an important trait for dietitians to possess by the year 2020 (Academy of Nutrition and Dietetics, 2014), which indicates that EI is an emerging trend in the field of dietetics. Currently, research related to job satisfaction and factors related to retention are limited and outdated for dietitians (Sauer et al., 2012). Also, dietitians are under-researched (Slawson, Clemens, \& Bol, 2000; Whelan, 2007), and the relationship between burnout, job satisfaction, and EI has not been examined for dietitians. Additional research is needed to examine this potential relationship to enhance professional value and improve the quality of patient services. 
Various researchers have noted the importance of EI (Dulewicz \& Higgs, 2000; Freshwater \& Stickley, 2004; Petrides \& Furnham, 2006; Mayer \& Salovey, 1997), and connections have been established between EI and burnout (Ciarrochi, Deane, \& Anderson, 2002; Laschinger, 2012; Maslach, 2004; Nikolaou \& Tsaousis, 2002) and job satisfaction (Akerjordet \& Severinsson, 2007; Laschinger, Leiter, Day \& Gilin, 2009; Maslach, 2004). Laschinger (2012) conducted a study that determined a connection between empowerment, burnout, and job satisfaction for newly graduated nurses. Similarly, Burks and Kobus (2012) concluded that empathy impacts burnout, and improves job satisfaction for medical students and health professionals. Burnout is prevalent for dietitians especially for beginner practitioners (Gingras, De Jong, \& Purdy, 2010), and job satisfaction has been noted to be low for dietitians due to lack of opportunities and avenues for advanced practice (Chen, Jaafar, \& Noor, 2012). If a relationship exists between EI, job satisfaction, and burnout, then it could promote EI as a desirable trait for dietitians to possess. Establishing EI as desirable could affect the education and training of dietetic professionals. EI may be the missing component needed within the dietetic profession (Fox, 2013) in order to support opportunities for advanced practice.

\section{Purpose of the Study}

The purpose of this convenience non-experimental quantitative study was to examine the relationship between EI, job satisfaction, and level of burnout for dietitians. For the proposed study, the independent variable was the level of self-reported EI. The dependent variables were level of self-reported job satisfaction and self-reported level of 
burnout. The intent of the study was to investigate the relationship that may exist for these variables, in order to promote social change within the field of dietetics. Since these variables have not been previously examined within the field of dietetics, the proposed study was exploratory in nature. Emotional skills can be developed (Satterfield \& Hughes, 2007); this development may positively impact client care (Larson \& Yao, 2005) and improve retention rates for health employees (Nikolaou \& Tsaousis, 2002). The results might lead researchers and leaders within the dietetic profession to (a) adjust dietetic student curriculum, (b) encourage continuing education or training for dietitians to improve EI skills and potentially increase the number of dietitians who obtain advanced level of practice, (c) improve client health outcomes, (d) improve client and practitioner rapport, (e) provide additional skills to dietitians to combat burnout and improve job satisfaction, and (f) encourage health organizations to promote the skills needed for EI.

\section{Nature of the Study}

The study compared the relationship between EI, job satisfaction, and burnout for registered dietitians as measured by the WLEIS (Wong \& Law Emotional Intelligence Scale), Job Diagnostic Survey, and Copenhagen Burnout Inventory (Appendix B). This investigation analyzed those relationships in order to discover whether EI was a valuable characteristic for a dietitian to possess.

The methodology of this study was a self-report quantitative convenience sample, utilizing valid measurement tools for EI, job satisfaction, and burnout. This methodology was selected for ease of collection and to increase the available sample size. The survey 
was distributed online via e-mail for registered dietitians. E-mail addresses of dietitians were obtained in 2014 from the Commission on Dietetic Registration. Utilizing an online survey tool broadened the scope of the study to dietitians in different states as well as different settings (rural and urban).

Research questions were developed to investigate the relationship that may exist between EI, job satisfaction, and burnout. The dependent variables included level of job satisfaction and level of burnout, and the independent variable was level of EI. Data processing and analysis occurred after the collection process and included descriptive and inferential statistics. I utilized both parametric and non-parametric testing for the survey tools since the survey format included Likert Scale measurements. Once analyzed, the results were interpreted and recommendations were suggested based on the results. Areas of potential social change based on results were included. Additionally, avenues for further research were suggested to promote continued investigation into the importance of EI, job satisfaction, and burnout for the dietetic practice.

\section{Research Questions and Hypotheses}

The hypothesis used for the current study was that registered dietitians with increased levels of EI are more likely to exhibit lower levels of burnout and increased levels of job satisfaction. The research questions for the study were as follows:

1. What is the level of EI for registered dietitians?

2. Does a relationship exist between level of EI and level of burnout for dietitians? 
$H_{0} 1$ - No relationship exists between level of EI and level of burnout for dietitians.

$H_{\mathrm{a}} 1$ - A relationship exists between level of EI and level of burnout for dietitians.

3. Does a relationship exist between level of EI and level of job satisfaction for dietitians?

$H_{0} 2$ - No relationship exists between level of EI and level of job satisfaction for dietitians.

$H_{\mathrm{a}} 2$ - A relationship exists between level of EI and level of job satisfaction for dietitians.

Dependent variable: Level of self-reported job satisfaction and self-reported burnout.

Independent variable: Level of EI calculated from a valid measurement tool.

\section{Theoretical Framework}

The theoretical framework to address the research questions includes EI theories. The construct of EI was described through the use of the Four-Branch Model shown in Figure 1 (Mayer \& Salovey, 1997). Mayer, Salovey, and Caruso (2008) stated that EI includes "(a) perceiving emotions in oneself and others accurately, (b) using emotions to facilitate thinking, (c) understanding emotions, emotional language, and the signals conveyed by emotions, and (d) managing emotions so as to attain specific goals" (p. 4). 


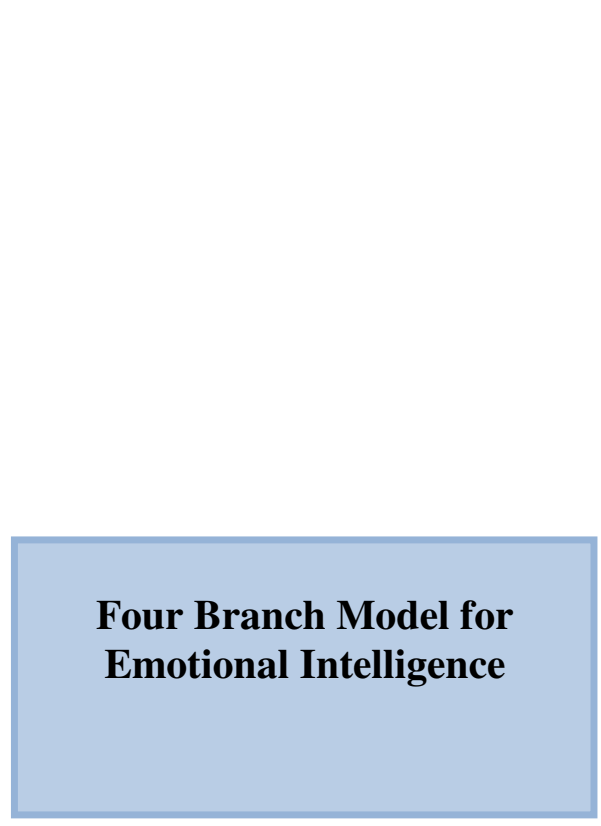

Perceiving emotions in oneself and others accurately

Using emotions to facilitate thinking

Understanding emotions, emotional language, and the signals conveyed by emotions

Figure 1: Four Branch Model for EI

EI allows for the understanding of emotions in order to facilitate thought-based problem solving. Emotions are dynamic and vary depending on personal interpretation of stimuli (Mayer, Salovey, Caruso, \& Sitarenios, 2001). The internal response to situations can influence actions and behaviors. Mayer et al. (2001) argued that the level of EI is unique from traditional intelligence and measurable (Mayer et al., 2001; Roberts, Matthews, \& Zeidner, 2001). Additionally, over time EI can develop and improve (Zijlmans et al., 2011). Similarly, Latour and Hosmer (2002) commented on the effectiveness of EI by stating that it is possible to learn interpersonal abilities. EI is 
adaptively beneficial because it removes the impulsive component of emotional reaction (Mayer et al., 2001; Mayer et al., 2008). The four branch model was the foundational underpinning of the current research. The four branch model gives comprehensive knowledge of key aspects of EI that need to be measured in order to compare EI effectively to burnout and job satisfaction.

\section{Definitions}

The definitions of key terms and abbreviations used for the study are as follows:

Emotional Intelligence (EI): EI is an individual's ability to control and manage their emotions (Zijlmans, Embregts, Gerits, Bosman, \& Derksen, 2011). EI was measured in this survey through the usage of the WLEIS scale based on the four-branch framework for EI.

Burnout: Burnout is a disease that arises from chronic negative workplace experiences (Maslach, 2004) and involves both mental and physical stress (Felton, 1998; Gorgens-Ekermans \& Brand, 2012). Burnout was measured by the Copenhagen Burnout Inventory $(\mathrm{CBI})$ that includes personal burnout, work-related burnout, and client-related burnout.

Job Satisfaction: Job satisfaction is overall feelings related to employment (Brady, Lordly, MacLellan, \& Gingras, 2012). Job satisfaction was measured utilizing section 4 of the Job Diagnostic Survey (JDS).

Dietitian: A dietitian is defined as a nutrition expert who has obtained the registered dietitian (RD/RDN) credential (Commission on Dietetic Registration, 2014b). 


\section{Assumptions}

The study was a self-report online convenience sample, and this type of methodology has assumptions. Assumptions for the study included honesty of responses by participants: (a) responses being free from participant bias, (b) dietitian participants having a basic level of computer literacy, (c) that online survey tools are similar to paper surveys, and (d) that the survey tool utilized is valid.

I solicited responses from dietitians, and the absence of the researcher during the collection process may change the responses gathered. Assumptions of the self-report include the honesty of responses from participants and that the questionnaire was completed. Since I was not present during the completion process, participants may have been inhibited from completing the survey if questions arose. I reduced this potential problem by keeping the questionnaire formatting simple and providing contact information. Questionnaires that utilize self-report responses may have participant bias (Birks \& Watt, 2007; Clarke, 2010; Libbrecht, Lievens, \& Schollaert, 2010; Meadows, 2003). Participants of the study may have anticipated the desired response of the researcher and thus altered their response based on how they felt they "should" respond. Therefore, I must assume that participants answered honestly, and free from bias. Even though bias was possible with self-report, this type of collection has advantages. Selfreport is advantageous when conducting research due to being inexpensive and easy to administer for large samples (Libbrechet et al., 2010; Meadows, 2003). This approach allowed for sampling the entire population of dietitians through the Commission on Dietetic Registration e-mail database. 
The use of an online convenience sample is associated with many assumptions that must be considered. The e-mail addresses of participants were gathered from an online database available through the Commission on Dietetic Registration. This database included dietitians living throughout the United States. I must assume that dietitians possess the computer literacy required to accurately complete the online survey. It was possible that the study solicited participants who were not adept with technology, but internet users are becoming more common in the general population (Hunter, 2012; Stewart, 2003). Schillewaert and Meulemeester (2005) commented that web-based surveys can be valid if used for specific populations who have internet access. Since email addresses have been supplied to the Commission on Dietetic Registration from dietitians, I assumed that dietitians have adequate computer literacy.

Due to the online collection process, I assumed that the results collected from an online format are accurate. Logistically, collecting data online may pose concerns regarding the comparison of paper versus digital collection. I assumed that online data collection would have similar results as traditional paper collection. Schillewaert and Meulemeester (2005) argued that online versus digital surveys did not show any measurable difference when results were compared. This supports the accuracy of online data collection for the current research study. Additionally, convenience sampling has been used when conducting research related to burnout (Taris, Le Blanc, Schaufeli, \& Schreures, 2005; Yeh et al., 2007), job satisfaction (Buys, Olckers, \& Schaap, 2007; Hackman \& Oldham, 1975), and EI (Libbrecht et al., 2010; Shi \& Wang, 2007). The data were analyzed to determine if outliers existed by utilizing the outlier labeling rule 
(Hoaglin \& Iglewicz, 1987). This analysis determined that outliers were present in both the WLEIS and JDS scales. Therefore, those data were removed before conducting further analysis.

Another assumption I made was that the pre-existing tools (WLEIS, JDS, and CBI) are reliable and valid when compiled into one survey tool. The WLEIS, JDS, and CBI have shown reliability and validity separately, but combining them may alter the survey tool effectiveness. Since there does not appear to be a study that has previously used these three tools together, I assumed that one component of the survey would not impact the responses for another component. Past research for these measurement tools have been conducted to indicate validity and reliability, and I assumed that the results of these studies are correct. Additionally, I assumed that the reliability and validity of each tool remains adequate once the tools are compiled together. A questionnaire needs adequate development and testing in order to adequately show validity and reliability. Tilden, Nelson, and May (1990) argued that a panel of experts allows for improved content validity for a survey tool, and should include a minimum of two experts. In order to reduce the potential concerns regarding combining the WLEIS, JDS, and CBI, a panel of dietetic peers (4 experts in the dietetic field) were surveyed (Appendix A). Functionality and validity were tested through this focus group. During this process, dietetic peers answered questions about the combined survey including validity evaluation (content validity, construct validity, face validity, item bias, consequential validity) and reliability evaluation (internal consistency, and potential for reliability) 


\section{Scope and Limitations}

The study was a convenience sample of dietitians whose e-mail addresses are accessible through the Commission on Dietetic Registration. There are limitations related to the data collection process. Limitations include utilizing an online survey format, a participant e-mail database that may not be updated to include only actively credentialed RD/RDNs, participants being retired, and limited options for field of dietetics within the survey tool demographic information. Since the survey was completed online, I experienced lower than ideal response rates. This was a limitation since I was not present during the collection process, and if a participant had a question they may not have completed the survey. A realistic response rate would be 5-10\% (Medway \& Fulton, 2012), but a 30\% response rate is ideal (Duncan, 2008; Medway \& Fulton, 2012). Even though an online survey was a potential limitation, there are ways to address limitations. Since the survey can be completed at any time, this allows the participants freedom to complete the survey in their free time. Additionally, an online survey removes potential bias resulting from the presence of the researcher during collection (Schillewaert \& Meulemeester, 2005). Online survey tools can be particularly useful to reach a wide variety of dietitians due to being able to reach participants that are located in geographically isolated areas (Cantrell \& Lupinacci, 2007). Additionally, utilizing an online survey decreases cost and time invested in the collection process (Hunter, 2012; Stewart, 2003). For this study, these factors allowed for greater representation of rural participants and increased the generalizability of the results. 
By utilizing the Commission on Dietetic Registration database, I made the assumption that the e-mail addresses were for dietitians who were registered (have obtained $\mathrm{RD} / \mathrm{RDN}$ credentialing). It is possible that the database of e-mail addresses utilized was not up to date, and therefore included e-mail addresses of those who are no longer credentialed. Additionally, it is possible that a dietitian maintained her or his $\mathrm{RD} / \mathrm{RDN}$ credential but retired. Retired dietitians would not be able to adequately answer the survey since some questions are work related. Finally, it is possible that since the demographic information section of the survey was constructed by the researcher, adjustments were needed to ensure clarity. Care was taken to ensure that the demographic information section was adequate, but it is possible that specific areas of dietetics were unintentionally omitted.

This study served as a starting point for further research to determine if the results are generalizable to the population of dietitian practitioners. Future research will investigate EI, job satisfaction, and burnout for dietitians in more detail.

\section{Significance of the Study}

The results of this research expand on the current literature on EI and incorporate the field of dietetics. The field of EI is growing, and research into specific health professions will assist with identifying EI as a valuable characteristic in the health field. Additionally, the relationship EI may have with job satisfaction and burnout for dietitians could advance knowledge in the discipline. Investigating the relationship between EI, job satisfaction, and burnout for dietitians has the potential to incite positive social change at the personal, professional, and organizational level. Organizational training may result 
from the conclusions of the proposed study, as well as improved client outcomes and retention rates for dietitians. Training and education within the field of dietetics may also expand to include components of EI in order to provide an increased level of clientcentered care. The current study may also provide insight into increasing the level of practitioners achieving a level of advanced-practice in the field of dietetics. EI for dietitians has the potential to be protective against burnout and low levels of job satisfaction.

\section{Summary}

EI remains a fairly new concept, and further research will allow for an improved understanding of EI for dietitians, and how it relates to burnout and job satisfaction. The relationship between EI, job satisfaction, and burnout has not been specifically analyzed for the dietetic profession. The conclusion of the research strengthens current literature on EI, as well as promotes change at the professional, organizational, and academic level. Chapter 2 of the dissertation includes relevant literature to the study, and Chapter 3 presents research design, procedure, details of each of the survey tools that were be used, and a description of what statistical tests were utilized for the study. 
Chapter 2: Literature Review

Introduction

The relationship between EI, burnout, and job satisfaction was yet to be analyzed for dietitians. Understanding how EI impacts the rate of burnout and job satisfaction of dieticians could help increase the level of practitioners who reach advanced-practice. Multiple literature database searches were conducted in order to identify publications that are relevant to the above study. Libraries utilized in the study included Walden University Online Library. Search terms included emotional intelligence, burnout, job satisfaction, dietitians, empathy, and altruism. The scope of literature reviewed included foundational articles conducted in the 1970s; however, the majority of articles used published within the past fourteen years. Literature was collected and analyzed for inclusion. A literature review matrix was utilized for organizing common themes. The literature was organized in order to effectively investigate the current consensus on EI, job satisfaction, and burnout. The theoretical foundations behind EI were analyzed, and various models for measuring EI were examined.

\section{Theoretical Foundation for Emotional Intelligence}

EI is an overall awareness that an individual has over emotions, an ability to control reactions, and an ability to critically evaluate situations. EI is comprised of compassion, empathy, and altruism. Seal and Andrews-Brown (2010) stated "emotional intelligence is the intelligent use of emotions" (p. 144). In other words, EI is the harmonious combination of emotion and intelligence (Akerjordet \& Severinsson, 2007; Freshwater \& Stickley, 2004). 
EI is more than just managing emotions; it is understanding emotions (Mayer et al., 2001). The core of EI is adequately identifying emotions. Mayer, DiPaolo, and Salovey (1990) argued that EI allows an individual to understand what he or she is feeling and how emotions affect behaviors. However, the concept of EI can be difficult to characterize due to multiple definitions and interpretations (Seal \& Andrews-Brown, 2010). Additionally, EI is often broadly defined (Mayer, Salovey, \& Caruso, 2004b). In order to adequately define EI, its foundations must be understood.

Specifically, the foundation of EI is deeply rooted in social intelligence (Davies, Stankov, \& Roberts, 1998; Killian, 2012; Law et al., 2004; Seal \& Andrews-Brown, 2010), and social intelligence has been described as having both dynamic and static qualities (Clarke, 2006). This shifting characteristic of social intelligence aligns with EI because emotional reactions are unique, and unconventional solutions may be needed for difficult scenarios (Mayer et al., 2001). Emotions are ever changing, and how an individual reacts to a given situation can provide predictions for subsequent behaviors. EI can provide improved insight into future behaviors (Mayer et al., 2008). EI allows for analysis of the consequences that occur from negative emotions. In turn, analyzing reactions to emotions can impact the overall disposition that an individual has. Davies et al. (1998) and Killian (2012) examined EI by utilizing a self-report convenience sample, and obtained adequate response with this methodology. Recently, the use of the internet to obtain research related to EI has been successful in providing large sample sizes. Utilizing an online data collection format may hold advantages to further the 
development of EI research to unique populations, due to extending the potential participant pool.

\section{Emotional Intelligence and Altruism}

EI also has a solid foundation in altruism. Altruism is the concept of selflessness but selflessness can be difficult to define in a practical sense (Burks \& Kobus, 2012; McGaghie, Mytko, Brown, \& Cameron, 2002). Altruism is particularly important in the health field because it is viewed as a core competency (McGaghie et al., 2002; Stickley \& Freshwater, 2002). Compassion and altruism create a cycle that is vital for professional care. In addition, altruism can be developed and improved (McGaghie et al., 2002). EI and altruism are fundamentally related and this links the concepts together; therefore, altruism is an important aspect of the benefits of EI. Burks and Kobus (2012) searched the literature for specific altruistic terms and analyzed the results. It was determined that altruism is needed in order to provide compassionate care, and is a core foundation of EI. This type of analysis is useful when adequate literature is present on a particular topic.

\section{Emotional Intelligence and Empathy}

EI is closely related to empathy (Arora et al., 2010; Davies et al., 1998; Mayer, DiPaolo, \& Salovey, 1990). Therefore, it is not possible to foster and develop EI without the foundation of empathy. These two skills together may allow for greater understanding of client attitudes and thoughts (Fox, 2013). EI is especially important for health practitioners because it allows for relationship building with clients (Burks \& Kobus, 2012; Killian, 2012), and having empathy for clients may allow for improved client outcomes (Burks \& Kobus, 2012; Fox, 2013; Hojat et al., 2004; Shapiro, 2002). Empathy 
improves patient care due to the increase trust the client has with the provider, and this results in more thorough and accurate information contributed by the client (Larson \& Yao, 2005).

Empathy has also been established as a core competency for physicians (Bellini \& Shea, 2005; Shapiro, 2002) and nurses (Stickley \& Freshwater, 2002). Additionally, Shapiro, Morrison, and Boker (2004) argued that empathy is a necessary component of professionalism for health practitioners. Mood can have an impact on well-being and outlook on life. Additionally, it is possible to develop empathy from the manipulation of emotions (Mayer \& Salovey, 1997; Shapiro et al., 2004). Fostering and displaying empathy towards clients assists health practitioners in providing advanced care, and this may hold true for the dietetic profession as well. Empathy is one of the core foundations of EI, and EI is not possible without empathy. Previous research connecting EI and empathy has utilized both article review (Arora et al., 2010) and convenience repeated measures design (Shapiro et al., 2004), but that connection has not been investigated for the dietetic profession and therefore article review analysis would not be appropriate for the current research study. Convenience sampling, however, provides multiple advantages for preliminary research involving a dispersed population of registered dietitians throughout the United States.

\section{Various Foundations of Emotional Intelligence}

EI is a unique construct compared to traditional intelligence (Ciarrochi et al., 2002), and testing for these constructs results in different outcomes (Bar-on, Tranel, Denburg, \& Bechara, 2003; Daus \& Ashkanasy, 2005; Killian, 2012; Mayer \& Salovey, 
1997; Mayer et al., 2001). Mayer et al. (2008) concluded that an EI scale shows different results that that of traditional intelligence testing. This demonstrates that EI has effectively met the criteria to be considered a unique construct (Mayer, Caruso, \& Salovey, 2000; Mayer et al., 2004a).

Specifically, EI was determined to have a unique pattern when assessed, can be operationally defined, and can develop with age and experience (Mayer, Caruso, \& Salovey, 2000). The establishment of EI as a unique construct allows researchers to analyze EI effectively. In order to ensure validity and reliability, an appropriate tool was utilized. There are various foundations of EI that analyze the construct differently. Currently, there are three foundations used to describe EI. Each foundation analyzes EI in a different manner (Schutte et al., 1998). Each of these foundations measure EI in a distinctive way during the evaluation process. Even though each foundation views EI in a unique way, there is overlap. 


\section{Foundations of \\ Emotional Intelligence}

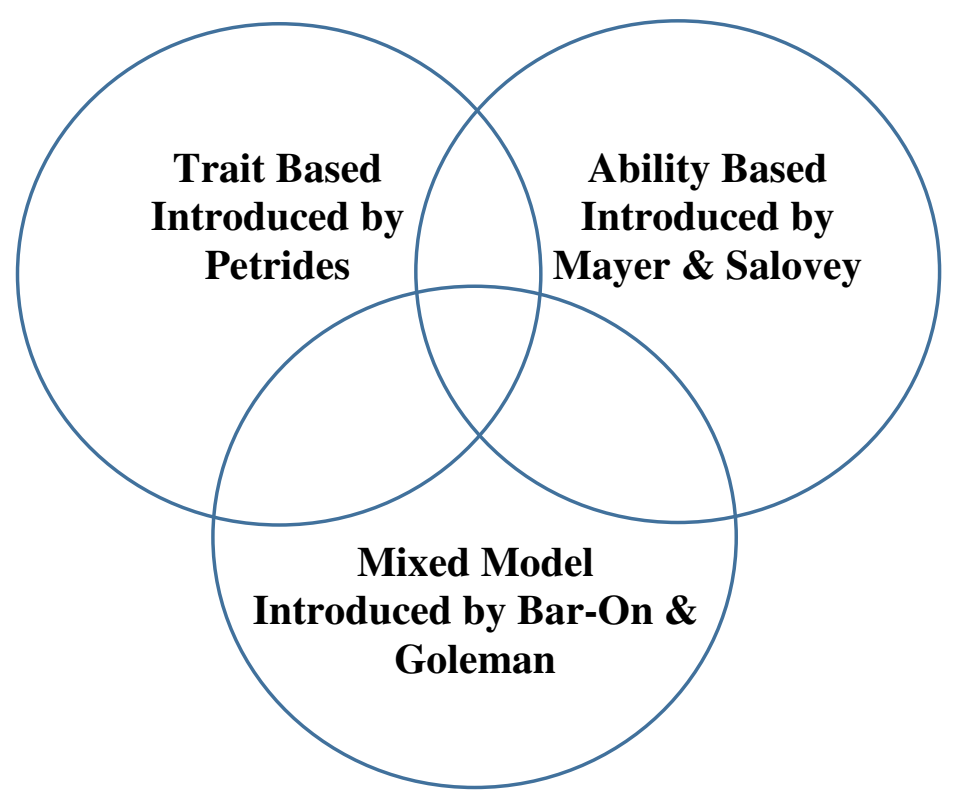

Figure 2: Foundations of Emotional Intelligence

\section{Trait-Based Emotional Intelligence}

There are different methods to measure EI, and trait-based measurement analyzes

EI in terms of personality. Trait-based EI was originally introduced by Petrides and Furnham. It is closely tied with personality traits (Petrides \& Furnham, 2006). Since certain aspects of personality are innate it may not be possible to develop EI within a person. Trait based EI is too closely linked to personality (Mikolajczak, 2009), and it may be difficult to specifically measure EI independently from personality. This may create validity concerns when utilizing trait-based EI measurements. Additionally, trait-based EI has potential flaws, such as vagueness and combining too many components related to personality under the umbrella of EI (Brannick et al., 2009; Killian, 2012). This can 
create concerns for researchers that trait-based measures may not be truly measuring EI, but rather a variety of constructs.

\section{Ability-Based Emotional Intelligence}

A second measurement of EI is ability-based. Mayer and Salovey (1997) utilize the ability-based measurement of EI. This is often considered the foundation for the modern development of EI (Codier, Muneno, Franey, \& Matsuura, 2010; Maul, 2012; Mayer \& Cobb, 2000; Seal \& Andrews-Brown, 2010), and specifically defined EI (Mikolajczak, 2009). Ability-based EI measures the perception that an individual has to interpret emotions. The ability-based measurement of EI analyzes the adaptive reactions that an individual has to emotions. This basis includes the four-branch model of EI which was utilized as the underlying backbone for the study.

Ability-based EI is flawed because it is subjective in nature (Killian, 2012), and reliability issues may be a concern (Brannick et al., 2009). Additionally, Maul (2012) argued that there appears to be limitations to the ability-based EI due to restricted indicators used for determining the level of EI. Daus and Ashkanasy (2005) asserted that ability-based EI has been rigorously analyzed even though some research exists that may have unsubstantiated claims. It is important to view the concept of EI holistically and inspect literature thoroughly, in order to prevent misinformation.

\section{Mixed Based Emotional Intelligence}

The third measurement of EI is based on emotional competence and actual behaviors (Seal \& Andrews-Brown, 2010). Goleman (1995) and Bar-on (2003) have established that EI is a mixture between trait and ability and has since been one of the 
most popular models of EI (Dulewicz \& Higgs, 2000; Mayer \& Cobb, 2000; Schutte et al., 1998; Seal \& Andrews-Brown, 2010). Bar-on argued that EI is based on patterns or skills (Seal \& Andrews-Brown, 2010). Defining EI as a unique construct from traditional intelligence allows for the analysis of the level of EI that an individual possesses. The Bar-on mixed based EI has also been noted to have validity issues (Schutte et al., 1998).

Conte (2005) concluded that each of the EI measures has some validity concerns and that more research is needed to establish legitimacy. Additionally, when the models are compared for consistency in scoring, correlation was not found (Brannick et al., 2009). The discrepancy between the three models of EI may be due to the complexity of emotions. Emotions are internal and universal, but the reaction to stimuli can be varied (Mayer et al., 2001). Emotions are multi-faceted and many components, both physical and mental, combine to form emotions (Mayer et al., 2001). One important component of EI is empathy, which has also been established as both a trait and ability (Shapiro, 2002).

EI is difficult to measure because there are multiple ways that emotions occur and are expressed and assorted ways to interpret emotions (Clarke, 2010; Mayer et al., 2008; Mayer \& Salovey, 1997). There are multiple ways to interpret emotions and situations depending on past experiences; positive versus negative reactions. Determining if participants are genuine is another challenge for researchers examining EI (Mayer et al., 2001). EI scales determine how the majority of the population would react to scenarios, compared to the "right/wrong" answers found when measuring traditional intelligence.

Researchers often choose one model to study, and fail to integrate the models together (Seal \& Andrews-Brown, 2010). There is currently a lack of standardization and 
consistency with EI measurement tools (Arora et al., 2010). Even though three models of EI exist, they may all be valid. EI can be viewed as a trait and skill (Birks \& Watt, 2007; Doherty et al., 2013; Mikolajczak, 2009). Even though there are different models of EI, they are connected by common themes (Mikolajczak, 2009).

There has been multiple attempts to measure EI through trait-based measures (Bar-on, 2003), and ability-based measures (Ciarrochi et al., 2000; Mayer et al., 2004b), but controversy over the best way to measure EI remains (Law et al., 2004). Since trait and ability measurement are different aspects of EI, it is not likely to have a generalization when comparing results (Karim, 2010). Traditional EI tests measure different aspects of EI and outcomes between tests are not always consistent. Additionally, traditional EI tests are lengthy, and there is a need for a brief EI measurement tool that is valid (Schutte et al., 1998). Even though different models exist, all EI models complement one another and common themes emerge (Ciarrochi et al., 2000; Law et al., 2004). Due to the confusion for EI testing, it may be more beneficial to measure EI using a new holistic construct, which merges all components of EI (Karim, 2010).

Seal and Andrews-Brown (2010) integrated the three different models of EI into one framework. An integrated model describes how emotional ability and potential capacity impact patterns and behaviors. Unfortunately, the integrated model has not been tested as rigorously as the components but offers a complete view of EI (Seal \& Andrews-Brown, 2010). Mikolajczak (2009) also presented a unified EI model that links knowledge, abilities, and dispositions. 


\section{Development of Emotional Intelligence}

Even though an integrated model has not been established as the gold standard for EI measurement, there is support for the concept that EI can be developed (Clarke, 2006; Dulewicz \& Higgs, 1999; Mayer \& Salovey, 1997; Mayer et al., 2001; Othman, Abdullah, \& Ahmad, 2008). Improving EI skills creates an awareness of emotions and understanding of oneself (Clarke, 2010; Zijlmans et al., 2011). EI can be advantageous for health professionals and can improve overall well-being and success (Bar-On, 2001; Fox, 2013; Goleman, 1995; Oginska-Bulik, 2005). Fernandez (2007) argued that public health training tends to leave out the development of interpersonal skills. Increased understanding of EI can allow individuals to forecast how emotions will impact behavioral outcomes (Mayer et al., 2008; Mayer \& Salovey, 1997; Shapiro, 2002). Knowledge of EI translates effectively into the workplace, as career-related relationships improve through the usage of EI (Mayer et al., 2008). Similarly, Hughes (2003) argued that dietitians should be investigated for workplace development in order to improve competency. Additionally, Nikolaou and Tsaousis (2002) determined that EI can increase work effectiveness for professionals working in mental health institutions. A self-report questionnaire was utilized, but results may be limited due to the authors specifically analyzing mental health institutions for the study (Nikolaou \& Tsaousis, 2002).

Othman et al. (2008) elaborated on how EI relates to work effectiveness by compiling literature related to EI and work effectiveness. Increased EI can give service professionals an advantage when it comes to career development since EI facilitates the interpretation of emotions in order to achieve organizational and career goals (Othman et 
al., 2008). Even though the classification of service professional can encompass dietitians, dietitians were not specifically analyzed. Teaching the components of EI can be difficult because concepts like empathy can be difficult to define (DasGupta \& Charon, 2004; Hojat et al., 2004). If empathy is not already innately present in the practitioner, self-reflection is needed in order to foster empathy. It is possible to improve emotional skills (Mayer, DiPaolo, \& Salovey, 1990), and training can improve client relationships (Satterfield \& Hughes, 2007).

There are different levels of EI, and one can progress and refine EI ability (Clarke, 2010; Law et al., 2004; Mayer \& Salovey, 1997; Mikolajczak, 2009). In order to improve skills in EI, an understanding of the fundamental levels of EI is necessary (Mayer \& Salovey, 1997).

EI is composed of identifying emotions in oneself and others (Fernandez, 2007). Constructively analyzing emotions can assist in improved organizational environment and assist with factors related to employee retention. There has been a solid foundation of literature to support practitioner development of EI skills (Clarke, 2006), and compassion is necessary for health professional retention (McGaghie et al., 2002). Additionally, emotions are used to facilitate thinking and problem solving (Clarke, 2006; Mayer et al., 2001). Understanding the components of EI leads to the development of EI which can be of benefit to health care providers.

\section{Emotional Intelligence and Dietitians}

Currently, EI is still a relatively new concept in the general literature (Mayer \& Cobb, 2000; Seal \& Andrews-Brown, 2010). EI is growing in popularity (Akerjordet \& 
Severinsson, 2007; Ciarrochi et al., 2002; Conte, 2005; Dulewicz \& Higgs, 1999;

Mikolajczak, 2009), and research in EI still developing (Akerjordet \& Severinsson, 2007;

Brannick et al., 2009; Ciarrochi et al., 2002). EI research has been completed on a variety of health professionals, but research involving dietitians is lacking (Whelan, 2007). Consequently, EI has not been analyzed for dietitians in relation to job satisfaction and burnout. Literature that is present for dietitians related to components of EI is outdated (Sauer et al., 2012). Birks et al. (2009) analyzed EI with a variety of health professions, but registered dietitians were not included. A convenience sample was utilized for students in dental, medical, nursing, and mental health fields, and results indicated that EI impacts stress levels. A potential limitation to the study is the usage of only students for the sample group. A more comprehensive view of EI should include actual practitioners. Additionally, dietitians were not included in the study. Examining this potential relationship could greatly impact the quality of services provided to clients. A successful dietitian should not only be competent but compassionate.

EI has been refined into core competencies that are particularly useful for dietitians. These components include self-awareness, self-regulation, motivation, empathy, and social skills (Fox, 2013). Each of these components plays a vital role in the overall level of EI displayed by dietitians, but empathy may be the most important component of EI for a dietetic professional to achieve. Sims and Kohli (1983) argued that empathy should be viewed as a prerequisite skill for dietitians, due to the complex relationship clients have with food. 
Dietitians with higher levels of empathy may be more successful in their job (Sims \& Kohli, 1983). Sims and Kohli (1983) commented on the resourcefulness of dietitians by stating that the varied roles that dietitians take in the field make them an innovative member of an interdisciplinary team. This assessment shows that dietitians are important to the health field, but the study is outdated.

\section{Burnout and Emotional Intelligence}

Burnout is a disease that arises from chronic negative workplace experiences (Maslach, 2004), and involves both mental and physical stress (Felton, 1998; GorgensEkermans \& Brand, 2012). Health professionals often deal with challenging and stressful work environments, which may lead to increased rates of burnout (Burks \& Kobus, 2012; Felton, 1998; Krasner et al., 2009; Nikolaou \& Tsaousis, 2002), and lowered retention rates (Bogaert et al., 2009). Additionally, Lee et al. (2010) analyzed healthcare managers and concluded that burnout is related to inadequate career progression, and lack of opportunity. Burnout among employees also results in increased costs for organizations (Shirom, 2005).

Factors related to burnout vary, but often consist of a feeling of lack of control (Felton, 1998; Gingras et al., 2010; Krasner et al., 2009; Munn-Giddings, Hart, \& Ramon, 2005; Oginska-Bulik, 2005). Burnout is especially important in the health care

field due to burnout impacting the level of care for clients (Bogaert et al., 2009; Bombeke et al., 2010; Burks \& Kobus, 2012; Felton, 1998; Gingras et al., 2010; Krasner et al., 2009; Maslach \& Jackson, 1981; Zijlmans et al., 2011). Level of care is only one 
consequence of burnout. Staff may also see alternate employment, and this high level of employee turnover has an impact on client outcomes (Maslach, \& Jackson, 1981).

There exists a relationship between the stress that can lead to burnout and EI (Deshpande \& Joseph, 2009; Law et al., 2004; Pau \& Croucher, 2003; Petrides \& Furnham, 2006), but more research is needed for specific health professions in order to refine and specify the correlation (Birks et al., 2009; McQueen, 2004). Burnout is a concern for any health organization, and there are factors that may assist with preventing or reducing level of burnout for employees. Burnout has similarities to depression (Shirom, 2005), and emotion management may be helpful in reducing the rate of burnout. Additionally, Oginska-Bulik (2005) argued that coping with emotions assists with handling occupational stress.

EI allows individuals to take control of emotions in order to encourage stressreducing behaviors (Fernandez, 2007; Tsaousis \& Nikolaou, 2005), conflict-handling, and ethical concerns (Gorgens-Ekermans \& Brand, 2012). Additionally, an understanding of EI allows individuals to identify emotions, and thoughtfully reflect on the impact of these emotions. Improved EI skills allow individuals better regulation of emotions (Petrides \& Furnham, 2006). Stress related work factors decreases the level of empathy that employees display towards clients (Doherty et al., 2013; Krasner et al., 2009; Satterfield \& Hughes, 2007; Shanafelt et al., 2005). Similarly, the level of EI impacts the job stress experienced by nurses (Akerjordet \& Severinsson, 2007; Despande \& Joseph, 2009). EI has been found to mitigate workplace and organizational stress (Arora et al., 2010). A correlation exists between increased levels of burnout and decreased levels of 
empathy (Brazeau, Schroeder, Rovi, \& Boyd, 2010). EI is a skill and can deteriorate (Doherty et al., 2013), and level of empathy may change depending on work environment.

Organizations should strive to prevent burnout in employees, and EI appears to lessen the potential for burnout (Tsaousis \& Nikolaou, 2005). Organizations should foster EI to maintain employee empathy (Doherty et al., 2013). EI can also provide techniques for dealing with difficult situations that may be emotionally straining (Syvantek \& Rahim, 2002). EI allows for an individual to gain greater understanding of emotions and the subsequent reactions related to the stressful stimulus which in turn can reduce stress and burnout.

Nikolaou and Tsaousis (2002) provided information on the relationship between EI and occupational related stress and commitment. Mental health workers that possessed increased levels of EI displayed increased commitment to organizational goals (Nikolaou \& Tsaousis, 2002). Additionally, an inverse relationship exists between EI and stress (Deshpande \& Joseph, 2009; Nikolaou \& Tsaousis, 2002). The variables of organizational commitment and decreased levels of stress lead to improved retention rates for employees.

Burks and Kobus (2012) argued that the burnout and decreased levels of altruism may become more prevalent as medical professionals progress in their careers. Altruism is not the only characteristic that can degrade over time. As health practitioners progress through their career, they lose empathy (Bellini \& Shea, 2005; Bombeke et al., 2010; Hojat et al., 2004; Shapiro, 2002). 
Moreover, EI can provide protection from work-related stressors (Birks \& Watt, 2007; Ciarrochi et al., 2002; Oginska-Bulik, 2005). Reflecting on emotions reinforces the ability to deal with emotions in a positive way, and can assist with EI development (Dulewicz \& Higgs, 1999). Losing touch with emotions either through denial or emotional dissonance can create stress (Oginska-Bulik, 2005). Additionally, a relationship exists between EI and how health workers perceive stress. As the level of EI increases, the perceived stress at work decreases (Oginska-Bulik, 2005).

Stress is a major factor related to employee burnout, and lack of emotional control can lead to increased levels of stress which has a negative impact on health (Krasner et al., 2009; Tsaousis \& Nikolaou, 2005). EI allows individuals to manage emotions adaptively thereby decreasing stress levels (Clarke, 2006; Mayer \& Salovey, 1997; Pau \& Croucher, 2003; Tsaousis \& Nikolaou, 2005). Tsaousis and Nikolaou (2005) argued that increased EI improves physical and psychological health with correlates with the participation of stress-reducing behaviors. Even though this potential relationship was supported, the study analyzed a convenience sample of students taking a psychometric course (Tsaousis \& Nikolaou, 2005). A potential limitation exists due to the sole utilization of students for the study sample. Additional research should be conducted to determine if EI impacts stress for other populations.

Additional research is needed to compare the potential connection between EI and stress for various health professions (Birks et al., 2009). Even though a lot of research has been conducted on burnout, questions remain for specific occupations and how to prevent burnout. Additionally, various health professions have been analyzed in relation to levels 
of burnout, but there is limited research for dietitians (Gingras et al., 2010; Kolodny \& Chan, 1996; Devine, Jastran, \& Bisogni, 2004). Dietitians are often involved in demanding work situations, and are an important player in the health team. EI can assist with health organizational demands (Deshpande \& Joseph, 2009). The ability for a dietitian to cope with a difficult situation, and prevent negative consequences to clients is vital to successful client care. Burnout impacts the emotional well-being that is displayed by a health practitioner, and this can have an impact on overall career satisfaction and quality of care.

\section{Job Satisfaction and Emotional Intelligence}

Job satisfaction can be defined as overall feelings related to employment, and can have a major impact on the quality of work performed. Brady et al. (2012) argued that gaining a better grasp on how components of self-and profession are connected, allow for enhanced career satisfaction. Additionally, job satisfaction has been found to be related to attitude and emotional control (Diefendorff, Richard, \& Croyle, 2006). EI facilitates the promotion of intellectual growth, through thought based off of emotions (Othman et al., 2008). Additionally, improving job satisfaction leads to improved empathy (Haas et al., 2000) and communication between clients and health provider (Cody, Ferguson, \& Desbrow, 2011; Haas et al., 2000).

Understanding the relationship that emotions have on career satisfaction is particularly important for health care organizations, as reduced retention rates may have a negative impact on quality of care (Dunn, Arnetz, Christensen, \& Homer, 2007; Felton, 1998). Additionally, job satisfaction can impact quality of care in the health setting (Chen 
et al., 2012; Haas et al., 2000). EI is linked to organizational commitment, and EI behavior results in employees feeling empowered, which has a positive impact on job satisfaction (Young-Ritchie, Laschinger, \& Wong, 2009). Dunn et al. (2007) utilized a noncontrolled prospective intervention study for physicians, and determined that improved job satisfaction rates decreased turnover rates. The study was relatively small, and noted significant physician turnover through the course of the study. Additional research involving EI and job satisfaction should aim to include a larger sample size in order to increase generalizability of results. Additionally, organizational success is a growing concern and employee job satisfaction is an important component of overall organizational success (Hackman \& Oldham, 1975).

Dietitians play an important role in the health care team, and they have a higher level of satisfaction when practitioners feel that they are helpful to the population being served (Sauer et al., 2012). Chen et al. (2012) concluded that dietitians were moderately satisfied at work, but were dissatisfied with advancement opportunities. Additionally, helping individuals has been noted as a factor related to increased levels of job satisfaction for registered dietitians (Stone, Vaden, \& Vaden, 1981; Whaley \& Hosig, 2000). Also, the development of work related skills has been noted to contribute to increased levels of job satisfaction (Sauer et al., 2012). Job satisfaction for dietitians can be improved through career advancement (Cody et al., 2011). Moreover, Birks and Watt (2007) stated that additional research should be conducted for different health practitioners in terms of EI and job satisfaction. 


\section{Emotional Intelligence, Job Satisfaction, and Burnout}

Connecting EI, burnout, and job satisfaction can assist health organizations who focus on client-centered care. Codier et al. (2010) utilized a content analysis purposive sample on stories provided by nurses. Research established that a connection existed between EI, job satisfaction, and burnout (Codier et al., 2010). Utilizing a content analysis design provides in depth look at the thoughts of participants, but can be time consuming and costly. Furthermore, a connection exists between job satisfaction and burnout (Laschinger et al., 2009). Lee et al. (2010) concluded similarly by stating that job satisfaction is negatively related to emotional exhaustion, and that deteriorating work life leads to burnout. Fostering an organizational environment that establishes a positive and supportive outlook can prevent burnout and improve job satisfaction (Felton, 1998). Emotional health can have a substantial impact on job satisfaction (Wong \& Law, 2002), and rates of burnout (Gingras et al., 2010; Birks \& Watt, 2007).

Additionally, possessing empathy in the health care field can increase the level of job satisfaction, and reduce the incidence of burnout (Burks \& Kobus, 2012). Dunn et al. (2007) came to a similar conclusion by stating that if physicians possessed decreased symptoms of burnout, they displayed increased empathy. Additionally, a relationship was discovered between job satisfaction and burnout. The connection between EI, burnout, and job satisfaction in physicians may hold true for dietetic professionals as well.

\section{Emotional Intelligence and Advanced Practice}

Othman et al. (2008) argued that EI can give professional advantages when it comes to career development, but only examined service management professionals. 
Maslach and Jackson (1981) concluded similarly on the advantages of EI, and noted the importance of looking at specific professions. The relationship that EI has on individuals in the dietetic field may hold similar advantages. Due to lack of opportunity, dietitians are leaving the field of dietetics in order to achieve career goals (Skipper, 2006; Wildish \& Evers, 2010). In order for dietitians to achieve a level of advanced practice, organizations must be able to retain employees. EI may play an important role in dietitian retention rates due to the complexity of the dietetic field, and the multifaceted relationship that clients have with food/nutrition.

Currently, literature analyzing the dietetic field is limited, but research has been conducted on the importance of EI related skills and other health professionals. Hooker et al. (2012) argued that the demand for registered dietitians is expected to grow substantially in the next few years. The demand for dietetic professionals and the lack of literature on the dietetic profession warrant further research-based investigation. Shanafelt et al. (2005) asserted that emotional well-being is related to the competency displayed by physicians. Furthermore, EI is intertwined with competencies established for the Accreditation Council for Graduate Medical Education (ACGME) for medical education (Arora et al., 2010). Additionally, EI increases the emotional competency a nurse has with clients and can impact overall quality of care (Akerjordet \& Severinsson, 2007; Deshpande \& Joseph, 2009; Freshwater \& Stickley, 2004; McQueen, 2004). Dietitians are an integral part of successful health care, and relating and understanding client challenges is a core competency that dietitians must achieve in order to ensure lasting behavior change and improved health outcomes. Wildish and Evers (2010) stated 
that improved retention rates occur for dietitians who have achieved a level of advanced practice. Achieving continued growth in the field of dietetics requires practical training of required skills (Brady et al., 2012; Cant \& Aroni, 2008; Clarke, 2006). Moreover, Nikolaou and Tsaousis (2002) argued that increased organizational success leads to advanced practice.

EI can result in increased professional success for dietitians as it improves the connectedness a practitioner has with clients. EI impacts communication. Practitioner reactions either verbal or nonverbal can greatly impact the quality of care (Cant \& Aroni, 2008). Currently, there is limited understanding on the client/dietitian relationship, and this lack of evidence could be detrimental to health outcomes (Cant \& Aroni, 2008). Additionally, the understanding that a practitioner displays to a client creates a trusting relationship between dietitian and client (Cant \& Aroni, 2008). Increased skills in EI can assist with regulating emotions in order to improve actions and reactions (Fox, 2013).

\section{Social Change}

Examining the relationship between EI, job satisfaction, and burnout has the potential to promote change in the dietetic field. Bombeke et al. (2010) argued that clientcentered care is declining, even though interest in client-centered care continues to grow (Reed, Conrad, Hernandez, Watts, \& Marcus-Smith, 2012). Health practitioner selfawareness has the potential to improve client relationships, and an innovative approach is needed to improve health delivery (Reed et al., 2012). Medical students often feel overwhelmed by the complex emotions experienced while practicing medicine, especially when dealing with challenging situations. Similarly, McQueen (2004) argued that nurses 
do not have adequate training to provide appropriate emotional support to clients. There is currently insufficient empathy training available for health professionals (Larson \& Yao, 2005). In order to deal with these emotions, organizations can equip employees with skills in EI.

The human aspect of medicine is an important component of client-centered care. In order to holistically treat clients, a relationship must be present between practitioner and client (Larson \& Yao, 2005; McQueen, 2004). Freshwater and Stickley (2004) argue that a human interaction is an important aspect of the practitioner/client relationship and is often overlooked in order to provide technical training. Additionally, the human aspect of care has been reduced due to increased regulations (Dulewicz \& Higgs, 2000). Increased regulation also has negatively impacted client centered care (Deshpande \& Joseph, 2009). Emotions are deeply entrenched in healthcare practice, and interpersonal relationships are an important part of providing care. Specifically, the nursing field has become more technical, and stringent regulations and technological advancements are often the culprit (Stickley \& Freshwater, 2002).

Another important component of EI is employee independence. Work environments should be empowering to ensure retention rates of nurses, and employee empowerment and burnout have an impact on job satisfaction (Laschinger, 2012; Laschinger et al., 2009). Similarly, Burks and Kobus (2012) state that lack of employee independence contributes to increased rates of burnout in the health care setting. If a relationship exists, then health organizations can assess the level of EI in order to analyze factors related to employee retention. 
There appears to be a link between altruism/empathy and true professionalism displayed by a health practitioner (Brazeau et al., 2010; Cohen, 2007; Satterfield \& Hughes, 2007; Shanafelt et al., 2005). Similarly, Hojat et al. (2004) argued that empathy is closely related to the level of competency a medical student possesses. Without a humanistic view of care, it is impossible to show true professionalism (Freshwater \& Stickley, 2004). According to Cohen (2007), "In the absence of humanistic grounding, professionalism lacks authenticity; it is a thin veneer resting on a fragile and undependable frame" (p. 1029). Professionalism has also been linked to competency and quality of care (Calhoun et al., 2008). Additionally, there appears to be a positive relationship between professionalism and EI (Codier et al., 2010). EI also contributes to professional identity (Akerjordet \& Severinsson, 2007), and strengthens professional competence (Akerjordet \& Severinsson, 2004; Pau \& Croucher, 2003). Similarly, there is a connection between empathy and professionalism (Brazeau et al., 2010). Displaying true professionalism in the dietetic profession should be a priority in order to distribute the greatest level of care to clients.

\section{Summary and Conclusions}

It would be advantageous for organizations to select future employees who possess increased levels of EI (Law et al., 2004; Wong \& Law, 2002), as this characteristic allows for improved client relationship (Abdullah \& Ahmad, 2008). Additionally, Diefendorff et al. (2006) argued that if emotional control is considered a required skill, employees are more likely to display this characteristic. EI can give professionals a client-centered advantage which relates to organizational success 
(Dulewicz \& Higgs, 2000), and further investigation is needed to analyze how EI impacts organizational behavior (Ashkanasy \& Daus, 2005). Deshpande \& Joseph (2009) expanded on the importance of EI by stating that EI should be evaluated during the hiring process for nurses, and can improve the way a nurse reacts to an ethical dilemma. Additionally, level of empathy should be analyzed for medical school admissions (Hemmerdinger, Stoddart, \& Lilford, 2007; Hojat et al., 2004), as well as play a part in continuing education (Shapiro, 2002).

Altruism and empathy development must be integrated into health care training in order to provide compassionate client-centered care (Burks \& Kobus, 2012; Cohen, 2007; Shapiro, 2002). Diefendorff et al. (2011) argued that organizations should set the expectation of emotional control displayed by employees in the health care field. Setting the acceptable norms within an organization can encourage the development of EI. In order to understand how EI impacts various fields, research should be conducted for different professions (Othman et al., 2008).

The future of dietetic related research should focus on the retention of qualified professions (Sauer et al., 2012). EI may be the missing link to ensure dietetic retention rates for health organizations (Fox, 2013). The relationship between EI, burnout, and job satisfaction has not been thoroughly analyzed for dietetic professionals, and further research was needed in this area. A foundation of the concepts of EI, job satisfaction, and burnout have been established. Chapter 3 details the research design utilized for the current study, description of sampling, methodology, and hypotheses. 


\section{Chapter 3: Research Method}

\section{Introduction}

The purpose of the study was to investigate the relationship between EI, burnout, and job satisfaction for registered dietitians. The study was a convenience quantitative non-experimental research design. EI has been found to be an advantageous skill for various professions, but dietitians have not been analyzed in this regard. Burnout and job satisfaction have been linked to EI, but the connection between all three variables remains under-researched. Conducting an analysis of how EI impacts burnout and job satisfaction for dietitians has the potential to improve retention rates and increase the number of practitioners who achieve advanced practice. This connection has multiple beneficial ramifications for social change at the personal and organizational level.

In order to effectively measure EI, burnout, and job satisfaction, a survey tool was compiled from pre-existing measurements that have been previously analyzed for reliability and validity. Instrumentation for data collection was the compilation of the Wong and Law Emotional Intelligence Scale, Section 4 of the Job Diagnostic Survey, the Copenhagen Burnout Inventory, and demographic information. Each of these scales are free to use for research purposes. The tools utilized in the study (WLEIS, CBI, and JDS) are a self-report Likert Scale, which allowed for efficient collection of data, and cohesiveness throughout the survey. The survey was distributed online to registered dietitians via an e-mail list available from the Commission on Dietetic Registration. This e-mail list is available for research purposes, in order to broaden the presence of dietitians 
in research. This database allows for access to e-mail addresses of dietitians throughout the United States, which increased the sample size available.

\section{Research Design \& Rationale}

The independent variable used for the study was level of EI. The dependent variables for the study were burnout and job satisfaction. The study was exploratory in nature, due to the lack of current literature on the topic. The research design utilized was non-experimental convenience. This type of design was selected in order analyze the level of EI, burnout, and job satisfaction for dietitians in a timely and effective manner. Utilizing convenience sampling is consistent with the methodology used for existing research in EI (Birks et al., 2009; Brannick et al., 2009; Deshpande \& Joseph, 2009; Doherty et al., 2013; Nikolaou \& Tsaousis, 2002; Oginska-Bulik, 2005; Wong \& Law, 2002), burnout (Gorgens-Ekermans \& Brand, 2012; Laschinger et al., 2009; Yeh et al., 2007), and job satisfaction (Chen et al., 2012; Cody et al., 2011; Laschinger, 2012). Also, utilizing an easy to administer and time efficient survey allowed for increased sample size, which assisted with generalizing results to the dietetic population.

\section{Methodology}

\section{Population}

The population utilized for this study was registered dietitians in the United States. As of December $1^{\text {st }} 2013$ the Commission on Dietetic Registration stated that there are approximately 89,300 registered dietitians in the United States (Commission on Dietetic Registration, 2013a). A convenience sample was collected through e-mails gathered from the Commission on Dietetic Registration, and the sample included 
dietitians from a variety of states. Since e-mails were sent to dietitians throughout the United States, I have the potential to reach dietitians who serve under represented populations, and rural communities. Including these minority dietetic populations assisted in the generalizability of results. The study only examined registered dietitians. Due to the broad sampling possible with the study, the sample included a wide variety of different sub-sets of dietetic practice including community, clinical, administrative, and academic. Additionally, the increased sample size possible through mass e-mail sampling improved with the generalizability of the results.

\section{Sampling and Sampling Procedures}

The target population included registered dietitians. Dietitians are a valuable part of a multidisciplinary team and provide important support, but are in the minority compared to other health practitioners (Thorensen et al., 2008). Burton and Freeman (2005) conclude similarly by stating that dietitian services are not used as frequently as other health professionals. Additionally, the effectiveness displayed by dietitians is particularly important due to increased rates of chronic disease (Burton \& Freeman, 2005). Dietetic research is also important for improving patient care (Brotherton, 2012). Moreover, registered dietitians were selected due to the lack of current research for dietitians (Cantwell, Clarke, \& Bellman, 2006; Brotherton, 2009), and to investigate the relationship that may exist for EI, job satisfaction, and burnout.

A convenience sample was used due to ease of gathering data, and to procure adequate sample size for improved generalizability. Accurate sample size was vital to the validity of the study. If a sample size is too small, the results are inaccurate; if the sample 
size is too large then the study may be costly and time consuming. To calculate an adequate sample size, a priori power analysis was conducted.

The sampling frame was registered dietitians who are at least 18 years of age. Registered dietitians were recruited via e-mails obtained from the Commission on Dietetic Registration to participate in an online survey. Online surveys allow participants a greater level of control over the process, and may increase participation (Cantrell \& Lupinacci, 2007; Hunter, 2012; Stewart, 2003). The sample collected was representative of the dietitian population, as a wide variety of practitioners were represented. Online survey collection is selected for the study in order to obtain a variety of dietetic professionals, as well as a large sample size. Additionally, utilizing an online collection prevents human error with data entry (Cantrell \& Lupinacci, 2007; Hunter, 2012), and potential errors deciphering handwriting (Stewart, 2003). The online survey was available via Surveymonkey.com, which is a cost effective solution to maximizing sample size (Brandon, Long, Loraas, Mueller-Phillips, \& Vansant, 2014).

To determine appropriate sample size, the effect size, the alpha level, and power level were chosen. The effect size chosen for a study demonstrates the importance of the effect and gives practical meaning to research. Determining the appropriate effect size should be considered based off of the research being conducted. Fritz, Morris, and Richler (2012) argued that the effect size of 0.50 is appropriate for a medium/large importance of effect. Therefore, the effect size of 0.50 selected for the study. An alpha level ensures that results are accurate. Knapp (1990) argued that an alpha level of 0.01 is appropriate when conducting parametric testing, though an alpha level is 0.05 is often 
considered to be the standard (Cohen, 1992). Therefore, an alpha level of 0.05 was selected for this study. This alpha level selected is due to the use of both parametric and non-parametric testing, as well as the study being exploratory in nature. Additional research into the potential relationship between EI, burnout, and job satisfaction may require a more stringent alpha level due to the primary usage parametric testing.

In order to ensure that the study has the power to determine effect, the power level must be chosen. A common power value is 0.80 (Cohen, 1992; Ellis, 2010; Fritz et al., 2012). Effect size, the alpha level, and power level contribute to the determination of sample size. It is important that the sample size calculated is practical for the research being conducted. For the proposed study, a sample size calculator was utilized to determine an appropriate sample size (“Sample size calculator”, 2015). The Commission on Dietetic registration states that the population of registered dietitians as of December $1^{\text {st }}, 2013$ is 89,300 individuals (Commission on Dietetic Registration, 2013a). The confidence level was set at $95 \%$, and the confidence interval was set at 5 . The sample size needed was calculated to be 383 , the actual sample size of the study was 8,038 individuals.

\section{Procedures for Recruitment, Participation, and Data Collection}

E-mail addresses of registered dietitians were obtained from the Commission on Dietetic Registration. An e-mail was sent to the dietitians with a synopsis of the research study, and the purpose of the current study. The e-mail informed participants that participating in the study was voluntary, and no identifying information was collected. Additionally, participants were informed that completing the questionnaire served as 
consent to use the results for academic research purposes. Participants could exit the study at any time, and no debriefing was needed due to the lack of deception. Dietitians were given a direct link to access the survey in a digital format, as this may increase participation due to ease of access (Hunter, 2012). A time table of one month of collection was established, and is a common time frame used for online survey collection (Cantrell \& Lupinacci, 2007). The e-mail included contact information for the researcher, and how to request further information regarding the study. Once the initial contact email was sent, a follow-up e-mail was sent after two weeks. This e-mail reiterated the current study and again asked for participation. A follow-up e-mail is recommended in order to increase response rate (Hunter, 2012). In general, online survey tools result in reduced levels of response rate when compared to a paper survey. Previous research has indicated that the response rate for an online survey tool may be as high as $30 \%$ (Duncan, 2008), while others have cited lower response averages of around 17\% (Medway \& Fulton, 2012). For the research study, the population of registered dietitians has not been previously surveyed for EI, job satisfaction, and burnout. Due to this lack of previous research, the response rate for the study may be significantly lower due to level of knowledge/interest about the topic. If the study were to achieve a 20-30\% response rate it would be deemed an acceptable response rate (Duncan, 2008; Medway \& Fulton, 2012). Realistically, the response rate may as low as 5-10\% (Medway \& Fulton, 2012). Additionally, a section was included to thank dietitians who have already participated in the study. Debriefing was not needed, and no deception was used in the study. 
The sections of the survey included the WLEIS scale, section 4 of the Job Diagnostic Survey, and the Copenhagen Burnout Inventory. Each of these scales were previously developed and have been tested for validity and reliability. The last part of the survey tool included demographic information including age, sex, ethnicity, education, income, field of dietetic practice, and years of practice. The demographic section of the survey was created by the researcher. The demographic information was purposefully included at the end of the survey tool as to increase completion of the survey (Meadows, 2003). The online survey tool was set up in a simple manner, without the usage of graphical support as this can distract participants (Hunter, 2012; Cantrell \& Lupinacci, 2007).

\section{Instrumentation}

\section{Wong and Law Emotional Intelligence Scale}

The four-branch model was developed in order to reduce EI to the most common denominators, and originated from the ability based foundation of EI (Mayer \& Salovey, 1997). The four-branch model has been thoroughly analyzed in the literature, and further EI investigations should be based on this model (Ashkanasy \& Daus, 2005).

Additionally, the four-branch model has been specifically analyzed, compared to a broad view EI that is often cited without valid scientific inquiry (Mayer et al., 2004b). The four components of EI include emotion perception, regulation, understanding, and utilization (Mayer et al., 2004b; Wong \& Law, 2002).

Wong and Law (2002) developed a scale to measure EI (WLEIS), based on the four-branch model. The WLEIS scale was a free to use simple and practical way to 
measure EI effectively for a large sample and contains 16 questions on a 7 point Likert Scale (Wong \& Law, 2002). The WLEIS scale was divided into four subsections; selfemotions appraisal (SEA), others-emotions appraisal (OEA), use of emotion (UOE), and regulation of emotion (ROE). The subsections found in the WLEIS support the concept of EI being multifaceted (Shi \& Wang, 2007; Wong \& Law, 2002).

Karim (2010) concluded adequate reliability of each of the WLEIS scales due to adequate Cronbach alpha levels of 0.81 (SEA), 0.80 (OEA), 0.78 (UOE), and 0.79 (ROE), which indicates an acceptable reliability score (Bland \& Altman, 1997). Additionally, composite factor reliability was conducted for each WLEIS scale with values of 0.82 (SEA), 0.81 (OEA), 0.80 (UOE), and 0.81 (ROE). WLEIS scale has also been tested for construct validity in measuring EI (Karim, 2010; Law et al., 2004; Shi \& Wang, 2007; Wong \& Law, 2002), as well as reliability when compared to other EI measurements (Karim, 2010; Shi \& Wang, 2007; Wong \& Law, 2002). This reinforces the usage of the WLEIS scale because in order for a new EI tool to be valid, there must be consistency when compared to pre-existing EI tools (Schutte et al., 1998). Moreover, the WLEIS scale has been found to overlap with other measures of EI (Shi \& Wang, 2007). Additionally, the WLEIS scale has been noted as an important construct for future research (Law et al., 2004).

The WLEIS scale has been previously used for the general population (Karim, 2010) and University students (Libbrecht et al., 2010; Shi \& Wang, 2007). Currently, the WLEIS scale has not been used to determine the level of EI for dietitians. The WLEIS scale is time efficient due to being a self-report survey. Self-report of EI has been well 
researched (Birks \& Watt, 2007), but self-reported responses may include bias (Birks \& Watt, 2007; Clarke, 2010; Libbrecht et al., 2010). Even though disadvantages exist for self-report measurements, they are particularly useful due to being inexpensive and easy to administer for large samples (Libbrechet et al., 2010).

\section{The Copenhagen Burnout Inventory}

While the Copenhagen Burnout Inventory was the instrument of choice for the current study, the most popular measurement tool for assessing burnout has been the Maslach Burnout Inventory (MBI) (Kristensen, Borritz, Villadsen, \& Christensen, 2005). It is well established that burnout can result from working in the human service field (Kristensen et al., 2005), and the MBI scale is geared towards individuals working with the public. Even though a relationship exists between burnout and the human service field, the MBI format is not appropriate for all occupations. Additionally, the MBI is used so frequently that data may be unreliable due to the inability to compare results to other burnout measurement tools (Kristensen et al., 2005). The MBI has been updated to a general format with the goal of analyzing other professions. Disadvantages of the MBI remain due to all components of burnout being put into one model, instead of looking at them separately (Kristensen et al., 2005; Schaufeli \& Taris, 2005; Shirom, 2005; Yeh et al., 2007). Additionally, the potential relationship between variables in the MBI have not been analyzed. In order to accurately assess all occupations with regards to burnout, a new tool is needed.

The Copenhagen Burnout Inventory (CBI) was originally designed for the PUMA (Project on Burnout, Motivation and Job Satisfaction) study which was a longitudinal 
study that assessed the prevalence of burnout (Kristensen et al., 2005). Sonnentag (2005) argued that the CBI was developed in order to rejuvenate the tool used to measure burnout. The CBI has also been used to analyze burnout for Taiwan employees (Yeh et al., 2007). With adequate internal consistency shown, as evidenced by Cronbach's alpha of 0.86 , and a positive Pearson correlation between personal/work burnout of 0.78 (Yeh et al., 2007). The CBI has been analyzed for validity and reliability and has been used in conjunction with job satisfaction research with $r=0.72, p<0.01$ (Kristensen et al., 2005). The CBI was composed of three sections: personal burnout, work-related burnout, and client-related burnout, and was free to use for research purposes (Kristensen et al., 2005 p.197). Each of the three sections was based on theories of burnout and can stand alone; this format allowed for a more accurate measurement of burnout (Kristensen et al., 2005; Shirom, 2005). The three component system of the CBI is unique compared to other burnout tools, (Shirom, 2005) and supports that exhaustion is the main component of burnout (Kristensen et al., 2005). Additionally, each section of the CBI corresponds to different groups of people, and therefore, the CBI can be used for anyone in the population. The CBI was easy to use and administer (Kristensen et al., 2005; Yeh et al., 2007), and can determine the degree of burnout that an individual has (Kristensen et al., 2005).

\section{Job Diagnostic Survey}

The Job Diagnostic Survey (JDS) was developed by Hackman and Oldham (1975) and contains multiple dimensions of measuring employee motivation and productivity, and was free to use for research purposes. The JDS was composed of seven 
distinct sections, based on five job characteristics including skill variety, task identity, task significance, autonomy, and feedback (Hackman \& Oldham, 1975). The original JDS survey was tested for internal consistency reliabilities with Cronbach's alpha levels varying from $0.56-0.84$ when examining responses related to job satisfaction (Hackman \& Oldham, 1975). The original JDS has been revised to reword the reverse score items, due to measurement inconsistencies (Idaszak \& Drasgow, 1987). Even though reverse score items were removed in the revised version, a correlation matrix was conducted to conclude that the five job characteristics remained consistent in the revised version. Buys et al. (2007) tested scale reliability for the revised JDS and concluded that for each of the five job characteristics utilized in the JDS survey, there existed a positive reliability, as the Cronbach's alpha coefficient was between 0.67-0.79. According to Bland and Altman (1997) a Cronbach's alpha of 0.7-0.8 is deemed to be an acceptable value for reliability. The JDS has been previously used for a variety of professions for both American workers (Hackman \& Oldham, 1975), and workers in South Africa (Buys et al., 2007).

Additionally, the JDS has been previously utilized for professionals, managers, clerical, processing, and machine workers (Idaszak \& Drasgow, 1987). Section four of the JDS specifically analyzes job satisfaction, and breaks down satisfaction into five categories; job security, pay, social, supervisory, and growth (Hackman \& Oldham, 1975). This section is of particular importance when measuring job satisfaction and therefore was the only section utilized from the JDS in the current study. 


\section{Summary of Instrumentation Tools}

The WLEIS, CBI, and JDS were combined into one survey tool (Appendix B). In order to reduce the potential concerns regarding combining the WLEIS, CBI, and JDS, a panel of dietetic peers (4 experts in the dietetic field) was surveyed (Appendix A). Functionality and validity was tested through this focus group. During this process, dietetic peers answered questions about the compiled survey including validity evaluation (content validity, construct validity, face validity, item bias, consequential validity), and reliability evaluation (internal consistency, and potential for reliability).

\section{Operationalization}

EI was defined as an individual's ability to control and manage their emotions (Zijlmans, Embregts, Gerits, Bosman, \& Derksen, 2011). EI was measured in this survey through the usage of the WLEIS scale developed based on the four-branch framework for EI. Burnout was defined as a disease that arises from chronic negative workplace experiences (Maslach, 2004), and involves both mental and physical stress (Felton, 1998; Gorgens-Ekermans \& Brand, 2012). Burnout was measured by the Copenhagen Burnout Inventory that included personal burnout, work-related burnout, and client-related burnout. Job satisfaction was defined as overall feelings related to employment. Job satisfaction was measured by section 4 of the Job Diagnostic Survey. Each of the three survey tools utilized (WLEIS, JDS, CBI) quantifiably measured EI, job satisfaction, and burnout.

The level of EI, job satisfaction, and burnout for registered dietitians as assessed through the usage of three distinct survey tools. All three survey tools were compiled into 
a questionnaire for participants to complete. The data collected from EI, burnout, and job satisfaction were downloaded into SPSS, where descriptive and inferential statistics were conducted. The study utilized both parametric and non-parametric testing in order to achieve a greater level of significance for Likert Scale data. Assumptions were made with the data in order to utilize parametric testing, and the utilization of non-parametric testing justified these assumptions. Additionally, demographic information was collected in the survey, and frequency analysis was conducted on these data.

\section{Data Analysis Plan}

Data were collected through an online survey distributed via e-mail.

Instrumentation for data collection was the compilation of the WLEIS EI scale, Section 4 of the Job Diagnostic Survey and the Copenhagen Burnout Inventory. Additionally, demographic information including age, sex, ethnicity, field of dietetics, years of dietetic practice, education, and income were collected. Identifying information was not be collected, and all data were confidential. In order to ensure confidentiality, a nonidentifying ID number was assigned to each data set.

Data analysis were conducted using SPSS 21.0. Data were cleaned and screened. Missing values were accounted for through specific coding. SPSS was utilized to omit the values from analysis, in order to present valid statistics. The data were examined in order to determine if correlations exist between variables. Statistical tests that were utilized include descriptive statistics, and inferential statistics (including both non-parametric and parametric tests). Tables of distributions and frequencies were conducted for all variables. The current study addressed the following questions: 
1. What is the level of EI for registered dietitians?

2. Does a relationship exist between level of EI and level of burnout for dietitians? $H_{0} 1$ - No relationship exists between level of EI and level of burnout for dietitians.

$H_{\mathrm{a}} 1$ - A relationship exists between level of EI and level of burnout for dietitians.

3. Does a relationship exist between level of EI and level of job satisfaction for dietitians?

$H_{0} 2$ - No relationship exists between level of EI and level of job satisfaction for dietitians.

$H_{\mathrm{a}} 2$ - A relationship exists between level of EI and level of job satisfaction for dietitians.

The statistical tests that were conducted for the study include descriptive statistics of demographic information, which include age, sex, ethnicity, education, income, field of dietetic practice, and years of dietetic practice. Frequencies and distributions were also analyzed. Inferential statistics were also conducted in order to determine the relationship between EI, burnout, and job satisfaction for registered dietitians. In order to decide appropriate statistical tests, the scale of measurement, and purpose of analysis must be determined (McCrum-Gardner, 2008). If incorrect testing is conducted, the results are misleading (McCrum-Gardner, 2008).The study included both non-parametric and parametric testing for the Likert Scale data. Parametric testing is often used for Likert Scale tools, but certain criteria must be met in order to do so. Conducting non-parametric 
tests in addition to parametric will support conclusions, and prevent misleading results. Results were interpreted using SPSS output. A Pearson correlation of $p=0.05$ was used to determine significance. Pearson's $r$ is a correlation to determine if a relationship is linear, and can be between +1 to -1 . Previous research within the field of EI has concluded a correlation coefficient to be within the range of 0.59-0.65 (Birks, McKendree, \& Watt, 2009; Gorgens-Ekermans \& Brand, 2012). Therefore, the $r$ value of 0.60 was utilized for the current study. Correlations were computed between EI and job satisfaction, as well as between EI and burnout. Confidence intervals were set at $95 \%$.

\section{Non-parametric Testing}

Non-parametric testing is traditionally used when dealing with Likert Scales (McCrum-Gardner, 2008), due to the difficulty in determining the equality between levels (Jamieson, 2004). It has been argued that only non-parametric tests should be used for Likert Scales (Jamieson, 2004). If utilizing non-parametric testing, Likert Scale data is seen as ordinal in nature, and frequencies and percentages should be used in data analysis (Jamieson, 2004). Even though non-parametric testing is traditionally used, the results are not as powerful when compared to parametric testing (McCrum-Gardner, 2008). There remains controversy over the usage of parametric tests for ordinal level data. Kuzon, Urbanchek, \& McCabe (1996) argue that the calculations needed to conduct valid parametric tests require interval/ratio level data, and ordinal level data cannot be used in this manner. The non-parametric test that was conducted for the data is a chi square. Chi square is easy to compute and is a valuable test to determine statistical 
significance (McHugh, 2013). In addition to the chi square test, a Cramer's V test was conducted in order to measure statistical strength.

\section{Parametric Testing}

There is a disagreement when it comes to using inferential statistics for traditionally ordinal level data (Knapp, 1990). Even though controversy exists for ordinal level data, inferential statistics provide many benefits compared to descriptive statistics. Parametric testing produces more powerful conclusions, but utilizing this testing for Likert Scale can only be used if it can be justified (McCrum-Gardner, 2008). There has been some argument that parametric testing can be effectively conducted for Likert Scale tools if certain criteria are met. Additionally, it is common to assume Likert Scale data is interval in nature, not ordinal (Jamieson, 2004). Likert Scale data is not a true interval measurement, but it can be assumed that the difference between levels are equal (Knapp, 1990). In order to conduct parametric testing, non-parametric testing should also be conducted in order to determine result consistency. Additionally, using at least a 5-7 Likert Scale, and utilizing a stringent alpha level of at least 0.01 ensure that the results are accurate. An important component of parametric testing is that the data is normally distributed (Knapp, 1990; McCrum-Gardner, 2008). Utilizing a large sample size makes the usage of parametric testing more credible when using a Likert Scale (Jamieson, 2004). Since parametric testing was conducted for this study, these criteria are met. Interestingly, Gaito (1980) argued that scale measurement has nothing to do with statistical tests and is irrelevant. If this statement is true, it is not necessary to take precautions when conducting parametric tests with ordinal data. Moreover, using only 
interval/ratio level data for parametric tests is a misconception (Gaito, 1980).

Controversy remains over the usefulness and requirement of scale of measurement.

In order to produce the most accurate results, both non-parametric and parametric tests were conducted. Since assumptions were made by utilizing Likert Scale data for parametric tests, including non-parametric testing assisted with validating the usage of parametric testing. If the non-parametric tests conclude similarly to the parametric tests, then more powerful conclusions can be made about the data. The tests that were utilized for the data include linear regression, which was computed for EI compared to job satisfaction, and EI compared to burnout.

\section{Threats to Validity}

Potential threats to validity include both internal and external validity. Internal validity concerns may arise from the instrumentation tool. The combination of the WLEIS, JDS, and CBI into one combined tool may cause validity concerns with the instrumentation of the study. The combination and organization of this combined tool may impact the choices that participants make on the self-report survey. Additionally, these tools have not ever been utilized in the dietitian population. In order to combat this potential threat to validity, the survey tool presented the WLEIS, section four of the Job Diagnostic Survey, and Copenhagen Burnout Inventory in entirety, instead of integrating components of each survey haphazardly into the instrumentation tool. Since the WLEIS, JDS, and CBI have already been tested for validity and reliability, this reduced potential validity concerns when combining these tools into one multi-faceted survey. 
External validity concerns may arise from social desirability bias, which is a common concern for survey based research (Nederhof, 1985). The study had limitations related to the usage of a self-report tool. Utilizing the self-report method for EI skill may measure perceived EI skill, not the actual EI performance (Libbrecht et al., 2010; Roberts, Matthews, \& Zeidner, 2001). Additionally, self-report tools are susceptible to social desirability bias (Ciarrochi et al., 2000; Karim, 2010; Roberts, Matthews, \& Zeidner, 2001; Shi \& Wang, 2007). Participants may select certain responses based on how they feel the researcher wants them to respond. Offering anonymity through selfadministration of the survey tool, and lack of identifying information being collected will reduce the incidence of social desirability bias (Nederhof, 1985). In order to combat this potential threat to validity, I strived for an adequate sample size of at least 383 participants, in order to achieve closer representation of the dietetic population. Threats to validity are often a concern when conducting research, but ensuring a large sample size, proper instrumentation, and self-administration reduced the occurrence of potential validity concerns.

\section{Ethical Procedures}

The ethical protection of participants is of utmost importance, and the survey tool did not include deception. Participants were given a brief synopsis of the importance of the study, goals, and contact information if questions arise. Additionally, I was available via e-mail to answer any questions related to the study or the questions presented in the survey. The proposed research project was submitted to Walden University's IRB. An application to the IRB included a consent form, and letter of introduction. Participants 
were given an electronic link to access the survey, and this served as consent in order to participate in the study. The e-mail informed participants on the confidentiality of data, and that no identifying information was collected. Recruitment of participants was voluntary, and no coercion was used to encourage dietitians to participate. If a dietitian withdrew early from the study, the data were destroyed immediately and was used in the data analysis. Dietitians were asked to participate through e-mail. A follow-up e-mail was sent after two-weeks to ask for participation, and thank those who had completed the survey. If a dietitian refused to participate in the study, there were no repercussions. Data were collected confidentially, and stored electronically in a password protected file. Data were only accessible to the researcher of this study and will be destroyed five years after use.

\section{Summary}

This chapter included a description of research that was conducted, selection of the sample, instrumentation collaboration, and methodology. The validity and reliability of the measurement tools for EI, burnout, and job satisfaction were also addressed. I took a two pronged approach to analyzing the data through the use of descriptive and inferential statistics. Since the survey tools used within the study are Likert Scales, nonparametric and parametric testing occurred to determine result consistency. 
Chapter 4: Results

\section{Introduction}

This chapter includes the detailed results of the study. The study aimed to examine the relationship between EI, job satisfaction, and burnout for dietitians. Three research questions were utilized for the study, and responses from participants were analyzed. The research questions for the study are as follows:

1. What is the level of EI for registered dietitians?

2. Does a relationship exist between level of EI and level of burnout for dietitians? $H_{0} 1$ - No relationship exists between level of EI and level of burnout for dietitians.

$H_{\mathrm{a}} 1$ - A relationship exists between level of EI and level of burnout for dietitians.

3. Does a relationship exist between level of EI and level of job satisfaction for dietitians?

$H_{0} 2$ - No relationship exists between level of EI and level of job satisfaction for dietitians.

$H_{\mathrm{a}} 2$ - A relationship exists between level of EI and level of job satisfaction for dietitians.

Prior to data collection a panel of experts, which included four colleagues, completed a form to assess the survey tool. The survey utilized for the study was a compilation of the WLEIS, CBI, and Section 4 of the JDS. Even though each of these tools had been previously analyzed for validity and reliability, there had been no analysis 
of the effects of these tools being used in combination. The panel of experts were given the survey tool, definitions of terms, and a form to complete (Appendix A) to determine if the combined survey tool appeared reliable and valid. The results of the panel's analysis determined that minor format changes to improve cohesiveness of the survey should be made. Additionally, under the demographic information category, the wording of the question changed from "field of dietetic practice" to "primary area of dietetic practice." The category of "long-term" care under primary area of dietetic practice was also removed due to being redundant. The categories of "community, clinical, administrative, and academic" are major categories of dietary practice and the category of "long-term" would fit in to each of these categories. In order to remove unnecessary categories and to decrease confusion, the category of "long-term" was removed. Chapter 4 includes details regarding the data collection process and analysis as well as results of the study.

\section{Data Collection and Analysis}

The study was approved through Walden University IRB with the approval number 06-12-15-0252758. The sample utilized for the study was the population of U.S. dietitians, which was exactly 88,159 individuals as of June $23^{\text {rd }}, 2015$. E-mail addresses were obtained from the Commission on Dietetic Registration. Due to the large volume of e-mail addresses, it was necessary to break up the e-mails into 10,000 participant increments. SurveyMonkey allowed for an e-mail distribution of 10,000 e-mails a day, and so it took nine consecutive days to e-mail all dietitians. There were a total of $1,413 \mathrm{e}-$ mails removed by SurveyMonkey due to being invalid and 2,573 removed due to 
participants previously opting out of SurveyMonkey survey requests. Therefore, the actual number of participants e-mailed was 84,173 . Data collection time was a total of one month, and a reminder e-mail was sent out at the two week mark. The number of participants who completed the survey was $n=8,038$. This makes the response rate of the survey approximately $9.5 \%$. Response rate for online surveys can vary dramatically. A response rate of $9.5 \%$ is considered to be a realistic range given the online nature of the survey (Medway \& Fulton, 2012). An ideal the response rate is 20-30\% (Duncan, 2008; Medway \& Fulton, 2012), but unfortunately this goal was not met by the study. There are several potential reasons for the lower than expected response rate. It may have been negatively affected by the month in which data were collected. Participants were emailed at the beginning of July, which corresponds with a holiday. It is possible that the response rate would have been higher given a different month of data collection. Additionally, during the collection process there were approximately 50 e-mails $(0.6 \%)$ from dietitians who were self-reported to be no longer active credentialed RDs, and therefore were instructed to not complete the survey. This indicates that it is possible that the database needs to be updated, and that the total of 84,173 dietitians was not entirely accurate. There were no discrepancies in data collection as detailed from the plan presented in Chapter 3, and data collection went as planned.

\section{Descriptive Characteristics of the Sample}

Baseline descriptive analysis was conducted on demographic information, including age, gender, ethnicity, education, income level, primary area of dietetic practice, and years of dietetic practice. These data are presented in Figures 3-9. The age 
range of participants varied and is described in Figure 3. The majority of respondents to the survey were in the 50 and above age range and those with the lowest response were in the age range of 40-49 years old. Gender statistics for the survey were calculated and are described in Figure 4. The majority of respondents were female, with only $3.26 \%$ of the participants being male. The Commission on Dietetic Registration reports that $3.5 \%$ of registered dietitians are male (Commission on Dietetic Registration, 2013b), this indicates that the demographic results of the study are consistent with the population. Ethnicity demographic information was collected for participants (Figure 5) and the majority of respondents were White $(89.38 \%)$, and the remainder of ethnic categories ranged from $0-3 \%$. The Commission on Dietetic Registration reports that $81.8 \%$ of registered dietitians are White (Commission on Dietetic Registration, 2013b), which indicates that the demographic results of the study are similar to that of the population. Over half of respondents have obtained Master's level degrees (Figure 6), and Bachelor's Degrees were noted to be slightly less than half at $43.38 \%$. Only $4.17 \%$ of respondents indicated achieving a doctoral level degree, which is consistent with the $3.6 \%$ of doctoral level dietitians reported in the Compensation and Benefits Survey conducted by the Academy of Nutrition and Dietetics in 2013 (Rogers, 2014). Approximately two-fifths of respondents indicated an income level of $\$ 50,001-\$ 75,000$ with a response of $42.96 \%$ (Figure 7). Primary area of Dietetic Practice was as follows: clinical 56.79\%, community 23.51\%, administrative $12.79 \%$, and academic 6.91\% (Figure 8). The final demographic question regarded years of dietetic practice. Respondents indicated $16+$ years $46.12 \%$ of the time, and 1-5 years of practice as the second most selected at $22.78 \%$ (Figure 9). 
Overall, demographic information is useful in regard to identifying that the sample collected is consistent with the demographic information of the population. This similarity between the sample and the population allow for generalizability of results.

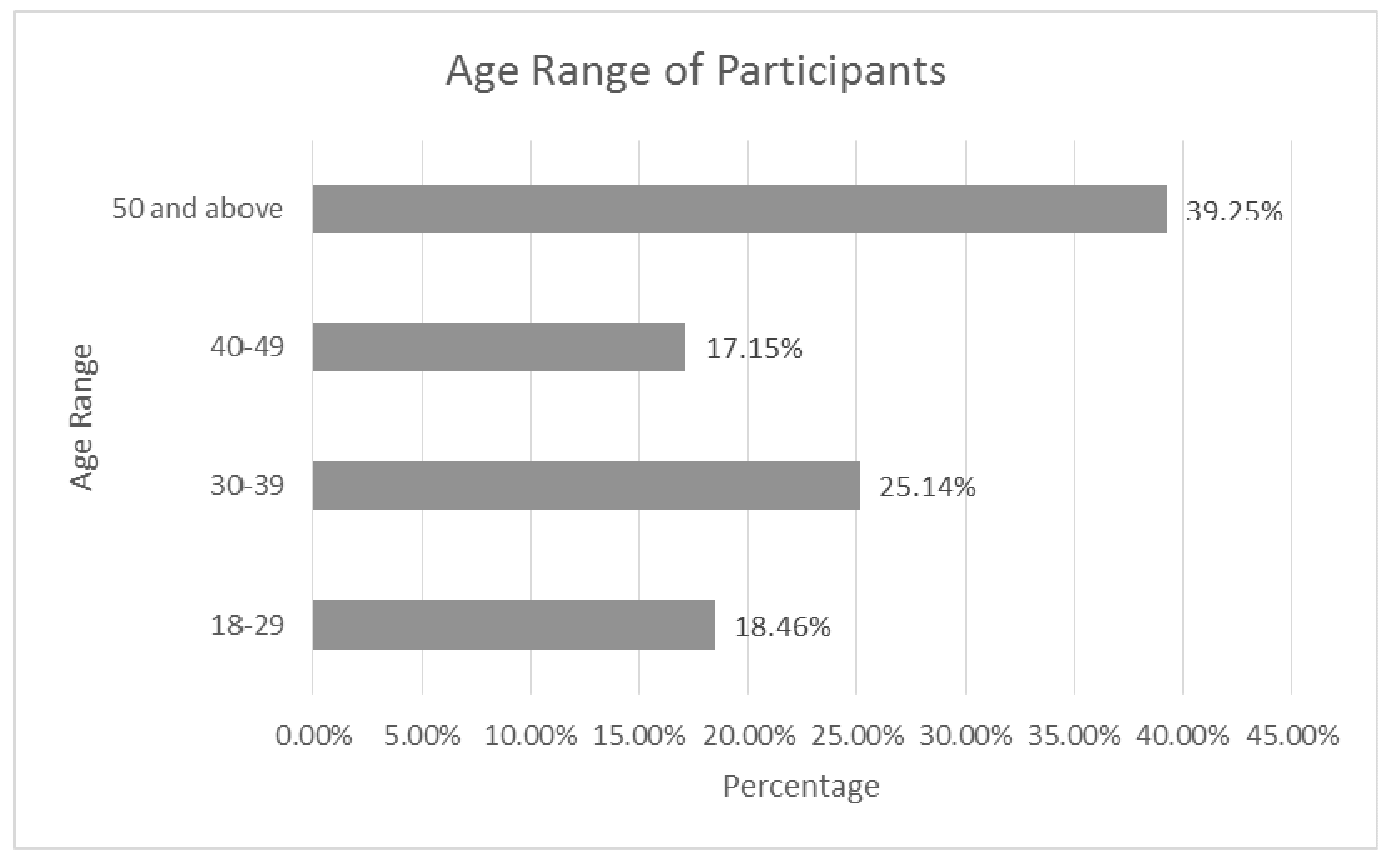

Figure 3: Age Range of Participants

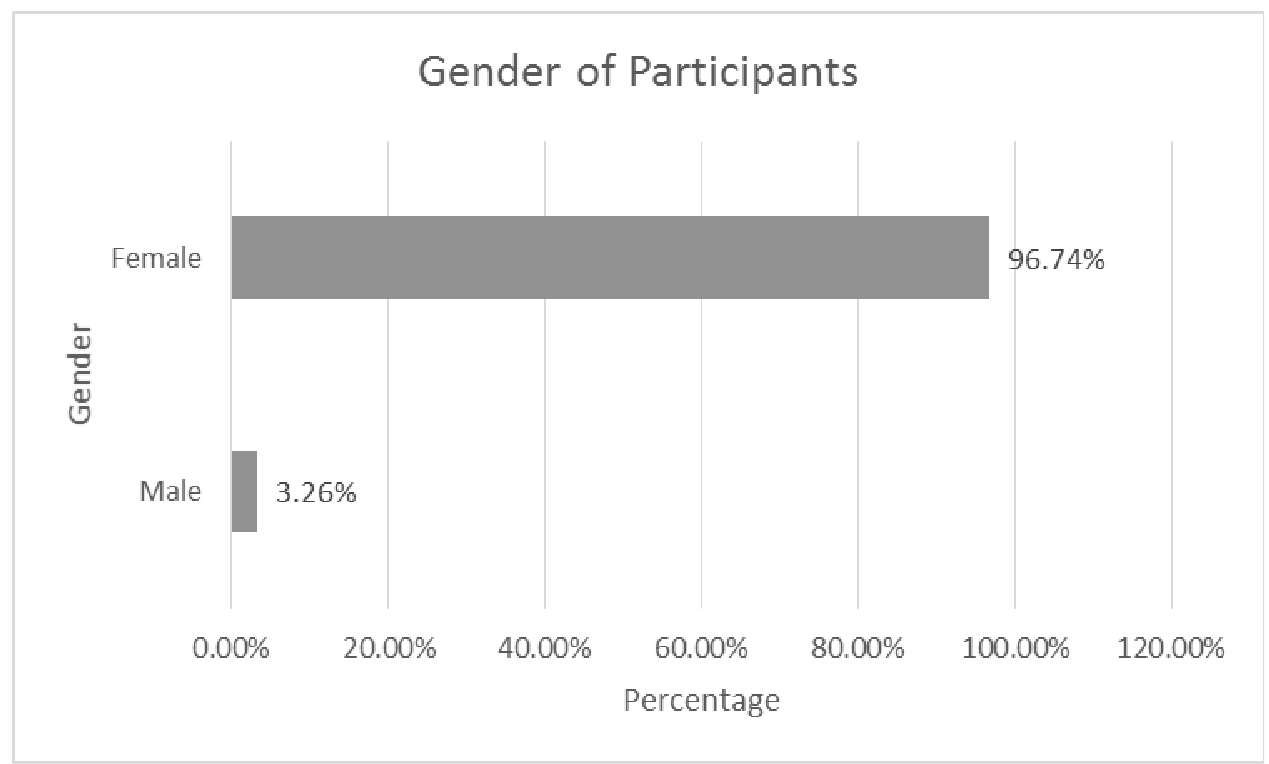

Figure 4: Gender of Participants 


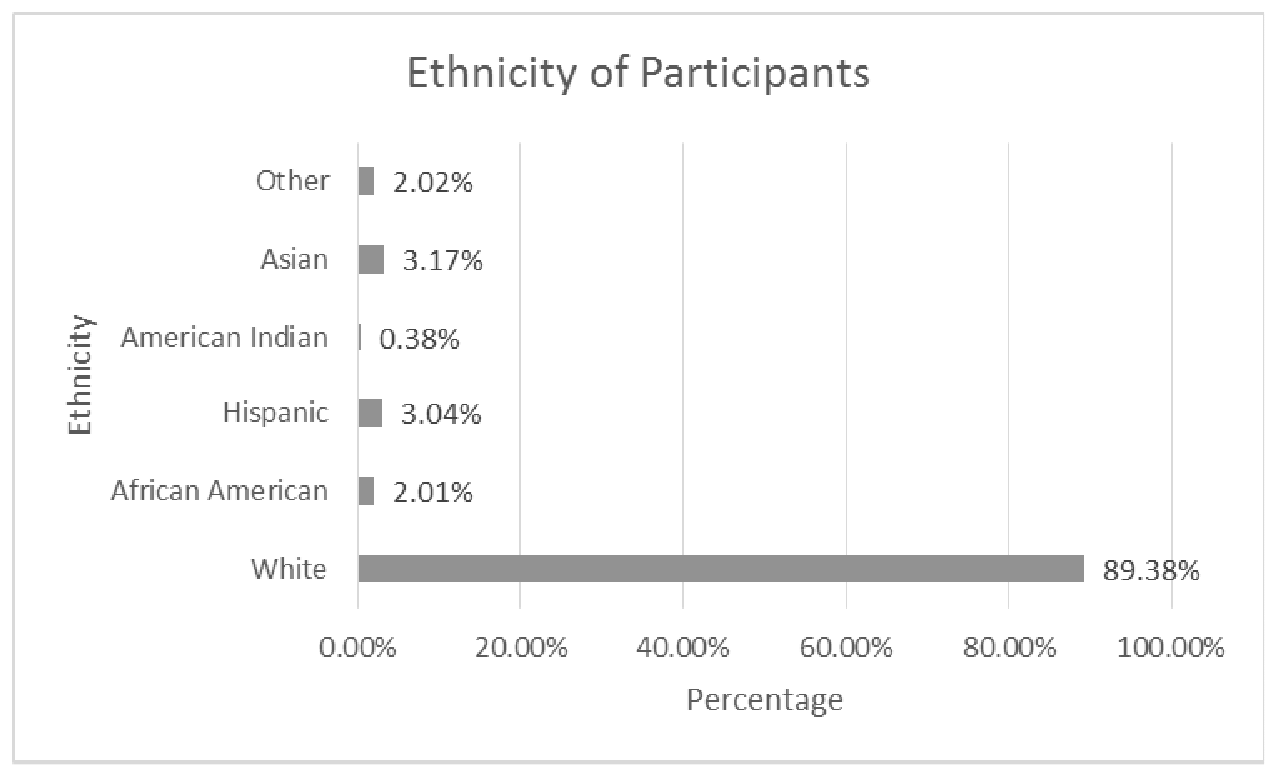

Figure 5: Ethnicity of Participants

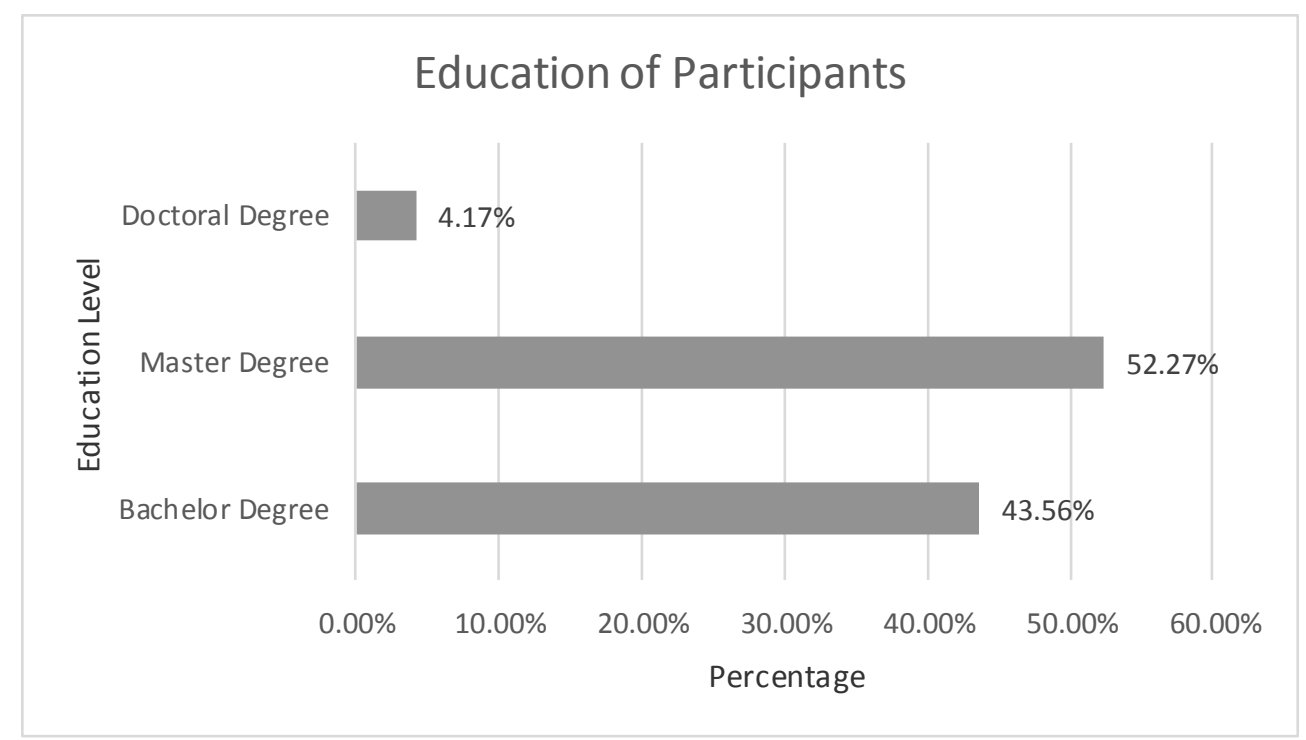

Figure 6: Education of Participants 


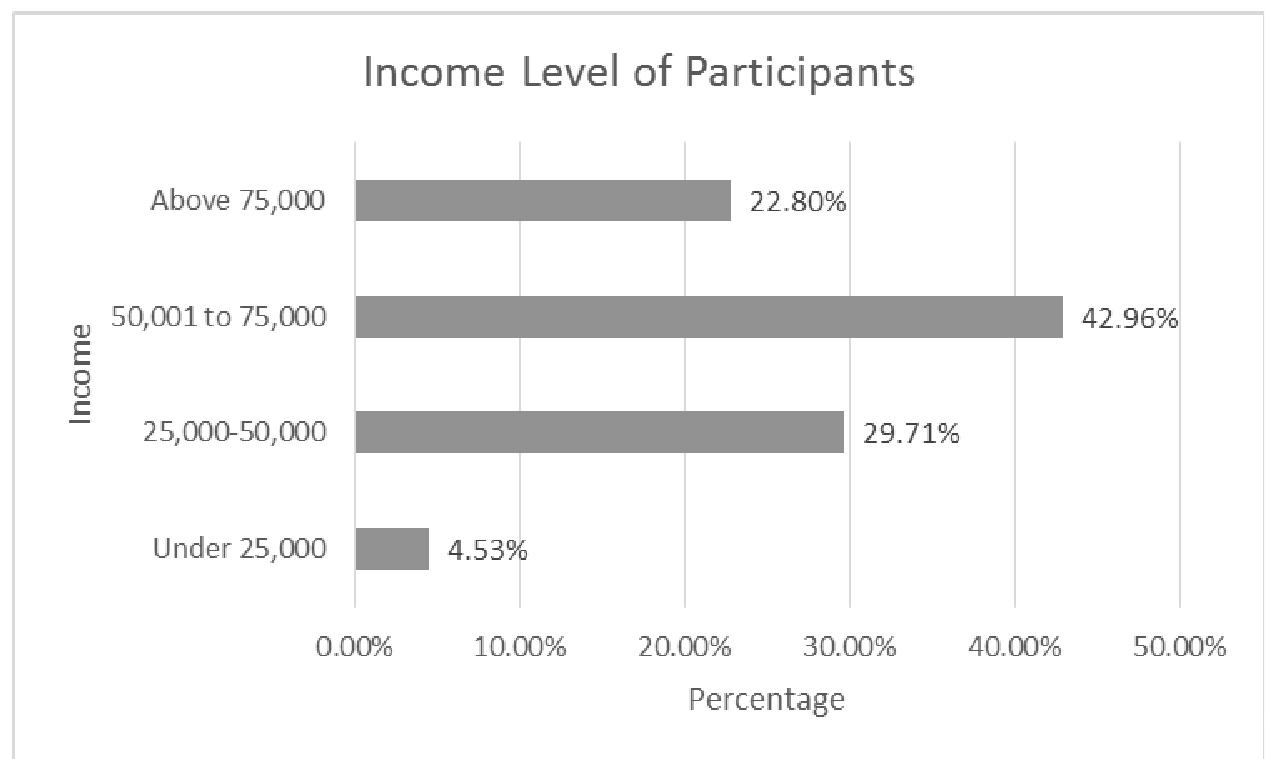

Figure 7: Income of Participants

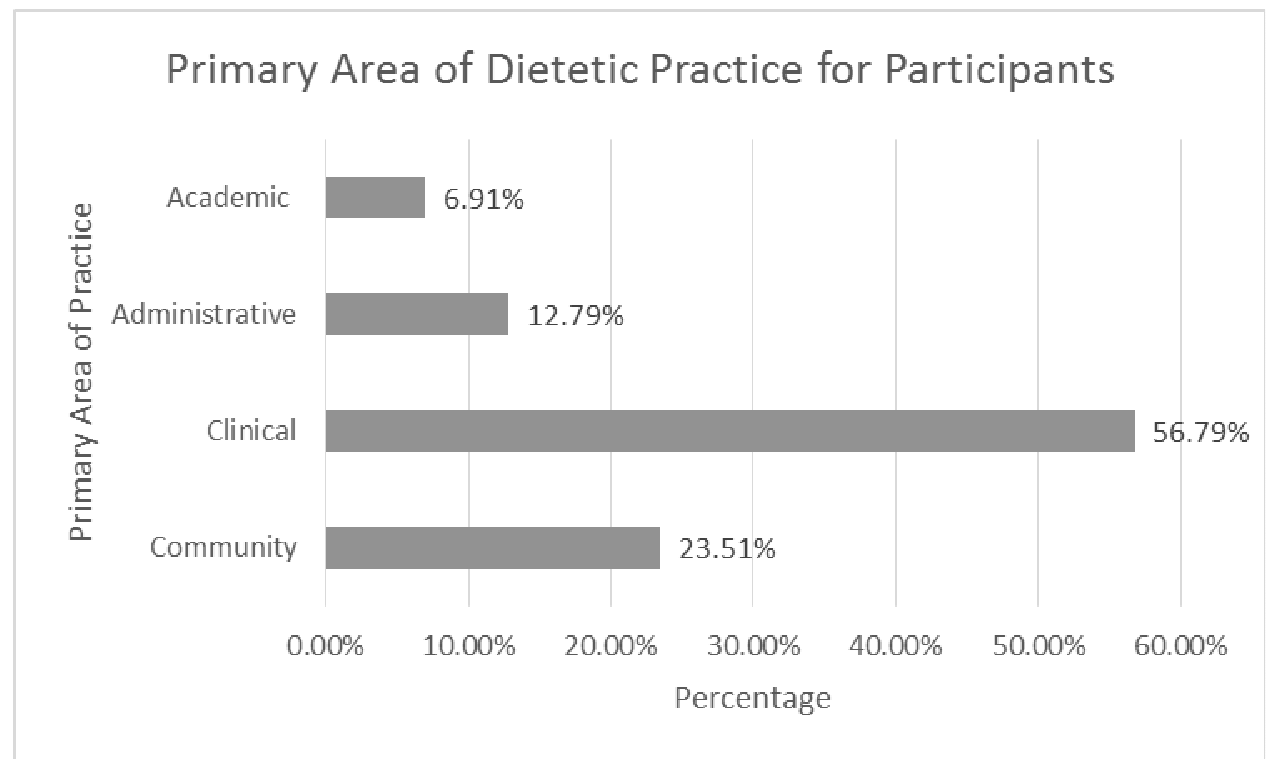

Figure 8: Primary Area of Dietetic Practice of Participants 


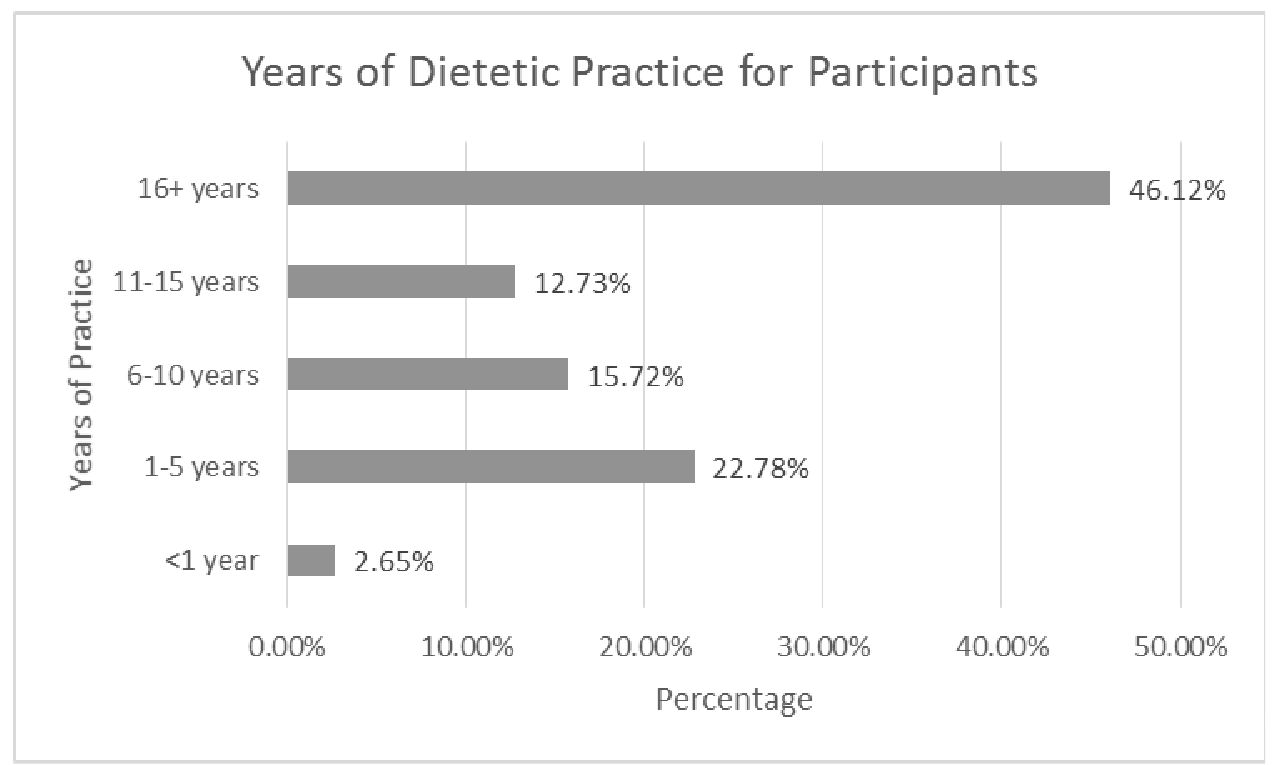

Figure 9: Years of Dietetic Practice of Participants

\section{Results}

\section{Research Question 1}

To determine the level of EI that dietitians possess I used the WLEIS tool which contained sixteen Likert Scale questions on a 7 point scale. In order to examine the data further, ad hoc tests of reliability and re-coding were conducted. The data were subsequently coded for analysis as follows (1) totally disagree, (2) disagree, (3) somewhat disagree, (4) neutral, (5) somewhat agree, (6) agree, (7) totally agree. To produce the most accurate and substantial analysis, the data were analyzed as both ordinal and interval level. In order to check the reliability of the WLEIS scale, a Cronbach's Alpha coefficient was conducted for the 16 questions utilized in the scale. The Inter-item correlation matrix for the Cronbach's Alpha reflected all positive items, indicating that the 16 questions for the WLEIS scale are measuring the same characteristic. The 
Cronbach's Alpha value was calculated to be 0.865 , suggesting a preferable internal consistency (Pallant, 2010).

The WLEIS data were recoded at the nominal level as low EI (value of $\leq 3.4$ ), neutral EI (value of 3.5-4.4), and high EI (value $\geq 4.5$ ). Frequency data were calculated based on coded data to conclude that $89.38 \%$ of participants indicated a high level of EI.

The WLEIS scale was also analyzed for skewness and kurtosis. The skewness value indicates the symmetry of the distribution, and was calculated to be -0.0763 . This indicates a clustering of values at the high end, or right hand side. The high end of the WLEIS scale corresponds with agreeable responses to high levels of EI. The kurtosis value indicates the peak of the data, and were calculated to be 1.352 . This indicates that the data for the WLEIS scale is peaked or gathered together. The mode was calculated for the 16 questions within the WLEIS scale with a value of 6 , which is coded for "agree" within in the scale, indicating increased levels of EI for dietitians. The data for the WLEIS scale were examined and formed into a histogram (Figure 10), which reflects high response on the upper end of the EI scale.

During the examination of the data for the WLEIS scale, the lower quartile was determined to be 5.37, and the upper quartile was determined to be 6.06 . In order to determine potential outliers, the outlier labeling rule was utilized. To determine the appropriate G value the factor number of 2.2 was chosen. Hoaglin \& Iglewicz (1987) determined that a $G$ value of 2.2 eliminates the problems associated with utilizing the original G value of 1.5 (Tukey, 1977), which often identifies outliers too often. After calculation, the cut off for outliers was determined to be 3.85 on the lower end, and 7.58 
on the upper end. Based on the extreme values table (Table 1), there are multiple lower end outliers. In order to correct for these low-end outliers, the data were cleaned by implementing a filter within SPSS to block cases that had a WLEIS score less than 3.85. 


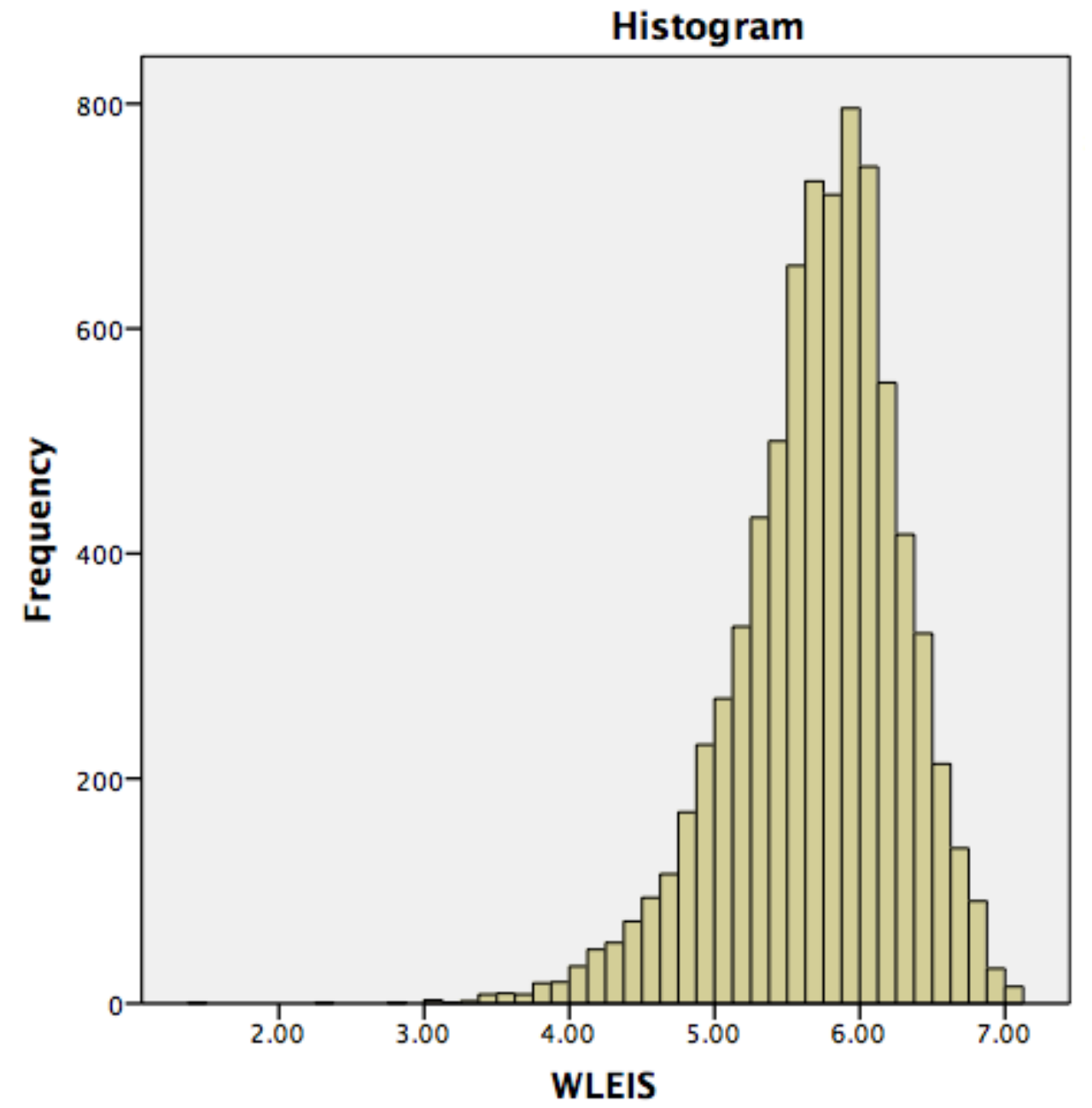

Figure 10: WLEIS Participant Data 
Table 1

Extreme Values for WLEIS

\begin{tabular}{|c|c|c|c|c|}
\hline & & & Case Number & Value \\
\hline \multirow{10}{*}{ WLEIS } & \multirow{5}{*}{ Highest } & 1 & 528 & 7.00 \\
\hline & & 2 & 651 & 7.00 \\
\hline & & 3 & 812 & 7.00 \\
\hline & & 4 & 948 & 7.00 \\
\hline & & 5 & 2401 & 7.00 \\
\hline & \multirow{5}{*}{ Lowest } & 1 & 7383 & 1.44 \\
\hline & & 2 & 3031 & 2.31 \\
\hline & & 3 & 5181 & 2.81 \\
\hline & & 4 & 3679 & 3.00 \\
\hline & & 5 & 6914 & 3.06 \\
\hline
\end{tabular}

Due to analyzing the Likert Scale data as both ordinal and interval level data, both a mean and standard deviation were calculated for the WLEIS scale. The mean for the WLEIS scale was determined to be 5.69, which is consistent with the mode. The standard deviation was calculated to be approximately 0.55 .

\section{Research Question 2}

To determine if a relationship exists for the level of EI and level of burnout for dietitians, I used the WLEIS and CBI. The CBI is comprised of seventeen Likert Scale questions on a five point scale. Additionally, the CBI is comprised of three distinct sections (personal burnout, work-related burnout, and client-related burnout). In order to examine the data further, ad hoc tests of reliability and re-coding were conducted. The data were subsequently coded as follows (1) always, (2) often, (3) sometimes, (4) seldom, (5) never/almost never; (1) to a very high degree, (2), to a high degree, (3) somewhat, (4) to a low degree, (5) to a very low degree. Question number 43 in the survey tool "Do you have enough energy for family and friends during leisure time" was reverse coded as 
follows (5) to a very high degree, (4) to a high degree, (3) somewhat, (4) to a low degree, (5) to a very low degree. To produce the most accurate and substantial analysis, the data were analyzed as both ordinal and interval level. Also to check the reliability of the CBI scale, a Cronbach's Alpha coefficient was conducted for the 17 questions utilized in the scale. The Inter-item correlation matrix for the Cronbach's Alpha reflected all positive items, indicating that the 17 questions for the CBI scale are measuring the same characteristic. The Cronbach's Alpha value was calculated to be 0.926 , suggesting a highly preferable internal consistency.

The WLEIS data were re-coded at the nominal level as low EI (value of $\leq 3.4$ ), neutral EI (value of 3.5-4.4), and high EI (value $\geq 4.5$ ). Additionally, the CBI data were re-coded at the nominal level as high burnout (value of $\leq 2.4$ ), neutral burnout (value 2.53.4), and low burnout (value $\geq 3.5$ ). The CBI data were analyzed to determine that $54.7 \%$ of participants have low burnout, and $7.31 \%$ of participants have high burnout. This indicates that the majority of dietitians report low rates of burnout. The data were then analyzed utilizing a chi-square. There is evidence to support a relationship between EI and burnout (chi value $\left.x^{2}=193.75, d f=2, p=0.000\right)$.

The CBI scale was also analyzed for skewness and kurtosis. The skewness value indicates the symmetry of the distribution, and was calculated to be -0.328 . This indicates a slight clustering of values to the right hand side. The high end of the CBI scale corresponds with responses related to low rates of burnout. The kurtosis value indicates the peak of the data, and was calculated to be -0.157 . This indicates that the data for the CBI scale is relatively flat and spread out. The mode was calculated for the 17 questions 
within the CBI scale with a value of 3 , which is coded for "sometimes" within in the scale.

During the examination of the data for the CBI scale, the lower quartile was determined to be 3.05, and the upper quartile was determined to be 4.0. In order to determine potential outliers, the outlier labeling rule was utilized, with a G value of 2.2. After calculation, the cut off for outliers was determined to be 1 on the lower end, and 6.09 on the upper end. The upper end of the outlier calculation is not possible due to the CBI being a 5 point Likert Scale. Therefore, the highest number possible for scoring is a 5. Based on the extreme values table (Table 2), there are no outliers, therefore data were not cleaned. 


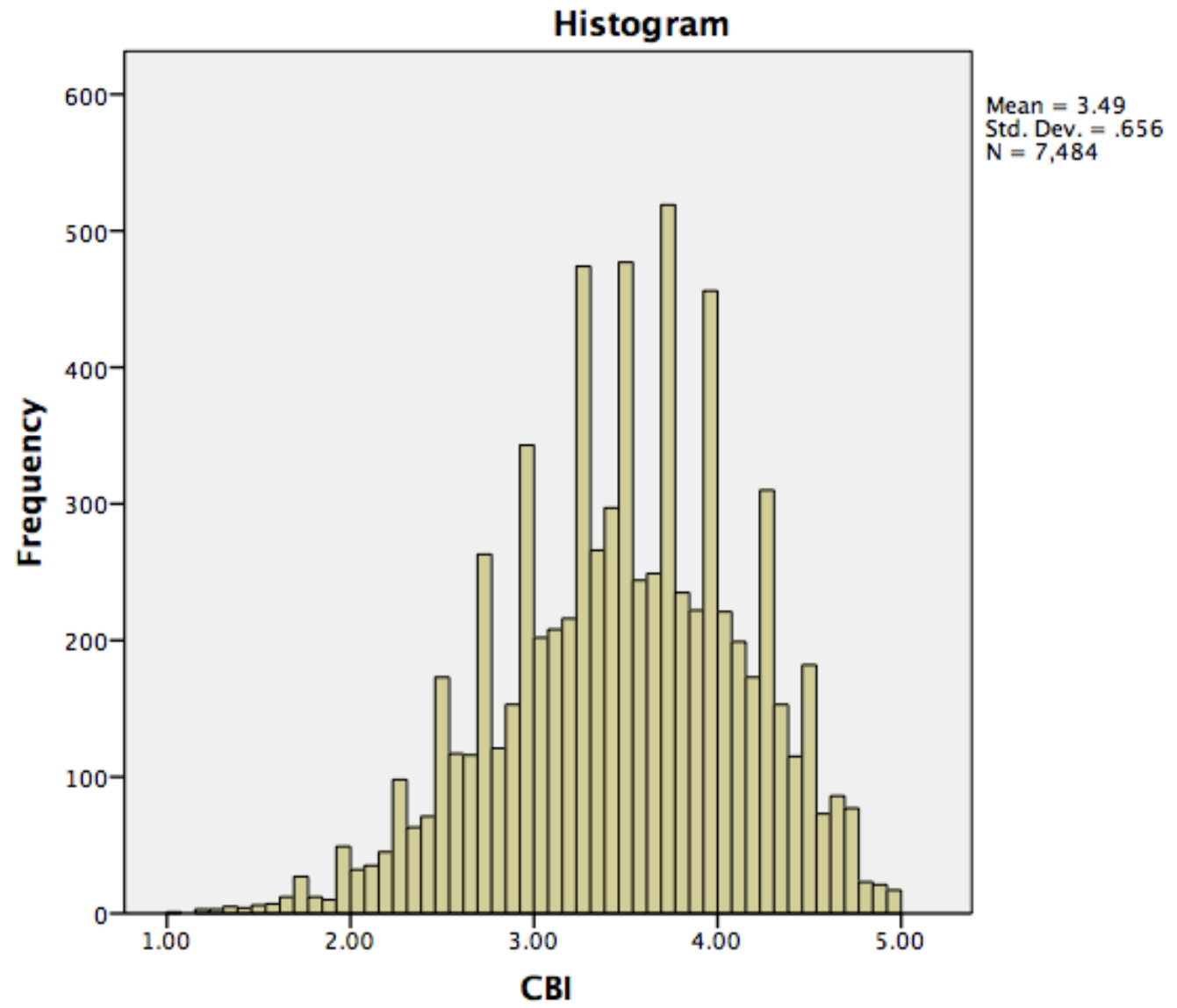

Figure 11: CBI Participant Data 
Table 2

Extreme Values for CBI

\begin{tabular}{llccc}
\hline & & Case Number & Value \\
\hline \multirow{6}{*}{ CBI } & & & 254 & 5.00 \\
& \multirow{4}{*}{ Highest } & 735 & 5.00 \\
& & 3 & 742 & 5.00 \\
& & 4 & 1261 & 5.00 \\
& & 5 & 2297 & 5.00 \\
& & 1 & 8024 & 1.06 \\
& 2 & 6014 & 1.18 \\
& Lowest & 3 & 942 & 1.18 \\
& & 4 & 532 & 1.18 \\
& & 5 & 6446 & 1.24 \\
\hline
\end{tabular}

Due to analyzing the Likert Scale data as both ordinal and interval level data, a mean and standard deviation were calculated for the CBI scale. The mean for the CBI scale was determined to be 3.49 , which is consistent with the mode. The standard deviation was calculated to be 0.656 .

A scatter plot (Figure 12) was constructed with EI WLEIS as the independent variable (x-axis) and burnout CBI as the dependent variable (y-axis). The scatter plot indicates that a positive correlation may exist between EI and burnout. Additionally, the data is clustered around the upper ends of both scales. This supports the skewness and kurtosis results that dietitians have high levels of EI, and relatively low burnout. 


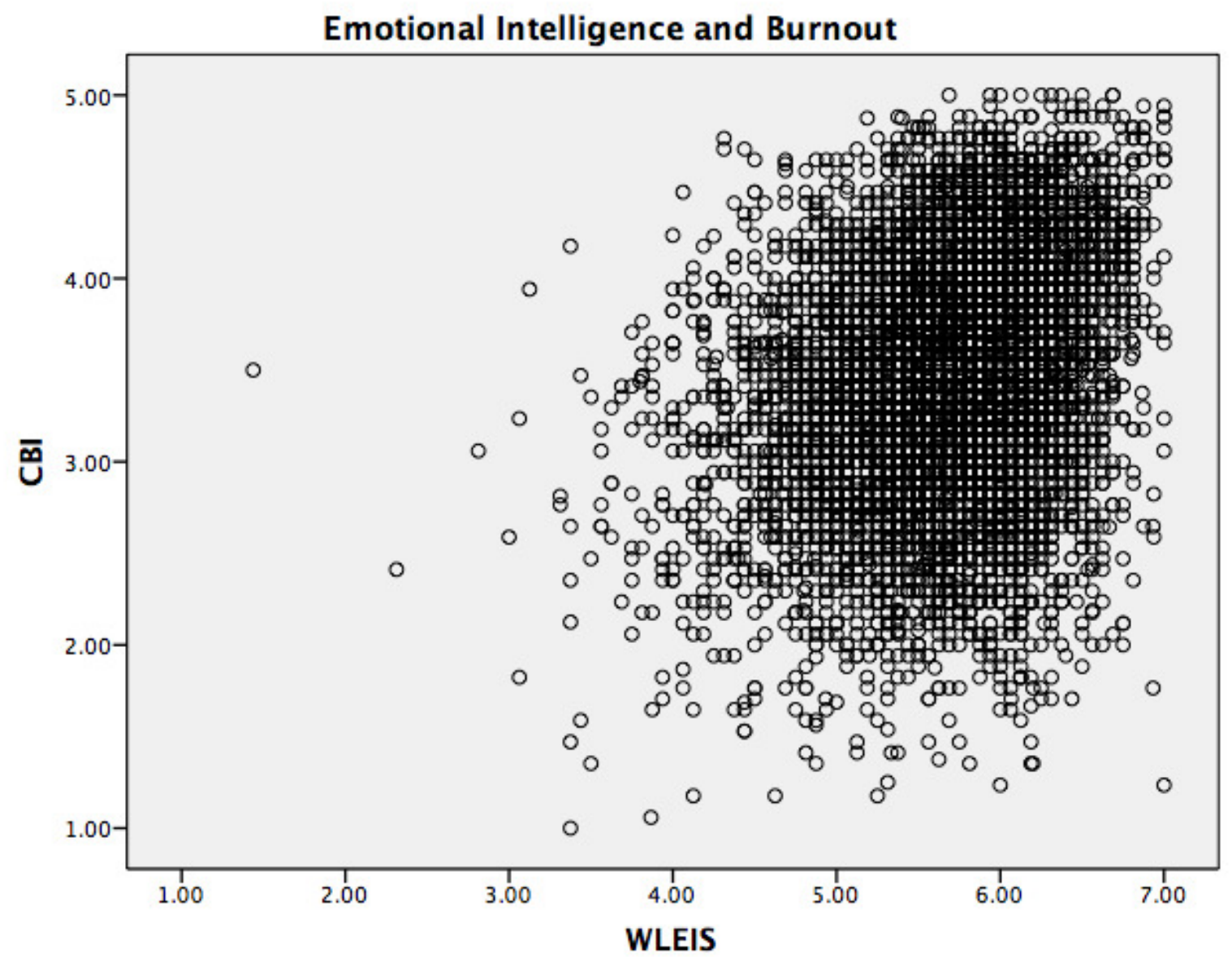

Figure 12: WLEIS/CBI Scatterplot

In order to assess the relationship between EI and burnout, correlation coefficients of both Pearson and Spearman rho were conducted. The Spearman's rho correlation is utilized for ordinal level data and was determined to be $r=0.271$ with a significance of 0.000, this indicates significance at the 0.01 alpha level. Additionally, the Pearson coefficient was conducted due to the assumption of utilizing the Likert Scale as an interval level data, and was determined to be $r=0.280$, with a significance of 0.000 . This value is consistent with the results obtained from the Spearman's rho coefficient, which justifies the usage of the Pearson coefficient. Pallant (2010) stated that a coefficient range 
of 0.10-0.29 was indicative of a small correlation. The results of this coefficient analysis conclude that there is a significant positive correlation between EI and burnout.

In order to further examine the relationship between EI and burnout a linear regression was conducted. EI was utilized as the independent variable, and burnout was used as the dependent variable. The $r^{2}$ value for the linear regression was calculated to be 0.075 (Table 3), which indicates that $7.5 \%$ of the variability in burnout can be accounted for by EI. Even though this value is small, the relationship between the variables is significant at 0.000 (Table 4). Additionally, a regression equation of $B=0.324 x E I+$ $1.646(\mathrm{~B}=$ burnout, $\mathrm{EI}=$ emotional intelligence $)$ can be composed out of the values listed from the linear regression. Due to the analysis results, the null hypothesis was rejected. Thus the alternative hypothesis were be accepted which concludes that a relationship exists between EI and burnout.

Table 3

Model Summary for WLEIS/CBI

\begin{tabular}{ccccc}
\hline Model & $\mathrm{R}$ & $\mathrm{R}$ Square & $\begin{array}{c}\text { Adjusted R } \\
\text { Square }\end{array}$ & $\begin{array}{c}\text { Std. Error of the } \\
\text { Estimate }\end{array}$ \\
\hline 1 & 0.273 & 0.075 & 0.074 & 0.630 \\
\hline
\end{tabular}


Table 4

Linear Regression WLEIS/CBI

\begin{tabular}{|c|c|c|c|c|c|c|c|}
\hline \multirow[t]{2}{*}{ Model } & \multicolumn{2}{|c|}{$\begin{array}{l}\text { Unstandardized } \\
\text { Coefficients }\end{array}$} & \multirow{2}{*}{$\begin{array}{c}\begin{array}{c}\text { Standardized } \\
\text { Coefficients }\end{array} \\
\text { Beta }\end{array}$} & \multirow[t]{2}{*}{$\mathrm{t}$} & \multirow[t]{2}{*}{ Sig } & \multicolumn{2}{|c|}{$\begin{array}{l}95.0 \% \text { Confidence } \\
\text { Interval for B }\end{array}$} \\
\hline & B & $\begin{array}{l}\text { Std. } \\
\text { Error }\end{array}$ & & & & $\begin{array}{l}\text { Lower } \\
\text { Bound }\end{array}$ & $\begin{array}{l}\text { Upper } \\
\text { Bound }\end{array}$ \\
\hline Constant & 1.646 & 0.076 & & 21.775 & 0.000 & 1.498 & 1.795 \\
\hline WLEIS & 0.324 & 0.013 & 0.273 & 24.493 & 0.000 & 0.298 & 0.350 \\
\hline
\end{tabular}

\section{Research Question 3}

To determine if a relationship exists for EI and job satisfaction for dietitians, I used the WLEIS and Section 4 of the JDS. The JDS is composed of fourteen Likert Scale questions on a 7 point scale. In order to examine the data further, ad hoc tests of reliability and re-coding were conducted. The data were subsequently coded as (1) extremely dissatisfied, (2) dissatisfied, (3) slightly dissatisfied, (4) neutral, (5) slightly satisfied, (6) satisfied, (7) extremely satisfied. To produce the most accurate and substantial analysis, the data were analyzed as both ordinal and interval level. In order to check the reliability of the JDS scale, a Cronbach's Alpha coefficient was conducted for the 14 questions utilized in the scale. The Inter-item correlation matrix for the Cronbach's Alpha reflected all positive items, indicates that the 14 questions for the JDS scale are measuring the same characteristic. The Cronbach's Alpha value was calculated to be 0.907, suggesting a highly preferable internal consistency.

The WLEIS data were re-coded at the nominal level as low EI (value of $\leq 3.4$ ), neutral EI (value of 3.5-4.4), and high EI (value $\geq 4.5$ ). Additionally, job satisfaction was 
re-coded at the nominal level as high burnout (value of $\leq 3.4$ ), neutral burnout (value 3.54.4), and low burnout (value $\geq 4.5$ ). The JDS data were analyzed to determine that $68.92 \%$ of participants have high job satisfaction. This indicates that the majority of dietitians report increased job satisfaction. The data were then analyzed utilizing a chisquare. There is evidence to support a relationship between EI and job satisfaction $\left(c h i^{2}\right.$ value $\left.x^{2}=180.53, d f=2, p=0.000\right)$.

The JDS scale was also analyzed for skewness and kurtosis. The skewness value indicates the symmetry of the distribution, and was calculated to be -0.819 . This indicates a clustering of values to the right hand side. The high end of the JDS scale corresponds with responses related to positive job satisfaction. The kurtosis value indicates the peak of the data, and was calculated to be 0.332 . This indicates that the responses for the questions within the JDS scale are slightly peaked. Interestingly, the kurtosis value of 0.985 was associated with the question "the degree to which I am fairly paid for what I contribute to this organization", meaning that the responses to this question by dietitians varied. The distributions of responses for this question are flat, with many responses at the extremes. The kurtosis value of 3.524 was associated with the question "the chance to help other people while at work", meaning that the responses to this question were clustered together. The mode was calculated for the 14 questions within the JDS scale with a value of 6 , which is coded for "satisfied" within in the scale. Results of the analysis indicate that dietitians are satisfied with their jobs, especially as it relates to helping others. There may be some dissatisfaction related to pay for dietitians, and further research should investigate this relationship further. The data for the JDS scale were 
examined and formed into a histogram (Figure 13), which reflects high response on the upper end of the job satisfaction scale.

During the examination of the data for the JDS scale, the lower quartile was determined to be 4.71 , and the upper quartile was determined to be 6.07 . In order to determine potential outliers, the outlier labeling rule was utilized, with a $\mathrm{G}$ value of 2.2. After calculation, the cut off for outliers was determined to be 1.72 on the lower end, and 9.08 on the upper end. The upper end of the outlier calculation is not possible due to the JDS being a 7 point Likert Scale. Therefore, the highest number possible for scoring is a 7. Based on the extreme values table (Table 5), there are outliers on the lower end. In order to correct for these low-end outliers, the data were cleaned by implementing a filter within SPSS to block cases that had a JDS score less than 1.72. 


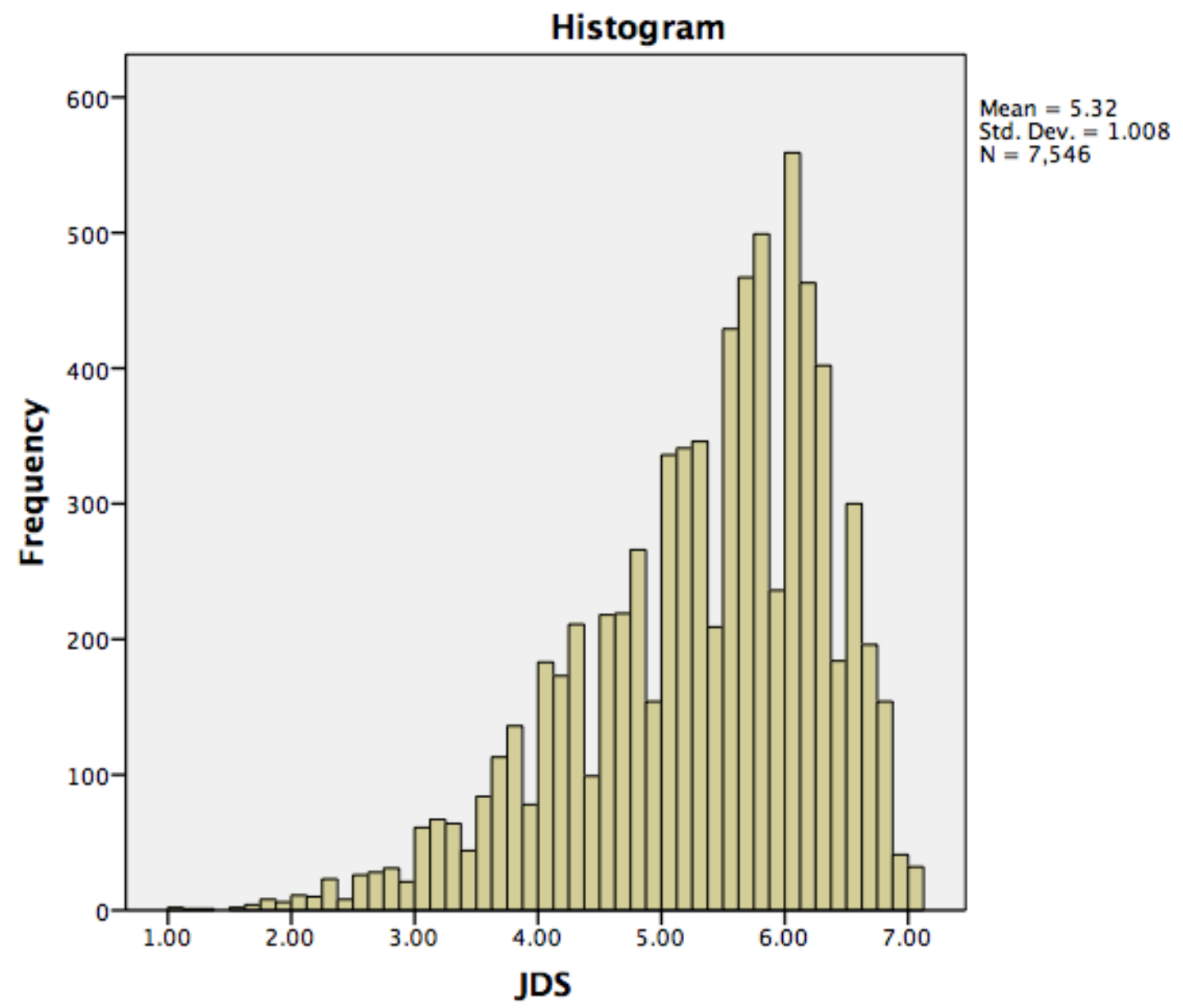

Figure 13: JDS Participant Data 
Table 5

Extreme Values for JDS

\begin{tabular}{|c|c|c|c|c|}
\hline & & & Case Number & Value \\
\hline \multirow{5}{*}{\multicolumn{2}{|c|}{ Highest }} & 1 & 468 & 7.00 \\
\hline & & 2 & 528 & 7.00 \\
\hline & & 3 & 553 & 7.00 \\
\hline & & 4 & 678 & 7.00 \\
\hline & & 5 & 1637 & 7.00 \\
\hline \multirow[t]{5}{*}{ JDS } & & 1 & 6446 & 1.00 \\
\hline & & 2 & 3227 & 1.00 \\
\hline & Lowest & 3 & 5340 & 1.14 \\
\hline & & 4 & 3281 & 1.36 \\
\hline & & 5 & 3285 & 1.50 \\
\hline
\end{tabular}

Due to analyzing the Likert Scale data as both ordinal and interval level data, both a mean and standard deviation were calculated for the JDS scale. The mean for the JDS scale was determined to be 5.31, which is consistent with the mode. The standard deviation was calculated to be 1 .

A scatter plot (Figure 14) was constructed with EI WLEIS as the independent variable (x-axis) and job satisfaction JDS as the dependent variable (y-axis). The scatter plot indicates that a positive correlation may exist between EI and job satisfaction. Additionally, the data are clustered around the upper ends of both scales. This supports the skewness and kurtosis results that dietitians have high levels of EI, and increased job satisfaction. 


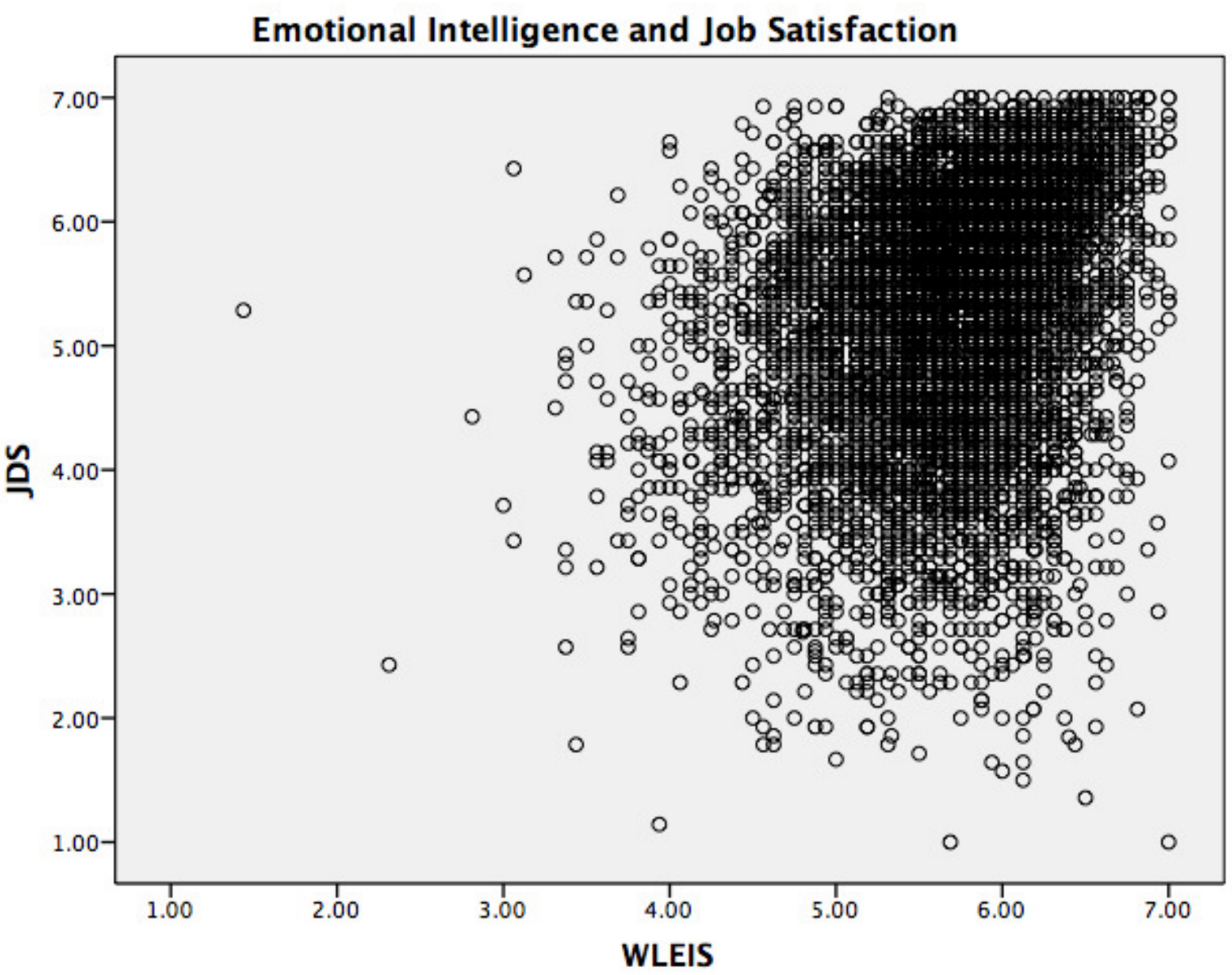

Figure 14: WLEIS/JDS Scatterplot

In order to assess the relationship between EI and job satisfaction, correlation coefficients of both Pearson and Spearman rho were conducted. The Spearman's rho correlation is utilized for ordinal level data and was determined to be $r=0.280$ with a significance of 0.000 , this indicates significance at the 0.01 alpha level. Additionally, the Pearson coefficient was conducted due to the assumption of utilizing the Likert Scale as an interval level data, and was determined to be $r=0.271$, with a significance of 0.000 . This value is consistent with the results obtained from the Spearman's rho coefficient, which justifies the usage of the Pearson coefficient. Pallant (2010) states that a 
correlation coefficient of $r=0.10-0.29$ is a small positive correlation between variables. The results of this coefficient analysis conclude that there is a significant positive correlation between EI and job satisfaction.

In order to further examine the relationship between EI and job satisfaction a linear regression was conducted. EI was utilized as the independent variable, and job satisfaction was used as the dependent variable. The $r^{2}$ value for the linear regression was calculated to be 0.070 (Table 6), which indicates that $7 \%$ of the variability in job satisfaction can be accounted for by EI. Even though this value is small, the relationship between the variables is significant at 0.000 (Table 7). Additionally, a regression equation $J S=0.478 \times E I+2.609(\mathrm{JS}=$ job satisfaction, $\mathrm{EI}=$ emotional intelligence $)$ can be composed out of the values listed from the linear regression. Due to the analysis results, the null hypothesis was rejected. Thus the alternative hypothesis were accepted which concludes that a relationship exists between EI and job satisfaction.

Table 6

Model Summary for WLEIS/JDS

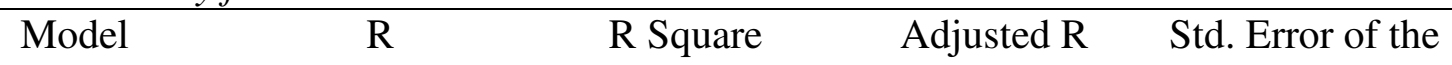

\begin{tabular}{ccccc} 
& & & Square & Estimate \\
\hline 1 & 0.264 & 0.070 & 0.069 & 0.963 \\
\hline
\end{tabular}


Table 7

\begin{tabular}{|c|c|c|c|c|c|c|c|}
\hline \multirow[t]{3}{*}{ Model } & \multicolumn{2}{|c|}{$\begin{array}{c}\text { Unstandardized } \\
\text { Coefficients }\end{array}$} & \multirow{3}{*}{$\begin{array}{c}\begin{array}{c}\text { Standardized } \\
\text { Coefficients }\end{array} \\
\text { Beta }\end{array}$} & \multirow[t]{3}{*}{$\mathrm{t}$} & \multirow[t]{3}{*}{ Sig } & \multicolumn{2}{|c|}{$\begin{array}{l}\text { 95.0\% Confidence } \\
\text { Interval for B }\end{array}$} \\
\hline & B & Std. & & & & Lower & Upper \\
\hline & & Error & & & & Bound & Bound \\
\hline Constant & 2.609 & 0.115 & & 22.659 & 0.000 & 2.383 & 2.834 \\
\hline WLEIS & 0.478 & 0.020 & 0.264 & 23.729 & 0.000 & 0.438 & 0.517 \\
\hline
\end{tabular}

Summary

The relationship between EI, job satisfaction, and burnout has not been previously analyzed for dietitians. Dietitians possess increased levels of EI, as evidenced by dietitian EI scores on the WLEIS scale. Therefore, research question \#1 concludes that dietitians possess increased levels of EI. Additionally, at least to some degree, EI has a positive correlation related to both increased job satisfaction and decreased burnout. For research question \#2 and \#3 the null hypothesis were rejected. This indicates that the alternate hypothesis was accepted and there is a relationship between EI and burnout, as well as EI and job satisfaction. The results of the study did pose many question regarding the exact relationship between these variables. Interestingly, both the concepts of job satisfaction and burnout are multifaceted, which allows for detailed analysis of the results of the study. 
Chapter 5: Discussion, Conclusions, and Recommendations

\section{Introduction}

In this chapter I discuss and examine the potential impact that EI has on job satisfaction and burnout for dietitians. Dietitians are often overlooked in the medical field, but provide a valuable skillset to improve client health outcomes (Thorensen et al., 2008). As a result of lack of opportunity, and stressful work environments health professionals are leaving the field due to burnout (Felton, 1998; Gorgens-Ekermans \& Brand, 2012). EI has already been shown to be beneficial for other health professionals as it relates to burnout and job satisfaction (Birks \& Watt, 2007; Codier et al., 2010). This relationship appears to translate to the dietetic field, as EI may relate to job satisfaction and burnout for dietitians as well. The four-branch model of EI describes the varied importance of possessing EI. EI allows for the perceiving of emotions accurately, using emotions to assist thinking, understanding emotions, and managing emotions to achieve desired outcomes (Mayer et al., 2008). Each of these components of EI can have an impact on job satisfaction and level of burnout (Ashkanasy \& Daus, 2005; Mayer et al., 2004a). Key findings of the study conclude that dietitians possess EI. Additionally, a relationship exists between EI and job satisfaction, as well as between EI and burnout.

\section{Interpretations of the Findings}

In answer to the first research question, dietitians possess an increased level of EI. Based on of the results from the WLEIS scale, dietitians indicate scores on the upper end of that scale. This corresponds to positive responses related to increased EI. Additionally, the scores on the WLEIS scale are clustered, indicating a consistent response to the 
questions. This supports previous research that various health professionals have increased levels of EI (Burks \& Kobus, 2012; Deshpande \& Joseph, 2009; Krasner et al., 2009). It would be interesting to further examine if dietitians are even aware of their level of EI or if EI is an inherent trait for dietitians. Even though the study determined that dietitians have EI, the WLEIS scale is multifaceted, and further analysis into the specific components of EI may provide additional insight into the EI/dietitian relationship.

For the second research question, EI has a positive correlation when compared to burnout. This supports previous research, which concluded that a relationship exists between EI and burnout (Ciarrochi et al., 2002; Laschinger, 2012; Maslach, 2004; Nikolaou \& Tsaousis, 2002). It is important to note that correlation does not mean causation, and there may be other factors related to this correlation that were not examined for this study. Results of the analysis indicate that dietitians may not have burnout, but further research is needed. Dietitians had a slight skew towards lower burnout rates but the peak of the data was flat and spread out indicating a diverse response in relation to burnout. Even though there is a slight skew towards decreased burnout, it is only slight and therefore more research is needed. The data for the CBI scale were examined and formed into a histogram (Figure 12), which reflects a somewhat increased response on the upper end of the burnout scale (indicating low burnout). Nevertheless, the relationship between EI and burnout has not been previously analyzed for the dietetic population.

Burnout is common in the health care field (Felton, 1998), and previous research has concluded that dietitians have reduced levels of burnout, especially when compared 
to other health professions (Gingras et al., 2010). This conclusion supports the results found in this study, as dietitians have somewhat low levels of burnout. The framework utilized for the study was the four-branch model for EI. Burnout is multifaceted and is related to emotions. The four components of the model include emotion perception, regulation, understanding, and utilization (Mayer et al., 2004b; Wong \& Law, 2002). Each of these components is important to reducing the occurrence of burnout and supports the conclusion of the study that EI has a correlation with burnout. Even though a correlation between EI and burnout was found, the correlation was small. Caution should be taken to ensure that the results are not over-generalized and thus exceeding the data, findings, and scope. The results of this study may prompt further research into the exact relationship between EI and burnout to see what specific aspect of burnout has the highest correlation to EI.

For the third research question, it was determined that EI has a positive correlation when compared to job satisfaction. This supports previous research that concluded that a relationship exists between EI and job satisfaction (Akerjordet \& Severinsson, 2007; Laschinger et al., 2009; Maslach, 2004). Again, it is important to note that correlation does not mean causation, and that there may be other factors related to this correlation that were not examined for this study. The relationship between EI and job satisfaction has not been previously analyzed for the dietetic population. Previous researchers indicate that dietitians are generally satisfied with their career (Visser \& Marais, 2012; Sauer et al., 2012). This corresponds to the results found for the current study, as the dietitians studied are generally satisfied with their jobs. Interestingly, in the 
analysis of the results of the study, there was a varied response to the question "the degree to which I am fairly paid for what I contribute to this organization" in the JDS. The literature indicates that income has been a constant contributor to job dissatisfaction for dietitians (Rehn, Stallings, Wolman, \& Cullen, 1989; Sauer et al., 2012; Sims \& Khan, 1986; Visser \& Marais, 2012). Separating out pay from job satisfaction may further the understanding of the relationship between EI and job satisfaction for dieticians. Additionally, further research may help to highlight the need for adequate pay for dietitians to improve overall job quality.

The current research study only examined the overall level of job satisfaction and level of burnout. Further research is needed to break down these concepts to examine if specific aspects of job satisfaction (pay, helping of others) have a stronger correlation in relation to EI. Additionally, further examination of specific subsections burnout (personal burnout, work-related, and client-related) may assist both professionals and organizations in understanding how EI can be a beneficial trait to possess and foster. The framework utilized for the study was the four-branch model for EI. Job satisfaction, which is multifaceted and is related to emotions. The four components of the model include emotion perception, regulation, understanding, and utilization (Mayer et al., 2004b; Wong \& Law, 2002). Each of these components is important to the overall concept of EI and therefore relate to improving job satisfaction and support the conclusion of the study that EI has a correlation with job satisfaction. Even though a correlation between EI and job satisfaction was found, the correlation was small. Caution should be taken to ensure that the results are not over generalized and thus exceeding the data, findings, and scope. 
The results of this study prompt further research into the exact relationship between EI and job satisfaction to see what specific component of job satisfaction has the highest correlation to EI.

\section{Limitations of the Study}

There were limitations related to the data collection process. Limitations included utilizing an online survey format, the participant e-mail database not including only actively credentialed RD/RDNs, participants being retired, limited options for field of dietetic practice within the survey tool, and lack of questions regarding part-time or fulltime employment status. The survey tool was utilized through an online format, which may have impacted the response rate (Hunter, 2012; Stewart, 2003). The study resulted in a $9.5 \%$ response rate, which is realistic (Medway \& Fulton, 2012) but not ideal (Duncan, 2008; Medway \& Fulton, 2012). Even though the online survey tool may have impacted response rate, however, I was still able to survey over 8,000 dietitians. Additionally, utilizing an online format reduced time and costs that are associated with paper surveys.

The e-mail addresses of dietitians obtained from the Commission on Dietetic Registration were supposed to be actively credentialed RD/RDNs. As data collection began, e-mails came in from participants who no longer had an active RD/RDN credential. This may have a limited the study because some of the population solicited for it may not have met the study criteria. Additionally, some participants were still actively credentialed RD/RDNs but were no longer working active in the field of dietetics. This could potentially have skewed results. 
One type of e-mail response received from participants was from retired RD/RDNs. The only restrictions the study placed on participants were that they be actively credentialed RD/RDNs and at least 18 years of age. Since many of the questions included aspects relating to job and client interaction, it would have been beneficial to exclude retired participants from the participant pool by implementing a screener to eliminate them. There are some questions that would still be applicable to retired $\mathrm{RD} / \mathrm{RDNs}$ including those questions regarding EI. It is possible that the number of blank responses recorded may be the result of participants who did not find specific questions applicable to them.

Another potential limitation was found in the demographic information. One of the questions asked for primary field of dietetic practice, clinical, community, academic, or administrative. Though these fields are the most common and traditional paths for registered dietitians, participants voiced the need for more options. Fields of practice inadvertently excluded included private practice dietitians and corporate dietitians. Additionally, it would have been beneficial to include an "other" option at the end of that question on the survey tool. This would have allowed participants to more accurately portray their specific field of practice.

Another potential limitation was the absence of a question asking if participants were working part-time, full-time, or were unemployed. This question would have given additional insight into aspects related to burnout and job satisfaction. The time commitment to the job that a participant expressed on the survey may have impacted the responses related to level of burnout and satisfaction within the job. 
Overall, the results of the study create a solid baseline for the examination of EI, job satisfaction, and burnout for dietitians. There are potential limitations to generalizing these results, and caution should be taken to ensure that assumptions related to the absolute accuracy of the RD/RDN e-mail database are not made. Additionally, the limitations identified will be helpful to future researchers to refine the survey process.

\section{Future Recommendations}

Future recommendations for continued research include further examining the relationship between EI, job satisfaction, and burnout for dietitians. Relating these potential relationships with age, income, field of practice, and number of hours worked are possible avenues. Additionally, including more options for primary field of practice will allow the researcher to examine if certain pathways in the career of dietetics impact the levels of EI, job satisfaction, and burnout. Breaking down the specific components present within the scales of both the CBI and JDS will allow for further analysis of the specific correlations as they relate to EI. For example, it is possible that specific areas of the CBI scale related to burnout (personal burnout, work-related burnout, or client-related burnout) may have a stronger correlation to increased EI. This information would be valuable to the field because it would allow organizations to build upon EI skills in order to improve clinician satisfaction and performance.

During the collection process, many dietitians voluntarily e-mailed their own personal experiences with working as a dietitian. Even though these responses are not part of the official research analysis, they provided additional insight into further research avenues. Based on e-mails received, there may be a need to analyze the specific aspects 
of burnout. E-mails were received that detailed causes of burnout and reasons for leaving dietetics in order to obtain a position with better pay and professional opportunities. The results of this study reflect that dietitians are not suffering burnout, but this finding may be due to the multifaceted approach of the Copenhagen Burnout Inventory. Further research that specifically analyzed pay and opportunity in regard to burnout with dieticians may find different results.

\section{Social Implications}

There are many social implications that may arise from the results of this study. Previously, there was no examination of EI, job satisfaction, and burnout for dietitians. This study provides a foundation for investigating this relationship further. The concept of burnout is not new, and the effect it has on health professionals is clear. Additionally, job satisfaction impacts many aspects of the daily interaction between provider and client. Understanding the relationship between EI, job satisfaction, and burnout may lead to EI being viewed as a beneficial trait for dietitians to possess in order to reduce burnout and improve job satisfaction. Additionally, EI has been previously attributed to improved client outcomes (Larson \& Yao, 2005). These benefits of EI may promote change for dietetic training by incorporating EI training in the future.

\section{Organizational Implications}

Change may also occur at the organizational level. In order for dietitians to maintain licensure, they must obtain continuing education credits. Many organizations promote opportunities for health professionals to gain continuing education credits by hosting conferences, seminars, and events. As research continues in the field of EI, 
organizations may value this skill for their employees. Promoting EI in health organizations may assist employees in handling stressful situations and environments. Additionally, client health outcomes may benefit from the introduction of EI training for staff.

Change may also occur at the organizational level due to the positive relationships that exist between EI and job satisfaction and EI and burnout. If organizations promote EI there may be secondary beneficial effects. If dietitians experience increased job satisfaction and decreased rates of burnout they are more likely to continue within the practice of dietetics and thus reach a level of advanced practice. This advancement leads to better understanding of dietetics and additional opportunities within the field.

\section{Conclusion}

The results of this study reflect three specific outcomes. The first outcome of the study is that dietitians possess EI. Dietitians are somewhat satisfied within their job, and have decreased levels of burnout. Additionally, there is a slight positive correlation between EI and job satisfaction, as well as EI and decreased burnout. These results are consistent with previous research for both dietitians and various other health professionals. EI is an exciting concept emerging in the literature for health professionals. Analyzing and understanding the significance that EI has for dietitians may allow for dietitians to improve their level of satisfaction at work. This may provide additional opportunities for advanced practice not currently present within the field. 
References

Academy of Nutrition and Dietetics. (2014) Continuum of professional progression \& growth. Retrieved July 03, 2014, from www.eatright.org.

Akerjordet, K., \& Severinsson, E. (2004). Emotional intelligence in mental health nurses talking about practice. International Journal of Mental Health Nursing, 13, 164170. doi: 10.1111/j.1440-0979.2004.0328.x

Akerjordet, K., \& Severinsson, E. (2007). Emotional intelligence: A review of the literature with specific focus on empirical and epistemological perspectives. Journal of Clinical Nursing, 16(8), 1405-1416. doi: 10.1111/j.13652702.2006.01749.x

Arora, S., Ashrafian, H., Davis, R., Athanasiou, T., Darzi, A., \& Sevdalis, N. (2010). Emotional intelligence in medicine: A systematic review through the context of the ACGME competencies. Medical Education, 44, 749-764. doi: 10.1111/j.13652923.2010.03709.x

Ashkanasy, N., \& Daus, C. (2005). Rumors of the death of emotional intelligence in organizational behavior are vastly exaggerated. Journal of Organizational Behavior, 26, 441-452. doi: 10.1002/job.320

Bar-on, R., Tranel, D., Denburg, N., \& Bechara, A. (2003). Exploring the neurological substrate of emotional and social intelligence. Brain, 126, 1790-1800. doi: 10.1093/brain/awg177

Bellini, L., \& Shea, J. (2005). Mood change and empathy decline persist during three 
years of internal medicine training. Academic Medicine, 80(2), 164-167. doi: 10.1097/00001888-200502000-00013

Birks, Y., McKendree, J., \& Watt, I. (2009). Emotional intelligence and perceived stress in healthcare students: A multi-institutional, multi-professional survey. $B M C$ Medical Education, 9(61), 1-8. doi: 10.1186/1472-6920-9-61

Birks, Y., \& Watt, I. (2007). Emotional intelligence and patient-centered care. Journal of the Royal Society of Medicine, 100, 368-374. Retrieved from http://jrs.sagepub.com/

Bland, J., Altman, D. (1997). Statistics notes: Cronbach's alpha. BMJ, 314(7080), 572. doi: http://dx.doi.org/10.1136/bmi.314.7080.572

Bogaert, P., Meulemans, H., Clarke, S., Vermeyen, K., \& Van de Heyning, P. (2009). Hospital nurse practice environment, burnout, job outcomes and quality of care: Test of a structural equation model. Journal of Advanced Nursing, 65(10), 21752185. doi: 10.1111/j.1365-2648.2009.05082.x

Bombeke, K., Symons, L., Debaene, L., De Winter, B., Schol, S., \& Van Royen, P. (2010). Help, I'm losing patient-centeredness! Experiences of medical students and their teachers. Medical Education, 44, 662-673. doi: 10.1111/j.13652923.2010.03627.x

Brady, J., Lordly, D., MacLellan, D., \& Gingras, J. (2012). New dietetic practitioners' perspectives. Canadian Journal of Dietetic Practice and Research, 73(3), 117121. Retrieved from http://dcjournal.metapress.com/home/main.mpx

Brandon, D., Long, J., Loraas, T., Mueller-Phillips, J., \& Vansant, B. (2014). Online 
instrument delivery and participant recruitment services: Emerging opportunities for behavioral accounting research. Behavioral Research in Accounting, 26(1), 123. doi: 10.2308/bria-50651

Brannick, M., Wahi, M., Arce, M., Johnson, H., Nazian, S., \& Goldin, S. (2009) Comparison of trait and ability measures of emotional intelligence in medical students. Medical Education, 43, 1062-1068. doi: 10.1111/j.13652923.2009.03430.x

Brazeau, C., Schroeder, R., Rovi, S., \& Boyd, L. (2010). Relationships between medical student burnout, empathy, and professionalism climate. Academic Medicine, 85(10), S33-S36. doi: 10.1097/ACM.0b013e3181ed4c47

Brotherton, A. (2009). Developing a research strategy for dietitians. Journal of Human Nutrition and Dietetics, 22(1), 1-2. doi: 10.1111/j.1365-277X.2008.00937.x

Brotherton, A. (2012). Dietetic research impact and influence: The power of strong coalitions. Journal of Human Nutrition and Dietetics, 25(5), 409-410. doi: 10.1111/j.1365-277X.2012.01293.x

Burks, D., \& Kobus, A. (2012). The legacy of altruism in health care: The promotion of empathy, prosociality and humanism. Medical Education, 46, 317-325. doi: 10.1111/j.1365-2923.2011.04159.x

Burton, S., \& Freeman, J. (2005). Marketing the dietetics profession to consumers and stakeholders: A social and professional imperative. Nutrition \& Dietetics, 62(4), 158-160. doi: 10.1111/j.1747-0080.2005.00024.x

Buys, M., Olckers, C., \& Schaap, P. (2007). The construct validity of the revised job 
diagnostic survey. South African Journal of Business Management, 38(2), 33-40. Retrieved from http://reference.sabinet.co.za/sa_epublication/busman

Calhoun, J., Dollett, L., Sinioris, M., Wainio, J., Butler, P., Griffith, J., \& Warden, G. (2008). Development of an interprofessional competency model for healthcare leadership. Journal of Healthcare Management, 53(6), 375-389. Retrieved from http://www.ache.org/Publications/SubscriptionPurchase.aspx\#jhm

Cant, R., \& Aroni, R. (2008). Exploring dietitians' verbal and nonverbal communication skills for effective dietitian-patient communication. Journal of Human Nutrition and Dietetics, 21, 502-511. doi: 10.1111/j.1365-277X.2008.00883.x

Cantrell, M., \& Lupinacci, P. (2007). Methodological issues in online data collection. Journal of Advanced Nursing, 60(5), 544-549. doi: 10.1111/j.13652648.2007.04448.x

Cantwell, B., Clarke, C., \& Bellman, J. (2006). Building a vision of dietitian services in primary health care. Canadian Journal of Dietetic Practice and Research, 67(1), S54-57. doi: 10.3148/67.0.2006.S54

Chen, A., Jaafar, S., \& Noor, A. (2012). Comparison of job satisfaction among eight health care professions in private settings. The Malaysian Journal of Medical Sciences, 19(2) 19-26. Retrieved from http://www.mjms.usm.my/

Ciarrochi, J., Chan, A., \& Caputi, P. (2000). A critical evaluation of the emotional intelligence construct. Personality and Individual Differences, 28, 539-561. Retrieved from http://www.journals.elsevier.com/personality-and-individualdifferences/ 
Ciarrochi, J., Deane, F., \& Anderson, S. (2002). Emotional intelligence moderates the relationship between stress and mental health. Personality and Individual Differences, 32, 197-209. doi: 10.1016/S0191-8869(01)00012-5

Clarke, N. (2006). Developing emotional intelligence through workplace learning: Findings from a case study in healthcare. Human Resource Development International, 9(4), 447-465. doi: 10.1080/13678860601032585

Clarke, N. (2010). Developing emotional intelligence abilities through team-based learning. Human Resource Development Quarterly, 21(2), 119-137. doi: 10.1002/hrdq.20036.

Codier, E., Muneno, L., Franey, K., \& Matsuura, F. (2010). Is emotional intelligence an important concept for nursing practice? Journal of Psychiatric and Mental Health Nursing, 17(10), 940-948. doi: 10.1111/j.1365-2850.2010.01610.x

Cody, S., Ferguson, M., \& Desbrow, B. (2011). Exploratory investigation of factors affecting dietetic workforce satisfaction. Nutrition \& Dietetics, 68, 195-200. doi: 10.1111/j.1747-0080.2011.01533.x

Cohen, J. (1992). Statistical power analysis. American Psychological Society, 1(3), 98101. doi: 10.1111/1467-8721.ep10768783

Cohen, J. (2007). Linking professionalism to humanism: What it means, why it matters. Academic Medicine, 82(11), 1029-1032. doi:

10.1097/01.ACM.0000285307.17430.74

Cohen, M., \& Gagin, R. (2005). Can skill-development and training alleviate burnout in 
hospital social workers? Social Work in Health Care, 40, 83-97. Retrieved from http://www.tandfonline.com/toc/wshc20/current\#.UpOXm4Hveu0

Commission on Dietetic Registration (2013a). Number of registered dietitians per state as of December 1, 2013. Retrieved June 23, 2014, from http://www.cdrnet.org/certifications/number-of-registered-dietitians-by-state Commission on Dietetic Registration. (2013b). Registered Dietitian Demographics as of December 1, 2013. Retrieved August 3, 2015, from https://www.cdrnet.org/certifications/registered-dietitians-demographics

Commission on Dietetic Registration (2014, December 20). Retrieved from http://www.cdrnet.org/

Conte, J. (2005). A review and critique of emotional intelligence measures. Journal of Organizational Behavior, 26, 433-440. doi: 10.1002/job.319

Cox, T., Tisserand, M., \& Taris, T. (2005). The conceptualization and measurement of burnout: Questions and directions. Work \& Stress: An International Journal of Work, Health \& Organizations, 19(3), 187-191. doi:

$10.1080 / 02678370500387109$

DasGupta, S., \& Charon, R. (2004). Personal illness narratives: Using reflective writing to teach empathy. Academic Medicine, 79(4) 351-356. doi: 10.1097/00001888200404000-00013

Daus, C., \& Ashkanasy, N. (2005). The case for the ability-based model of emotional intelligence in organizational behavior. Journal of Organizational Behavior, 26, 453-466. doi: 10.1002/job.321 
Davies, M., Stankov, L., \& Roberts, R. (1998). Emotional intelligence: In search of an elusive construct. Journal of Personality and Social Psychology, 75(4), 989-1015. doi: 10.1037/0022-3514.75.4.989

Deshpande, S., \& Joseph J. (2009). Impact of emotional intelligence, ethical climate, and behavior of peers on ethical behavior of nurses. Journal of Business Ethics, 85, 403-410. doi: 10.1007/s10551-008-9779-z

Demirel, E., \& Sarlak, K. (2009). The effect of the emotional intelligence on job satisfaction. Connecting Health and Humans, 710-711. Retrieved from http://ebooks.iospress.nl/bookseries/studies-in-health-technology-and-informatics

Devine, C., Jastran, M., \& Bisogni, C. (2004). On the front line: Practice satisfactions and challenges experienced by dietitians and nutrition professionals working in community setting in New York State. Journal of the American Dietetic Association, 104, 787-792. Retrieved from http://www.adajournal.org/

Diefendorff, J., Erickson, R., Grandey, A., \& Dahling, J. (2011). Emotional display rules as work unit norms: A multilevel analysis of emotional labor among nurses. Journal of Occupational Health Psychology, 16(2), 170-186. doi: $10.1037 / \mathrm{a} 0021725$

Diefendorff, J., Richard, E., \& Croyle, M. (2006). Are emotional display rules formal job requirements? Examination of employee and supervisor perceptions. Journal of Occupational Psychology, 79, 273-298. doi: 10.1348/096317905X68484

Doherty, E., Cronin, P., \& Offiah, G. (2013). Emotional intelligence assessment in a 
graduate entry medical school curriculum. BMC Medical Education, 13(38), 2-8. doi: 10.1186/1472-6920-13-38

Dulewicz, V., \& Higgs, M. (1999). Can emotional intelligence be measured and developed? Leadership \& Organization, 20(5), 242-252. doi:

$10.1108 / 01437739910287117$

Dulewicz, V., \& Higgs, M. (2000). Emotional intelligence: A review and evaluation study. Journal of Managerial Psychology, 15(4), 341-372. doi:

$10.1108 / 02683940010330993$

Duncan, N. (2008). The adequacy of response rates to online and paper surveys: What can be done? Assessment \& Evaluation in Higher Education, 33(3), 301-314. doi: $10.1080 / 02602930701293231$

Dunn, P., Arnetz, B., Christensen, J., \& Homer, L. (2007). Meeting the imperative to improve physician well-being: Assessment of an innovative program. Journal of General Internal Medicine, 22(11) 1544-1552. doi: 10.1007/s11606-007-0363-52

Ellis, P. (2010). The essential guide to effect sizes: Statistical power, meta-analysis, and the interpretation of research results. Cambridge, United Kingdom: Cambridge University Press.

Felton, J. (1998). Burnout as a clinical entity-its importance in health care workers. Occupational Medicine, 48, 237-250. doi:10.1093/occmed/48.4.237.

Fernandez, C. (2007). Emotional intelligence in the workplace. Journal of Public Health Management \& Practice, 13(1), 80-82. Retrieved from http://journals.lww.com/jphmp/pages/default.aspx 
Food \& nutrition conference \& expo (2013). Retrieved June 23, 2014, from http://www.eatright.org/fnce/

Fox, M. (2013). Putting emotional intelligence to work. Journal of the Academy of Nutrition and Dietetics, 113(9), 1138-1143. Retrieved from http://www.adajournal.org/

Freshwater, D., \& Stickley, T. (2004). The heart of the art: Emotional intelligence in nurse education. Nursing Inquiry, 11(2), 91-98. Retrieved from http://onlinelibrary.wiley.com/journal/10.1111/\%28ISSN\%291440-1800

Fritz, C., Morris, P., \& Richler, J. (2012). Effect size estimates: Current use, calculations, and interpretations. Journal of Experimental Psychology, 141(1), 2-18. doi: $10.1037 / \mathrm{a} 0024338$

Gaito, J. (1980). Measurement scales and statistics: Resurgence of an old misconception. Psychological Bulletin, 87(3), 564-567. doi: 10.1037//0033-2909.87.3.564

Gardner, G., Chang, A., Duffield, C., \& Doubrovsky, A. (2013). Delineating the practice profile of advanced practice nursing: A cross-sectional survey using the modified strong model of advanced practice. Journal of Advanced Nursing, 69(9), 19311942. doi: http://dx.doi.org.ezp.waldenlibrary.org/10.1111/jan.12054

Gardner, L., \& Stough, C. (2003). Exploration of the relationship between work-place, emotional intelligence, occupational stress and employee health. Australian Journal of Psychology, 55, 181-195.

Gingras, J., De Jonge, L., \& Purdy, N. (2010). Prevalence of dietitian burnout. Journal of 
Human Nutrition and Dietetics, 23, 238-243. doi: 10.1111/j.1365-277X. 2010.01062.x

Goleman, D. (1995). Emotional intelligence. New York: Bantam.

Goleman, D., Boyatzis, R. E., \& McKee, A. (2004). Primal leadership: Learning to lead with emotional intelligence. Boston: Harvard Business School Publishing.

Gorgens-Ekermans, G., \& Brand, T. (2012). Emotional intelligence as a moderator in the stress-burnout relationship: A questionnaire study on nurses. Journal of Clinical Nursing, 21, 2275-2285. doi: 10.1111/j.1365-2702.2012.04171.x

Gutierrez, A., Candela, L., \& Carver, L. (2012). The structural relationships between organizational commitment, global job satisfaction, developmental experiences, work values, organizational support, and person-organization fit among nursing faculty. Journal of Advanced Nursing, 68(7), 1601-1614. doi: 10.1111/j.13652648.2012.05990.x

Haas, J., Cook, F., Puopolo, A., Burstin, H., Cleary, P., \& Brennan, T. (2000). Is the professional satisfaction of general internists associated with patient satisfaction? Journal of General Internal Medicine, 15, 122-128. Retrieved from http://www.sgim.org/jgim-home

Hackman, J., \& Oldham, G. (1975). Development of the job diagnostic survey. Journal of Applied Psychology, 60(2), 159-170. doi: 10.1037/h0076546

Hemmerdinger, J., Stoddart, S., \& Lilford, R. (2007). A systematic review of tests of empathy in medicine. BMC Medical Education, 7(24), 24-31. doi: 10.1186/1472$6920-7-24$ 
Hoaglin, D., \& Iglewicz, B. (1987). Fine tuning some resistant rules for outlier labeling. Journal of American Statistical Association, 82, 1147-1149. doi:

$10.1080 / 01621459.1987 .10478551$

Hojat, M., Mangione, S., Nasca, T., Rattner, S., Erdmann, J., Gonnella, J., \& Magee, M. (2004). An empirical study of decline in empathy in medical school. Medical Education, 38, 934-941. doi: 10.1111/j.1365-2929.2004.01911.x

Hooker, R., Williams, J., Papneja, J., Sen, N., \& Hogan, P. (2012). Dietetics supply and demand: 2010-2020. Journal of the Academy of Nutrition and Dietetics, 112(3), S75-S91. doi: 10.1016/j.jand.2011.12.024

Hughes, R. (2003). Competency development in public health nutrition: Reflections of advanced level practitioners in Australia. Nutrition \& Dietetics, 60(3), 205211.Retrieved from http://onlinelibrary.wiley.com/journal/10.1111/\%28ISSN\%291747-0080

Humpel, N., \& Caputi, P. (2001). Exploring the relationship between work stress, years of experience and emotional competency using a sample of Australian mental health nurses. Journal of Psychiatric and Mental Health Nursing, 8, 399-403. doi: 10.1046/j.1365-2850.2001.00409.x

Hunter, L. (2012). Challenging the reported disadvantages of e-questionnaires and addressing methodological issues of online data collection. Nurse Researcher, 20(1), 11-20. Retrieved from http://rcnpublishing.com/journal/nr

Idaszak, J., \& Drasgow, F. (1987). A revision of the job diagnostic survey: Elimination of 
a measurement artifact. Journal of Applied Psychology, 72(1), 69-74. doi: 10.1037/0021-9010.72.1.69

Jamieson, S. (2004). Likert scales: How to (ab)use them. Medical Education, 38, 12121218. doi: 10.1111/j.1365-2929.2004.02012.x

Karim, J. (2010). Examining the factor structure of Wong and Law's emotional intelligence scale with a Pakistani general population sample. The IUP Journal of Organizational Behavior, 9(1-2), 32-44. Retrieved from http://www.iupindia.in/Organizational_Behavior.asp

Killian, K. (2012). Development and validation of the emotional self-awareness questionnaire: A measure of emotional intelligence. Journal of Marital and Family Therapy, 38(3), 502-514. doi: 10.1111/j.1752-0606.2011.00233.x

Knapp, T. (1990). Treating ordinal scales as interval scales: An attempt to resolve the controversy. Nursing Research, 39(2), 121-123. doi: 10.1097/00006199199003000-00019

Kolodny, Z., \& Chan, M. (1996). Comparing job satisfaction, attitude, and degree of burnout between HIV/AIDS dietitians and general practice dietitians. AIDS Patient Care, 10, 368-371. Retrieved from http://www.liebertpub.com/APC

Krasner, M., Epstein, R., Beckman, H., Suchman, A., Chapman, B., Mooney, C., \& Quill, T. (2009). Association of an educational program in mindful communication with burnout, empathy, and attitudes among primary care physicians. Journal of the American Medical Association, 302(12), 1284-1293. doi:

10.1001/jama.2009.1384. 
Kristensen, T., Borritz, M., Villadsen, E., \& Christensen, K. (2005). The Copenhagen Burnout Inventory: A new tool for the assessment of burnout. Work \& Stress: An International Journal of Work, Health \& Organizations, 19(3), 192-207. doi: $10.1080 / 02678370500297720$

Kuzon, W., Urbanchek, M., \& McCabe, S. (1996). The seven deadly sins of statistical analysis. Annals of Plastic Surgery, 37(3), 265-272. doi: 10.1016/S02782391(97)90377-3

Larson, E., \& Yao, X. (2005). Clinical empathy as emotional labor in the patientphysician relationship. Journal of the American Medical Association, 293(9), 1100-1106. doi: 10.1001/jama.293.9.1100

Laschinger, H. (2012). Job and career satisfaction and turnover intentions of newly graduated nurses. Journal of Nursing Management, 20, 472-484. doi: 10.1111/j.1365-2834.2011.01293.x

Laschinger, H., Leiter, M., Day, A., \& Gilin, D. (2009). Workplace empowerment, incivility, and burnout: Impact on staff nurse recruitment and retention outcomes. Journal of Nursing Management, 17, 302-311. doi: 10.1111/j.13652834.2009.00999.x

Law, K., Wong, C., \& Song, L. (2004). The construct and criterion validity of emotional intelligence and its potential utility for management studies. Journal of Applied Psychology, 89(3), 483-496. doi: 10.1037/0021-9010.89.3.483

Lee, H., Spiers, J., Yurtseven, O., Cummings, G., Sharlow, J., Bhatti, A., \& Germann, P. 
(2010). Impact of leadership development on emotional health in healthcare managers. Journal of Nursing Management, 18, 1027-1039. doi: 10.1111/j.13652834.2010.01178.x

Libbrecht, N., Lievens, F., \& Schollaert, E. (2010). Measurement equivalence of the Wong and Law emotional intelligence scale across self and other ratings. Educational and Psychological Measurement, 70(6), 1007-1020. doi: $10.1177 / 0013164410378090$

Maslach, C. (2004). Different perspectives on job burnout. Psyc-CRITIQUES, 49(2), 168170. doi: $10.1037 / 004284$

Maslach, C., \& Jackson, S. (1981). The measurement of experienced burnout. Journal of Occupational Behavior, 2, 99-113. Retrieved from http://www.jstor.org/journals/01422774.html

Maul, A. (2012). Examining the structure of emotional intelligence at the item level: New perspectives, new conclusions. Cognition and Emotion, 26(3), 503-520. doi: $10.1080 / 02699931.2011 .588690$

Mayer, J., Caruso, D., \& Salovey, P. (2000). Emotional intelligence meets traditional standards for an intelligence. Intelligence, 27(4), 267-298. Retrieved from http://www.journals.elsevier.com/intelligence/

Mayer, J., \& Cobb, C. (2000). Educational policy on emotional intelligence: Does it make sense? Educational Psychology Review, 12(2), 163-183. doi: 10.1023/A:1009093231445

Mayer, J., DiPaolo, M., \& Salovey, P. (1990). Perceiving affective content in ambiguous 
visual stimuli: A component of emotional intelligence. Journal of Personality Assessment, 54(3\&4), 772-781. doi: 10.1080/00223891.1990.9674037

Mayer, J., \& Salovey, P. (1997). What is emotional intelligence? Emotional Development and Emotional Intelligence. New York: Basic Books.

Mayer, J., Salovey, P., \& Caruso, D. (2004a). A further consideration of the issues of emotional intelligence. Psychological Inquiry, 15(3), 249-255. Retrieved from http://www.tandfonline.com/toc/hpli20/current\#.U2etl7RH1pQ

Mayer, J., Salovey, P., \& Caruso, D. (2004b). Emotional intelligence: Theory, findings, and implications. Psychological Inquiry, 15(3), 197-215. Retrieved from http://www.tandfonline.com/toc/hpli20/current\#.U2etl7RH1pQ

Mayer, J., Salovey, P., \& Caruso, D. (2008). Emotional intelligence: New ability or eclectic traits? American Psychologist, 63(6), 503-517. doi: 10.1037/003066X.63.6.503

Mayer, J., Salovey, P., Caruso, D., \& Sitarenios, G. (2001). Emotional intelligence as a standard intelligence. Emotion, 1(3), 232-242. doi: 10.1037//1528-3542.1.3.232

Meadows, K. (2003). So you want to do research? 5: Questionnaire design. British Journal of Community Nursing, 8(12), 562-570. doi: http://dx.doi.org/10.12968/bjen.2003.8.12.11854

Medway, R., \& Fulton, J. (2012). When more gets you less: A meta-analysis of the effect of concurrent web options on mail survey response rates. Public Opinion Quarterly, 76(4), 733-746. doi: 10.1093/poq/nfs047

McCrum-Gardner, E. (2008). Which is the correct statistical test to use? British Journal 
of Oral and Maxillofacial Surgery, 46, 38-41. doi: 10.1016/j.bjoms.2007.09.002

McGaghie, W., Mytko, J., Brown, N., \& Cameron, J. (2002). Altruism and compassion in the health professions: A search for clarity and precision. Medical Teacher, 24(4), 374-378. doi: 10.1080/01421590220145734

McHugh, M. (2013). The chi-square test of independence. Biochemia Medica, 23(2), 143-149. doi:10.11613/BM.2013.018

McQueen, A. (2004). Emotional intelligence in nursing work. Journal of Advanced Nursing, 47(1), 101-108. Retrieved from http://onlinelibrary.wiley.com/journal/10.1111/\%28ISSN\%291365-2648

Mikolajczak, M. (2009). Going beyond the ability-trait debate: The three-level model of emotional intelligence. Journal of Applied Psychology, 5(2), 25-31. Retrieved from http://www.apa.org/pubs/journals/apl/

Munn-Giddings, C., Hart, C., \& Ramon, S. (2005). A participatory approach to the promotion of well-being in the work-place: Lessons from empirical research. International Review of Psychiatry, 17, 409-417. Retrieved from http://informahealthcare.com/journal/irp

Nederhof, A. (1985). Methods of coping with social desirability bias: A review. European Journal of Social Psychology, 15, 263-280. doi: 10.1002/ejsp.2420150303

Nikolaou, I., \& Tsaousis, I. (2002). EI in the workplace: Exploring its effects on occupational stress and organizational commitment. The International Journal of Organizational Analysis, 10(4), 327-342. doi: 10.1108/eb028956 
Oginska-Bulik, N. (2005). Emotional intelligence in the workplace: Exploring its effects on occupational stress and health outcomes in human service workers. International Journal of Occupational Medicine and Environmental Health, 18(2), 167-175. Retrieved from http://maneypublishing.com/index.php/journals/oeh/

Othman, A., Abdullah, H., \& Ahmad, J. (2008). Emotional intelligence, emotional labour and work effectiveness in service organizations: A proposed model. Vision, 12(1), 31-42. doi: 10.1177/097226290801200105

Pallant, J. (2010). SPSS Survival manual. New York, NY: McGraw-Hill.

Pau, A., \& Croucher, R. (2003). Emotional intelligence and perceived stress in dental undergraduates. Journal of Dental Education, 67(9), 1023-1028. Retrieved from www.jdentaled.org

Petrides, K., \& Furnham, A. (2006). The role of trait emotional intelligence in a genderspecific model of organizational variables. Journal of Applied Social Psychology, 36(2), 552-569. doi: 10.1111/j.0021-9029.2006.00019.x

Reed, P., Conrad, D., Hernandez, S., Watts, C., \& Marcus-Smith, M. (2012). Innovation in patient-centered care: Lessons from a qualitative study of innovative health care organizations in washington state. BMC Family Practice, 13(120), 3-9. doi: $10.1186 / 1471-2296-13-120$

Rehn, B., Stallings, S., Wolman, P., \& Cullen, R. (1989) Job satisfaction of South Carolina dietitians. Journal of the American Dietetic Association, 89(7), 979-981. doi:10.1016/S0002-8223(98)00394-0 
Roberts, R., Matthews, G., \& Zeidner, M. Does emotional intelligence meet traditional standards for an intelligence? Some new data and conclusions. Emotion, 1(3), 196-231. doi: 10.1037//1528-3542.1.3.196

Rogers, D. (2014). Compensation and benefits survey: Education and job responsibility to increased compensation. Journal of the Academy of Nutrition and Dietetics, 114, 17-33. doi: 10.1016/j.jand.2013.11.008

Sample size calculator (2015) Creative Research Systems. Retrieved January 08, 2015, from http://www.surveysystem.com/sscalc.htm

Satterfield, J., \& Hughes, E. (2007). Emotion skills training for medical students: A systematic review. Medical Education, 41(10), 935-941. doi: 10.1111/j.13652923.2007.02835.x

Sauer, K., Canter, D., Shanklin, C. (2012). Describing career satisfaction of registered dietitians with management responsibilities. Journal of the Academy of Nutrition and Dietetics, 112(8), 1129-1133. doi: 10.1016/j.jand.2012.06.013

Schaufeli, W. \& Taris, T. (2005). The conceptualization and measurement of burnout: Common ground and worlds apart. Work \& Stress: An International Journal of Work, Health \& Organizations, 19(3), 256-262. doi:

$10.1080 / 02678370500385913$

Schillewaert, N., \& Meulemeester, P. (2005). Comparing response distributions of offline and online data collection methods. International Journal of Market Research, 47(2), 163-178. Retrieved from https://www.mrs.org.uk/ijmr

Schutte, N., Malouff, J., Hall, L., Haggerty, D., Cooper, J., Golden, C., \& Dornheim, L. 
(1998). Development and validation of a measure of emotional intelligence.

Personality and Individual Differences, 25(2), 167-177. doi: 10.1016/s01918869(98)00001-4

Seal, C., \& Andrews-Brown, A. (2010). An integrative model of emotional intelligence: Emotional ability as a moderator of the mediated relationship of emotional quotient and emotional competence. Organization Management Journal, 7, 143152. doi: $10.1057 /$ omj. 2010.22

Shanafelt, T., West, C., Zhao, X., Novotny, P., Kolars, J., Habermann, T., \& Sloan, J. (2005). Relationship between increased personal well-being and enhanced empathy among internal medicine residents. Journal of General Internal Medicine, 20, 559-564. doi: 10.1111/j.1525-1497.2005.0108.x

Shapiro, J. (2002). How do physicians teach empathy in the primary care setting? Academic Medicine, 77(4), 323-328. doi:10.1097/00001888-200204000-00012

Shapiro, J., Morrison, E., \& Boker, J. (2004). Teaching empathy to first year medical students: Evaluation of an elective literature and medicine course. Education for Health, 17(1), 73-84. doi: 10.1080/13576280310001656196

Shi, J., \& Wang, L. (2007). Validation of emotional intelligence scale in Chinese university students. Personality and Individual Differences, 43, 377-387. doi: 10.1016/j.paid.2006.12.012

Shirom, A. (2005). Reflections on the study of burnout. Work \& Stress: An International Journal of Work, Health \& Organizations, 19(3), 263-270. doi:

$10.1080 / 02678370500376649$ 
Sims, L., \& Khan, J. (1986). Job satisfaction among public health nutrition personnel. Journal of the American Dietetic Association, 86(3), 334-338. Retrieved from http://www.ncbi.nlm.nih.gov/pubmed/3950277?dopt=Abstract

Sims, L., \& Kohli, M. (1983). Predictors of effectiveness among public health nutritionists. American Journal of Public Health, 73(12), 1376-1380. doi: 10.2105/AJPH.73.12.1376

Skipper, A. (2009). Advanced medical nutrition therapy practice. Sudbury, MA: Jones and Bartlett Publishers.

Slaski, M., \& Cartwright, S. (2002). Health, performance and emotional intelligence: An exploratory study of retail managers. Stress Health, 18, 63-68. doi: 10.1002/smi.926

Slawson, D., Clemens, L., \& Bol, L. (2000). Research and the clinical dietitian: Perceptions of the research process and preferred routes to obtaining research skills. Journal of the American Dietetic Association, 100(10), 1144-1148. doi: http://dx.doi.org/10.1016/S0002-8223(00)00336-9

Sonnentag, S. (2005). Burnout research: Adding an off-work and day-level perspective. Work \& Stress: An International Journal of Work, Health \& Organizations, 19(3), 271-275. doi: 10.1080/02678370500386473

Stewart, S. (2003). Casting the net: Using the internet for survey research. British Journal of Midwifery, 11(9), 543-546. doi: http://dx.doi.org/10.12968/bjom.2003.11.9.11689

Stickley, T., \& Freshwater, D. (2002). The art of loving and the therapeutic relationship. 
Nursing Inquiry, 9, 250-256. Retrieved from

http://onlinelibrary.wiley.com/journal/10.1111/\%28ISSN\%291440-1800

Stone, P., Vaden, A., \& Vaden, R. (1981). Dietitians in the early establishment stage of their careers. Journal of the American Dietetic Association, 79(1), 30-36.

Retrieved from http://www.adajournal.org/

Svyantek, D., \& Rahim, M. (2002). Links between emotional intelligence and behavior in organizations: Findings from empirical studies. International Journal of Organizational Analysis, 10(4), 299-301. doi: 10.1108/eb028954

Taris, T., Le Blanc, P., Schaufeli, W., \& Schreurs, P. (2005). Are there casual relationships between the dimensions of the maslach burnout inventory? A review and two longitudinal tests. Work \& Stress: An International Journal of Work, Health \& Organizations, 19(3), 238-255. doi: 10.1080/02678370500270453

Thorensen, L., Rothenberg, E., Beck, A., Irtun, O. (2008). Doctors and nurses on wards with greater access to clinical dietitians have better focus on clinical nutrition. Journal of Human Nutrition and Dietetics, 21, 239-247. doi: 10.1111/j.1365277X.2008.00869.X

Tilden, V., Nelson, C., \& May, B. (1990). Use of qualitative methods to enhance content validity. Nursing Research, 39(3), 172-175. doi: 10.1097/00006199-19900500000015

Tsaousis, I., \& Nikolaou, I. (2005). Exploring the relationship of emotional intelligence with physical and psychological health functioning. Stress and Health, 21, 77-86. doi: 10.1002/smi.1042 
Tukey, J. (1977). Exploratory data analysis. Reading, MA: Addison-Wesley.

Visser, J., \& Marais, D. (2012). Job satisfaction of South African registered dietitians. South African Journal of Clinical Nutrition, 25(3), 112-119. Retrieved from http://www.sajcn.co.za/

Whaley, G., \& Hosig, K. (2000). Male dietitians in five southern states: Some perspectives on the profession. Journal of the American Dietetics Association, 100(12), 1535-1537. Retrieved from http://www.adajournal.org/

Whelan, K. (2007). Knowledge and skills to encourage comprehensive research involvement among dietitians. The British Dietetic Association, 20, 291-293. doi: 10.1111/j.1365-277X.2007.00806.x

Wildish, D., Evers, S. (2010). A definition, description, and framework for advanced practice in dietetics. Canadian Journal of Dietetic Practice and Research, 71(1), e4-e11. Retrieved from http://dcjournal.metapress.com/home/main.mpx

Wong, C., \& Law, K. (2002). The effects of leader and follower emotional intelligence on performance and attitude: An exploratory study. The Leadership Quarterly, 13(3), 243-274. doi: 10.1016/S1048-9843(02)00099-1

Yeh, W., Cheng, Y., Chen, C., Hu, P., \& Kristensen, T. (2007). Psychometric properties of the Chinese version of Copenhagen burnout inventory among employees in two companies in Taiwan. International Journal of Behavioral Medicine, 14(3), 126-133. doi: 10.1007/BF03000183

Young-Ritchie, C., Laschinger, H., \& Wong, C. (2009). The effects of emotionally 
intelligence leadership behavior on emergency staff nurses' workplace empowerment and organizational commitment. Nursing Leadership, 22(1), 70-85. doi:10.12927/cjnl.2009.20614.

Zijlmans, L.,Embregts, P., Gerits, L., Bosman, A., \& Derksen, J. (2011). Training emotional intelligence related to treatment skills of staff working with clients with intellectual disabilities and challenging behavior. Journal of Intellectual Disability Research, 55(2), 219-230. doi: 10.1111/j.1365-2788.2010.01367.x 


\section{Appendix A: Panel of Experts}

Form for review and evaluation of validity and reliability by a panel of experts for the quantitative instrumentation of emotional intelligence, job satisfaction, and burnout for dietitians.

\section{Instructions:}

Please review the attached Quantitative Instrumentation of emotional intelligence, job satisfaction, and burnout for dietitians and the corresponding table of specifications and respond to the following questions regarding the construction, validity and potential reliability for the Quantitative Instrumentation emotional intelligence, job satisfaction, and burnout for dietitians in light of the phenomenon being researched, examined, assessed, evaluated or measured.

\section{Section I. VALIDITY EVALUATION}

A test, survey, questionnaire, evaluation or assessment instrument is valid to the extent that the instrument measures the construct(s) that the instrument purports to measure.

\section{Instrument Construction:}

1. (a). Are the instructions for completing the instrument clear?

Yes $\rho \quad$ No $\rho$ (if no, please explain)

Yes $\rho$ provided the following actions are taken:

1.(b). Is the application and results of the Quantitative Instrumentation of "emotional intelligence, job satisfaction, and burnout for dietitians" reflected in this instrument?

Yes $\rho \quad$ No $\rho$ (if no, please explain)

Yes $\rho$ provided the following actions are taken: 
1. (c). What items would you add?

1. (d). What items would you delete?

\section{Content Validity:}

Will the scores yielded by Quantitative Instrumentation of emotional intelligence, job satisfaction, and burnout for dietitians represent the content or conceptual domain of the construct being measured? In other words, does the instrument have adequate and appropriate items that constitute a representative sample of the complete domain of items used to generalize the construct being measured? Please see the attached table of specifications [instrument blueprint] that reflect which items and how many items within the instrument are designed to measure each type of content domain.

Yes $\rho \quad$ No $\rho$ (if no, please explain)

Yes $\rho$ provided the following actions are taken:

\section{Construct Validity:}

Quantitative Instrumentation of emotional intelligence, job satisfaction, and burnout for dietitians is designed..... Please see constructs definition:

3. (a) Does the Quantitative Instrumentation of emotional intelligence, job satisfaction, and burnout for dietitians represent concepts or constructs it should represent and does not represent concepts it should not represent? In other words, does the Quantitative Instrumentation of emotional intelligence, job satisfaction, and burnout for dietitians adequately represent the constructs it purports to represent?

Yes $\rho \quad$ No $\rho$ (if no, please explain) 
Yes $\rho$ provided the following actions are taken:

3. (b) Is the Quantitative Instrumentation of emotional intelligence, job satisfaction, and burnout for dietitians inclusive of the important dimensions or facets of the constructs it purports to measure.

Yes $\rho \quad$ No $\rho$ (if no, please explain)

Yes $\rho$ provided the following actions are taken:

3. (c) Does the Quantitative Instrumentation of emotional intelligence, job satisfaction, and burnout for dietitians avoids excess reliable variance, ensuring no items are easier or harder for some respondents in a manner relevant to the interpreted construct?

Yes $\rho \quad$ No $\rho$ (if no, please explain)

Yes $\rho$ provided the following actions are taken:

\section{Face Validity}

Does the Quantitative Instrumentation of emotional intelligence, job satisfaction, and burnout for dietitians look valid? Does it appear to represent a measure of the construct it purports to measure?

Yes $\rho \quad$ No $\rho$ (if no, please explain) 
Yes $\rho$ provided the following actions are taken:

\section{E. Item Bias}

Does the wording or placement of an item avoid affecting someone's response? (This includes the avoidance of double-barreled items, words or phrases, which raise emotional red flags, ambiguous wording, gender bias, racial/ethnic bias, and the manipulative placement of an item or wording of an item)

Yes $\rho \quad$ No $\rho$ (if no, please explain)

Yes $\rho$ provided the following actions are taken:

\section{F. Consequential Validity}

Does the Quantitative Instrumentation of emotional intelligence, job satisfaction, and burnout for dietitians embody desirable values and have potentially positive consequences for the discipline or field it reflects?

Yes $\rho \quad$ No $\rho$ (if no, please explain)

Yes $\rho$ provided the following actions are taken:

\section{Section II. RELIABILITY EVALUATION}

A test, survey, questionnaire, evaluation or assessment instrument is reliable to the extent that whatever construct(s) the instrument measures, it measures the construct(s) consistently.

\section{A. Internal Consistency}


Are the items that make up the Quantitative Instrumentation of emotional intelligence, job satisfaction, and burnout for dietitians consistent with each component and/or the constructs being examined, assessed, evaluated or measured?

Yes $\rho \quad$ No $\rho$ (if no, please explain)

Yes $\rho$ provided the following actions are taken:

\section{B. Potential for Reliability (Potential for Consistent Responses)}

Understanding that research participants completing this instrument will vary in their understanding and experience with emotional intelligence, job satisfaction, and burnout for dietitians and thus vary in their responses, is there anything about this instrument that would lead you to believe that this instrument would not consistently measure emotional intelligence, job satisfaction, and burnout for dietitians the application of consistently.

Yes (if yes, please explain) No

Yes $\rho$ provided the following actions are taken:

Please provide any additional comments, suggestions for improvement, and/or any other thoughts regarding the construction, how the survey to be easier to complete, validity and/or reliability of emotional intelligence, job satisfaction, and burnout for dietitians

Panel Member

Printed or typed name:

Title:

Department:

Organization:

Location:

Signature

Date 


\section{Appendix B: Survey Tool}

The following survey is a compilation of the WLEIS emotional intelligence questionnaire, Section 4 of the Job Diagnostic Survey, and the Copenhagen Burnout Inventory. Demographic information is also included. The purpose of this questionnaire is to examine the potential relationship between emotional intelligence, job satisfaction, and burnout for registered dietitians. No identifying information will be collected during this survey, and all information will be confidential. Completed results will be stored in a locked container. You may choose to stop the survey at any time.

\section{Wong and Law EI Scale (WLEIS)}

This section of the survey will evaluate emotional intelligence, and is divided into four sections (self-emotions appraisal, others-emotions appraisal, use of emotions, and regulation of emotion). Please answer the following questions by circling the appropriate

1 Totally Disagree choice.

2 Disagree

3 Somewhat Disagree

4 Neutral

5 Somewhat Agree

6 Agree

7 Totally Agree

\section{Self-Emotions Appraisal (SEA)}

1. I have a good sense of why I have certain feelings most of the time

$$
\begin{array}{lllllll}
1 & 2 & 3 & 4 & 5 & 6 & 7
\end{array}
$$

2. I have good understanding of my own emotions

$$
\begin{array}{lllllll}
1 & 2 & 3 & 4 & 5 & 6 & 7
\end{array}
$$

3. I really understand what I feel

$$
\begin{array}{lllllll}
1 & 2 & 3 & 4 & 5 & 6 & 7
\end{array}
$$

4. I always know whether or not I am happy

$$
\begin{array}{lllllll}
1 & 2 & 3 & 4 & 5 & 6 & 7
\end{array}
$$

\section{Others-Emotions Appraisal (OEA)}

5. I always know my friends' emotions from their behavior

$$
\begin{array}{lllllll}
1 & 2 & 3 & 4 & 5 & 6 & 7
\end{array}
$$

6. I am a good observer of other's emotions 


$$
\begin{array}{lllllll}
1 & 2 & 3 & 4 & 5 & 6 & 7
\end{array}
$$

7. I am sensitive to the feelings and emotions of others

$$
\begin{array}{lllllll}
1 & 2 & 3 & 4 & 5 & 6 & 7
\end{array}
$$

8. I have good understanding of the emotions of people around me

$$
\begin{array}{lllllll}
1 & 2 & 3 & 4 & 5 & 6 & 7
\end{array}
$$

\section{Use of Emotion (UOE)}

9. I always set goals for myself and then try my best to achieve them

$$
\begin{array}{lllllll}
1 & 2 & 3 & 4 & 5 & 6 & 7
\end{array}
$$

10. I always tell myself I am a competent person

$$
\begin{array}{lllllll}
1 & 2 & 3 & 4 & 5 & 6 & 7
\end{array}
$$

11. I am a self-motivating person

$$
\begin{array}{lllllll}
1 & 2 & 3 & 4 & 5 & 6 & 7
\end{array}
$$

12. I would always encourage myself to try my best

$$
\begin{array}{lllllll}
1 & 2 & 3 & 4 & 5 & 6 & 7
\end{array}
$$

\section{Regulation of Emotion (ROE)}

13. I am able to control my temper so that I can handle difficulties rationally

$$
\begin{array}{lllllll}
1 & 2 & 3 & 4 & 5 & 6 & 7
\end{array}
$$

14. I am quite capable of controlling my own emotions

$$
\begin{array}{lllllll}
1 & 2 & 3 & 4 & 5 & 6 & 7
\end{array}
$$

15. I can always calm down quickly when I am very angry

$$
\begin{array}{lllllll}
1 & 2 & 3 & 4 & 5 & 6 & 7
\end{array}
$$

16. I have good control of my own emotions

$$
\begin{array}{lllllll}
1 & 2 & 3 & 4 & 5 & 6 & 7
\end{array}
$$

\section{Job Diagnostic Survey Section 4: Job Satisfaction}

This section of the survey will evaluate job satisfaction. Please indicate how satisfied you are with each aspect of your job listed below.

1 Extremely Dissatisfied

2 Dissatisfied 
3 Slightly Dissatisfied

4 Neutral

5 Slightly Satisfied

6 Satisfied

7 Extremely Satisfied

1. The amount of job security I have

$\begin{array}{lllllll}1 & 2 & 3 & 4 & 5 & 6 & 7\end{array}$

2. The amount of pay and fringe benefits I receive

$$
\begin{array}{lllllll}
1 & 2 & 3 & 4 & 5 & 6 & 7
\end{array}
$$

3. The amount of personal growth and development I get in doing my job

$$
\begin{array}{lllllll}
1 & 2 & 3 & 4 & 5 & 6 & 7
\end{array}
$$

4. The people I talk to and work with on my job

$$
\begin{array}{lllllll}
1 & 2 & 3 & 4 & 5 & 6 & 7
\end{array}
$$

5. The degree of respect and fair treatment I receive from my boss

$$
\begin{array}{lllllll}
1 & 2 & 3 & 4 & 5 & 6 & 7
\end{array}
$$

6. The feeling of worthwhile accomplishment I get from doing my job

$$
\begin{array}{lllllll}
1 & 2 & 3 & 4 & 5 & 6 & 7
\end{array}
$$

7. The chance to get to know other people while on the job

$$
\begin{array}{lllllll}
1 & 2 & 3 & 4 & 5 & 6 & 7
\end{array}
$$

8. The amount of support and guidance I receive from my supervisor

$$
\begin{array}{lllllll}
1 & 2 & 3 & 4 & 5 & 6 & 7
\end{array}
$$

9. The degree to which I am fairly paid for what I contribute to this organization

$$
\begin{array}{lllllll}
1 & 2 & 3 & 4 & 5 & 6 & 7
\end{array}
$$

10. The amount of independent thought and action I can exercise in my job

$$
\begin{array}{lllllll}
1 & 2 & 3 & 4 & 5 & 6 & 7
\end{array}
$$

11. How secure things look for me in the future in this organization

$$
\begin{array}{lllllll}
1 & 2 & 3 & 4 & 5 & 6 & 7
\end{array}
$$

12. The chance to help other people while at work

$$
\begin{array}{lllllll}
1 & 2 & 3 & 4 & 5 & 6 & 7
\end{array}
$$


13. The amount of challenge in my job

$$
\begin{array}{lllllll}
1 & 2 & 3 & 4 & 5 & 6 & 7
\end{array}
$$

14. The overall quality of the supervision I receive in my work

$$
\begin{array}{lllllll}
1 & 2 & 3 & 4 & 5 & 6 & 7
\end{array}
$$

\section{Copenhagen Burnout Inventory}

This section of the survey will evaluate burnout, and will be divided into three sections (personal burnout, work-related burnout, and client-related burnout). Please circle the

1 Always appropriate response.

2 Often

3 Sometimes

4 Seldom

5 Never/Almost Never

\section{Part 1: Personal Burnout}

1. How often do you feel tired?

$$
\begin{array}{lllll}
1 & 2 & 3 & 4 & 5
\end{array}
$$

2. How often are you physically exhausted?

$$
\begin{array}{lllll}
1 & 2 & 3 & 4 & 5
\end{array}
$$

3. How often are you emotionally exhausted?

$$
\begin{array}{lllll}
1 & 2 & 3 & 4 & 5
\end{array}
$$

4. How often do you think: "I can't take it anymore"?

$$
\begin{array}{lllll}
1 & 2 & 3 & 4 & 5
\end{array}
$$

5. How often do you feel worn out?

$$
\begin{array}{lllll}
1 & 2 & 3 & 4 & 5
\end{array}
$$

6. How often do you feel weak and susceptible to illness?

$$
\begin{array}{lllll}
1 & 2 & 3 & 4 & 5
\end{array}
$$

\section{Part 2: Work-Related Burnout}

1. Is your work emotionally exhausting?

$$
\begin{array}{lllll}
1 & 2 & 3 & 4 & 5
\end{array}
$$

2. Do you feel burnt out because of your work?

$$
\begin{array}{lllll}
1 & 2 & 3 & 4 & 5
\end{array}
$$


3. Does your work frustrate you?

$$
\begin{array}{lllll}
1 & 2 & 3 & 4 & 5
\end{array}
$$

Respond with the following options:

1 To a very high degree

2 To a high degree

3 Somewhat

4 To a low degree

5 To a very low degree

4. Do you feel worn out at the end of the working day?

$$
\begin{array}{lllll}
1 & 2 & 3 & 4 & 5
\end{array}
$$

5. Are you exhausted in the morning at the thought of another day at work?

$$
\begin{array}{lllll}
1 & 2 & 3 & 4 & 5
\end{array}
$$

6. Do you feel that every working hour is tiring for you?

$$
\begin{array}{lllll}
1 & 2 & 3 & 4 & 5
\end{array}
$$

7. Do you have enough energy for family and friends during leisure time?

$$
\begin{array}{lllll}
1 & 2 & 3 & 4 & 5
\end{array}
$$

\section{Part 3: Client-Related Burnout}

1. Do you find it hard to work with clients?

$$
\begin{array}{lllll}
1 & 2 & 3 & 4 & 5
\end{array}
$$

2. Do you find it frustrating to work with clients?

$$
\begin{array}{lllll}
1 & 2 & 3 & 4 & 5
\end{array}
$$

3. Does it drain your energy to work with clients?

$$
\begin{array}{lllll}
1 & 2 & 3 & 4 & 5
\end{array}
$$

4. Do you feel that you give more than you get back when you work with clients?

$$
\begin{array}{lllll}
1 & 2 & 3 & 4 & 5
\end{array}
$$

\section{Demographic Information}

This section of the survey will collect demographic information. Please answer the following questions by circling the appropriate choice.

Age:

18-29

30-39

$40-49$

50 and above 


\section{Gender:}

Male

Female

\section{Ethnicity:}

White African American Hispanic American Indian Asian Other

\section{Education:}

B.S. degree

Masters

Doctoral Degree

Income Level:

Under 25,000

25,000 to $50,000 \quad 50,001$ to $75,000 \quad$ above 75,000

Primary Area of Dietetic Practice

Community Clinical

Administrative Academic

Years of Dietetic Practice

$<$ year $\quad 1-5$ years 6-10 years $\quad 11-15$ years $16+$ years

You have completed the survey. Thank you for your time. If you would like additional information about the survey, and/or information regarding the results please e-mail cara.perdue@waldenu.edu 